2. PECEIVED BV IIL ULI UONOC.

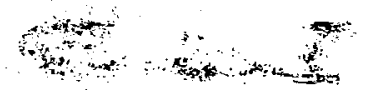

\title{
Behavior of Reinforced Concrete labs Subjected to Combined Punching Shear and Biaxial Tension
}

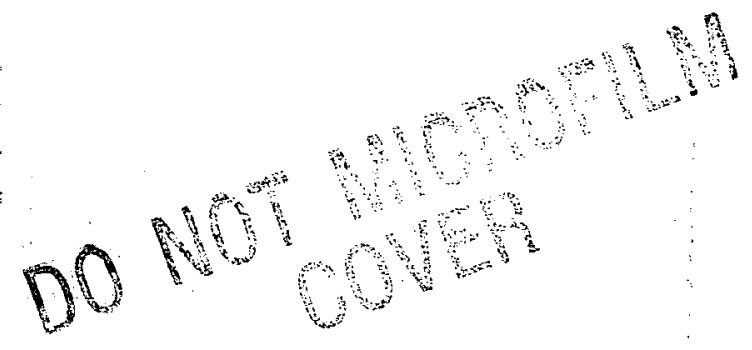

Prepared by W. C. Jau, R. N. White, P. Gergely

Department of Structural Engineering Cornell University

Prepared for

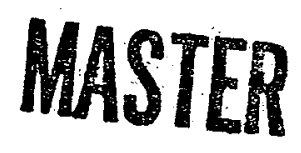

U.S. Nuclear Regulatory

Commission 


\section{NOTICE}

This report was prepared as an account of work sponsored by an aanncy of the United Siatcs Government. Neither the United States Government nor any agency thereot, or any of their employees, makes any warranty, expressed or implied, or assumes any legal liability of re. sponsibility for any third party's use, or the results of such use, of any information, apparatus, product or process disclosed in this report, or represents that its use by such third party would not infringe privately owned rights.

Availability of Reference Materials Cited in NRC Publications

Most documents cited in NRC publications will be available from one of the following sources:

1. The NRC Public Document Room, 1717 H Street, N.W Washington, DC 20555

2. The NRC/GPO Sales Program, U.S. Nuclear Regulatory Commission, Washington, DC 20555

3. The National Technical Information Service, Springfield, VA 22161

Although the listing that follows represents the majority of documents cited in NRC publications, it is not intended to be exhaustive.

Referenced documents available for inspection and copying for a fee from the NRC Public Docu. ment Room include NRC correspondence and irternal NRC memoranda: NRC Office of Inspection and. Enforcement bulletins, circulars, information notices, inspection and investigation notices; Licensee Event Reports; vendor reports and correspondence; Commission papers; and applicant and licensee documents and correspondence.

The following documents in the NUREG series are available for purchase from the NRC/GPO Sales Program: formal NRC staff and contractor reports. NRC-sponsored conference procecdings, and NRC booklets and brochures. Also available are Regulatory Guides, NRC regulations in the Code of Federal Regulations, and Nuclear Regulatory Commission /ssuances.

Documents available from the National Technical Information Service include NUREG series reports and technical reports prepared by other federal agencies and reports prepared by the Atomic Energy Commission, forerunner agency to the Nuclear Regulatory Commission.

Documents available from public and special technical libraries include all open literature items, such as books, journal and periodical articles, and transactions. Federal Register notices, federal and state legislation, and congressional reports can usually be obtained from these libraries.

Documents such as theses, dissertations, foreign reports and translations, and non-NRC conference proceedings are available for purchase from the organizatıon sponsoring the publicarion cited.

Single copies of NRC draft reports are available free upon written request to the Division of Tech. nical Information and Document Control, U.S. Nuclear Regulatory Commission, Washington, DC 20555

Copies of industry codes and standards used in a substantive manner in the NRC regulatory process are maintained at the NRC Library. 7920 Norfolk Avenue, Bethesda, Maryland, and are available there for reference use by the public. Codes and standards are usually copyrighted and may be purchased from the originating organization or, if they are American National Standards, from the American National Standards Institute, 1430 Broadway. New York, NY 10018.

GPO Printed copy price: $\$ 5.50$ 


\section{DISCLAIMER}

This report was prepared as an account of work sponsored by an agency of the United States Government. Neither the United States Government nor any agency Thereof, nor any of their employees, makes any warranty, express or implied, or assumes any legal liability or responsibility for the accuracy, completeness, or usefulness of any information, apparatus, product, or process disclosed, or represents that its use would not infringe privately owned rights. Reference herein to any specific commercial product, process, or service by trade name, trademark, manufacturer, or otherwise does not necessarily constitute or imply its endorsement, recommendation, or favoring by the United States Government or any agency thereof. The views and opinions of authors expressed herein do not necessarily state or reflect those of the United States Government or any agency thereof. 


\section{DISCLAIMER}

Portions of this document may be illegible in electronic image products. Images are produced from the best available original document. 


\section{Behavior of Reinforced Concrete Slabs Subjected to Combined Punching Shear and Biaxial Tension}

Manuscript Completed: April 1982

Date Published: September 1982

Prepared by

W. C. Jau, R. N. White, P. Gergely

Department of Structural Engineering Cornell University

Ithaca, NY 14853

\section{Prepared for}

Division of Engineering Technology

Office of Nuclear Regulatory Research

U.S. Nuclear Regulatory Commission

Washington, D.C. 20555

NRC FIN B5688 
Previous Reports in Concrete Structure Research Series

Analysis of Shear Transfer in Reinforced Concrete with Application to Containment Wall Specimens, P. Leombruni, 0. Buyukozturk, J.J. Connor, Massachusetts Institute of Technology, NUREG/CR-1085, October 1979.

Safety Analysis of Nuclear Concrete Containment Stmactures, P. Petrina, R. Sexsmith, R.N. White, Cornell University, NUREG/CR-1097, December 1979.

Shear Transfer in Large Scale Reinforced Concrete Containment Elements Report No. Z, R.G. Oesterle, H.G. Russell, Construction Technology Laboratories, Portland Cement Association, NUREG/CR-7374, April 1980.

Strength and Stiffness of Tensioned Reinforced Concrete Panels Subjected to Membrane Shear, Two-Woy Reinforcing, P.C. Perdikaris, R.N. White, P. Gergely, Cornell University, NUREG/CR-1602, July 1980.

Strength and Stiffness of Reinforced Concrete Pconels Subjected to Membrane Shear, Two-Way and Four-Way Reinforcing, C.H. Conley, R.N. White, P. Gergely, Cornell University, NUREG/CR-2049, April 1981.

Shear Troonsfer in Large Scale Reinforced Concrete Containment Elements Report No. 2, R.G. Oesterle, H.G. Russell, Construction Technology Laboratories, Portland Cement Association, NUREG/CR-2450, December 1981.

Behavioral Model for Reinforced Concrete Panels Under Cyclic Shear, Tsi-Ming Tseng, J. Calvo, 0. Buyukozturk, J. Connor, Massachusetts Institute of Technology, NUREG/CR-2451, December 1981.

Strength and Stiffness of Uniaxially Tensioned Reinforced Concrete Panels Subjected to Membrane Shear, S.I. Hilmy, R.N. White, P. Gergely, Cornell University, NUREG/CR-2788, June 1982. 
This investigation was a continuing study of peripheral (punching) shear strength of precracked, biaxially tensioned, orthogonally reinforced concrete slabs. This research was motivated by the need to determine the strength of a reinforced concrete containment vessel wall when subjected to combined internal pressure and punching shear loads normal to the wall. The study served to determine the effect of three major variables (shear span, size of loaded area, and reinforcing steel ratio) on punching shear strength of slabs that were precracked in biaxial tension and then held at one of the two tension levels ( 0 or $0.8 \mathrm{f}_{\mathrm{y}}$ ) during shear load application. Seven specimens, $4 \mathrm{ft}$. by $4 \mathrm{ft}$. by $6 \mathrm{in}$. thick, were designed and cast to simulate a section of the containment wall. Each specimen had orthogonal reinforcement in both faces, with reinforcing ratios similar to those found in containment vessels. Three pairs of identical specimens were used to study the influence of biaxial tension level and the three variables listed above, and the seventh specimen was loaded in punching shear without having been precracked in biaxial tension.

The test results, which supplement the results of an earlier parallel study by Abrams (reported in Appendix A of this report), indicate the following behavioral trends:

a. punching shear strength increases as the shear span is increased from $l_{s}=h$ to $l_{s}=3 h$, where $h$ is the slab thickness,

b. punching shear capacity increases with larger loading area but the unit shear strength measured at $d / 2$ from the face of the loaded area decreases, 
c. a larger steel ratio increases the punching shear capacity approximately as predicted by Long, and

d. the level of biaxial tension affects the ultimate load capacity only slightly for tension levels of at least $0.8 \mathrm{f}^{\text {* }}$

It was found that the ACI 349 and 359 Code design expressions for peripheral shear are excessively conservative, particularly for higher values of biaxial tension. A suitable design expression for solid slabs is $v_{u}={ }_{\wedge} F_{c}^{r}\left(4-f_{s} / f_{y}\right)$, where $f_{s}$ is the higher tension value in the orthogonal reinforcing, and $f_{c}^{\prime}$ is the concrete strength in psi.

The report also contains a summary of a literature review conducted to compare current approaches to punching shear behavior and the stress transfer mechanisms involved in the punching action. Equations from a number of researchers were also employed to predict the punching capacity of test slabs with zero biaxial tension, and a comparison of results is given. A finite element computer program was used to study the effect of edge restraint on elastic behavior of centrally loaded slabs. The results indicate that edge restraint can provide substantial increases in load capacity, along with decreases in slab displacements, provided that the slab is not excessively thin. 
1. INTRODUCTION . . . . . . . . . . . . . . . . . . . 1 1.1 General ..... . . . . . . . . . . . . . . . 1 1.2 Purpose and Scope .. . . . . . . . . . . . . . 2

2. LITERATURE REVIEW .. . . . . . . . . . . . . . . 4 2.1 General ................... . . 4 2.2 Expressions Dependent Mainly on Flexural Strength . . . . . 5 2.2.1 Kinnunen and Nylander .............. . 5 2.2.2 Yitzhaki ..................... 7 2.2 .3 Mattock . . . . . . . . . . . . . 8

2.3 Expressions Dependent Mainly on Concrete Strength . . . . . 9 2.3.1 Long and Bond . . . . . . . . . . . . . 9 2.3.2 Moe . . . . . . . . . . . . . . . . . 10 2.3.3 Concrete Plasticity . . . . . . . . . . . . .11 2.4 Effect of Edge Restraint . . . . . . . . . . . . . 13 2.4.1 Taylor and Hayes . . . . . . . . . . . . 13 2.4.2 Aoki and Seki .. . . . . . . . . . . . . 14 2.5 Predictions Based on Codes . . . . . . . . . . . . . 14 2.5.1 ACI 318-77 •. . . . . . . . . . . . . . . . . $2.5 .2 \mathrm{CP} 110$. . . . . . . . . . . . . . 15

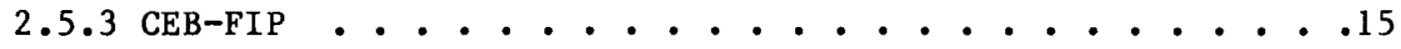
2.5 .4 ACI $349-76$. . . . . . . . . . . . . . 15

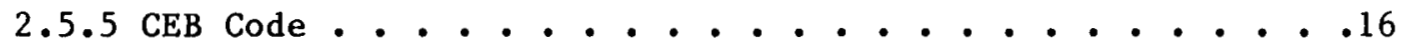
2.5.6 A Comparison between ACI 318-71 and CPl10 . . . . . 17 2.5.7 Discussion of CEB Model Code . . . . . . . . . . 17 
2.6 Fundamentals of Analysis

2.7 Slabs with Biaxial Tension . . . . . . . . . . . 19

2.7.1 Abrams . . . . . . . . . . . . . 19

2.7.2 Johnson and Arnouti ................ 19

2.8 Summary . . . . . . . . . . . . . . . . 19

3. EXPERIMENTAL INVESTIGATIONS . . . . . . . . . . . . . 21

3.1 General . . . . . . . . . . . . . . . . . 21

3.2 Test Specimen . . . . . . . . . . . . . . 21

3.3 Loading, Test Setup, and Instrumentation . . . . . . . . 23

3.4 Test Procedure . . . . . . . . . . . . . . 26

4. DISCUSSION OF EXPERIMENTAL RESULTS . . . . . . . . . . . 28

4.1 General . . . . . . . . . . . . . . . . . 28

4.1.1 General Behavior of Specimens without Biaxial Tension . . 30

4.1.2 General Behavior of Specimens with Biaxial Tension . . . 30

4.2 Series A . . . . . . . . . . . . . . . . 31

4.3 Series B . . . . . . . . . . . . . . . 32

4.4 Series C . . . . . . . . . . . . . . . 34

4.5 Series D . . . . . . . . . . . . . . 36

4.6 Summary . . . . . . . . . . . . . . . . . 37

4.6.1 Shear Span .... . . . . . . . . . . . 37

4.6.2 Steel Ratio . . . . . . . . . . . . 37

4.6.3 Loading Area . . . . . . . . . . . . . . 38

4.6.4 Biaxial Tension Level . . . . . . . . . . . 38

5. COMPARISON BETWEEN TEST DATA AND PREDICTIONS BY VARIOUS FORMULAS • • 39

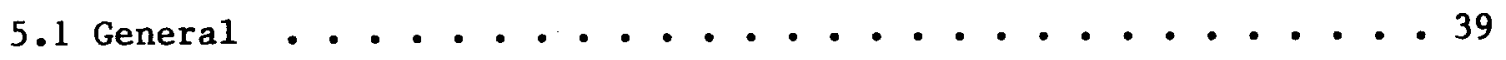

5.2 Yitzhaki's Equation . . . . . . . . . . . . 39 
5.3 Long's Equation . . . . . . . . . . . . . . 40

5.4 Moe's Equation . . . . . . . . . . . . . . . 40

5.5 Concrete Plasticity . . . . . . . . . . . . 4 4

5.6 Mattock's Method .................. 42

5.7 Abrams' Equation .................. 42

6. ANALYTICAL APPROACHES TO PUNCHING SHEAR AND DESIGN IMPLICATIONS • • 43

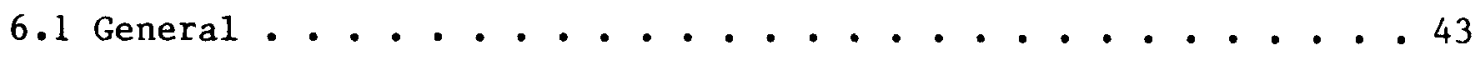

6.2 Effect of Edge Restraint on Homogeneous Circular Slab Behavior. 43

6.3 Elastic Analysis of Axisymmetrically Reinforced Slabs under

Concentrical Punching Shear Force . . . . . . . . 45

6.4 Design Implications . . . . . . . . . . . . . 45

7. SUMMARY, CONCLUSIONS, AND RECOMMENDATIONS FOR FUTURE RESEARCH • . 47

7.1 Summary . . . . . . . . . . . . . . . . 47

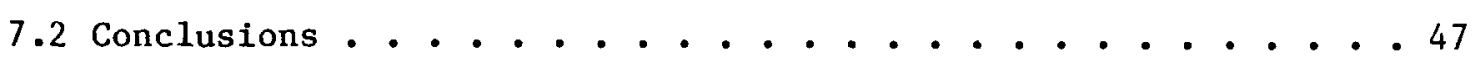

7.2.1 Effect of Biaxial Tension on Punching Shear Strength • . 48

7.2.2 Effect of Size of Loading Area on Overall Behavior . . 48

7.2.3 Effect of Shear Span on Load Capacity . . . . . . . 48

7.2.4 Effect of Reinforcement Ratio on U1timate Punching Shear

Strength . . . . . . . . . . . . . . . 48

7.3 Recommendations for Future Study . . . . . . . . . 4 49

7.3.1 Experimental Work . . . . . . . . . . . 49

7.3.2 Numerical Analysis . . . . . . . . . . . 49

TABLES . . . . . . . . . . . . . . . . . 50

FIGURES . . . . . . . . . . . . . . . . . . 55

REFERENCES. . . . . . . . . . . . . . . . . . . 83

APPENDIX A (Abrams' Results). . . . . . . . . . . . 85 
3.1 Gradation of Aggregates . . . . . . . . . . . . . . 50 4.1 Test Results .................... 51

5.1 Normalized Fallure Stresses from Test Results and as Predicted by Different Researchers . . . . . . . . . . . . . . 52

6.1 Finite Element Study of Effects of Edge Restraint . . . . . . 53 6.2 Finite Element Analysis of Slabs Simulating the Present Study . . . 54 
1.1 Typical Nuclear Containment Vessel . . . . . . . . . . 55

1.2 Containment with Horizontal and Vertical Cracking . . . . . . 56

1.3 Typical Detail for Vessel Wall . . . . . . . . . . . 57

2.1 Mechanical Model from Kinnunen and Nylander . . . . . . . . 58

2.2 Free-Body Diagrams of Moe's Mode1 . . . . . . . . . . . 59

2.3 Fallure Surface of Concrete Plasticity . . . . . . . . . 59

3.1 Test Specimen . . . . . . . . . . . . . . . . 60

3.2 Test Specimen with Loading, Supports, and Dial Gage Locations . . 61

3.3 Tension Reaction Frame Unit . . . . . . . . . . . . 62

3.4 Side View of Overhead Reaction Frame and Specimen . . . . . . . 63

3.5 Typical Precracking of Specimens . . . . . . . . . . 64

3.6 Representative Failure Path on the Top Surface . . . . . . . 66

3.7 Representative Failure Path on the Bottom Surface . . . . . 66

4.1 Load-Deflection Curves . . . . . . . . . . . . . 67

4.2 Sequence of Crack Formation near Load . . . . . . . . . . 70

4.3 Dowe1 Displacement (Exaggerated) . . . . . . . . . . 70

4.4 Typical Widened Crack under Biaxial Tension . . . . . . . . . 71

4.5 Typical Crack under Punching Load . . . . . . . . . . . 71

4.6 Free-Body Diagram of a Typical Element under Biaxial Tension and Punching Shear Load, Vertical Component . . . . . . . . . 72

4.7 Free-Body Diagram of a Typical Element under Biaxial Tension and Punching Shear Load, Internal Stresses. . . . . . . . . . 72

4.8 Fallure Surface . . . . . . . . . . . . . . . 73

4.9 Plot of Normalized Punching Shearing Stress vs. Biaxial Tension - 80

6.1 Typical Finite Element Mesh for Studying the Effect of Edge Restraint ....................... . 81

6.2 Finite Element Mesh for Simulating Specimen with Large Shear Span . 82 
CHAPTER 1

INTRODUCTION

\subsection{General}

A typical reinforced concrete containment vessel is composed of a large cylindrical shell with a hemispherical head, resting on a circular mat foundation (see Fig. 1.1). The nuclear reactor, power generator and any accidentally released steam and/or radiation are contained and isolated from the environment by the containment vessel. A large volume containment vessel is required to dissipate the energy released during a malfunction of the coolant system. Such an accident usually includes an increase in internal pressure which tensions the containment vessel in both meridional and circumferential directions. Due to the low tensile strength of concrete, the internal pressurization will cause cracks to form in these two directions (shown in Fig. 1.2). In order to resist internal pressurization, the containment walls, typically $41 / 2$ feet thick, are reinforced with single 18 bars on each face in the meridional direction and double \#18 bars in the hoop direction (see Fig. 1.3). In addition, a steel liner plate $1 / 4$ to $3 / 8$ inch thick is attached to the inner surface of the wall to prevent leakage of the vessel.

One of the extreme loading conditions imposed on nuclear containment vessels is the simultaneous internal pressurization of the vessel and the application of normal forces on the wall. The normal forces may be caused by missile impacts, pipe momentum, and jets of fluid or steam. They produce punching shearing stresses which are to be carried by the cracked, biaxially tensioned containment vessel wall. 


\subsection{Purpose and Scope}

The present study investigates the punching shear strength of precracked reinforced concrete slabs subjected to biaxial tension. No other prior experimental evidence exists concerning behavior under this stress state, except Abrams (1) and Johnson (2); this program is an extension of Abrams' work. The main parameters to be investigated in this research are 1) shear span, 2) size of loading area, 3) steel ratio, and 4) biaxial tension level.

Another purpose is to identify the need for and direction of future work in this area. Moreover, an evaluation of the current punching shear design expression for reinforced concrete nuclear containment vessels, and a revised empirical equation, are to be made.

Since the diameters of containment vessels are usually large, flat test specimens were considered a good approximation of a portion of the wa11. However, the specimens illustrated in Fig. 3.1 are not scale models of a containment vessel section, instead they provide sufficient resemblance to make extrapolations of results possible. The slabs contained twice the steel ratio in one direction as in the orthogonal direction, and the specimens were precracked and biaxially tensioned by tensioning the reinforcement. This is the same as the mechanism of tension transfer in a containment. Punching shear load was applied over a square area centered on the slab.

Punching shear force (controlled by increments of out-of-plane displacement) was applied to the precracked test slabs, after the desired biaxial tension level was applied by puliing the reinforcements extruding from slabs. Biaxial tension levels of $0.0 \mathrm{f}_{\mathrm{y}}$ and $0.8 \mathrm{f}_{\mathrm{y}}$ were used to 
determine the interaction between punching shear strength and biaxial tension for these specimens and a linear variation was assumed between $0.0 \mathrm{f}_{\mathrm{y}}$ and $0.8 \mathrm{f}_{\mathrm{y}} \cdot$ Additionally, these tests illustrated the general mode of behavior of cracked slabs subjected to this type of loading. Because the failure surface did not occur along the preformed cracks, it is not surprising that the precracking did not appreciably affect the ultimate punching shear strength. The current ACI Code was found to be overly conservative and a simple equation was suggested for design purposes. More research in this area, which should include full scale parametric studies of the variables (especially punching at penetrations and in thicker slabs) is recommended for final design equations which may be even more liberal than the one suggested here. 
CHAPTER 2

LITERATURE REVIEW

\subsection{General}

Although extensive research has been done on punching shear strength of reinforced concrete slabs, only two studies have included biaxial loading and precracking of specimens, namely those by Abrams ( 1 ) and Johnson (2). However, in order to have a thorough understanding of the punching shear phenomenon, papers not including membrane stress and tension cracks are examined here. In general, most research has been directed at explaining the behavior of floor systems and spread footings, which carry large bending stresses in addition to concentrated shearing forces. However, a number of the papers also give an approach to help understand the overall mechanism of punching shear.

In general, there are two basic approaches for deriving expressions for punching shear strength; they are 1) expressions dependent primarily on concrete strength, and 2) expressions dependent primarily on flexural effects. However, punching shear action is accompanied by flexural action for most cases, which has been verified by previous investigators.

Edge restraint (or support condition) has been claimed to be a crucial factor affecting the type of failure mode: shear or flexural failure. If the edge is restrained, the shear failure mode dominates, and if the edge is free and with low steel ratio, flexural failure mode controls.

Tests including tensile membrane stresses conducted by Abrams and Johnson are carefully studied for comparison with the present study. A concrete plasticity approach, which was developed in Europe and has received little attention in the U.S.A., is also reviewed. 


\subsection{Expressions Dependent Mainly on Flexural Strength}

\subsubsection{Kinnunen and Nylander}

Kinnunen and Nylander (3) proposed a failure model (Fig. 2.1)

to analyze the axisymmetric slab column system theoretically with assumptions based on experimental observations. At failure, extensive radial cracks divided the slab into several sectors, which were bounded by these radial cracks, inclined cracks and the perimeter of the slab. It was assumed that each sector rotated as a rigid body about the tip of the crack and was supported by an imaginary conical shell which developed from the column to the bottom of the shear crack. All the forces on the sector were proportional to the rotation of the slab, except for external loads and internal reactions. Failure was assumed to occur when tangential compressive concrete strain under the root of the shear crack reached a characteristic value.

In order to use this model, a depth of inclined crack, $y$, should be assumed first and the three equilibrium equations are solved by iteration. These equations are

$$
\begin{aligned}
V & =\pi \frac{B}{d} \frac{y}{d} \frac{1+2 \frac{y}{d} \frac{d}{B}}{1+\frac{y}{d} \frac{d}{B}} f(\alpha) \sigma_{t} h^{2} \\
\sigma_{t} & =825\left(0.35+0.3 \frac{f}{\text { cube }}\right)\left(1-0.22 \frac{B}{h}\right) 0 \leq \frac{B}{h} \leq 2 \\
& =460\left(0.35+0.3 \frac{f_{\text {cube }}}{150}\right) \quad 2 \leq \frac{B}{h}
\end{aligned}
$$

and

$$
\mathrm{R}_{1} \Delta \phi+\mathrm{R}_{2}=\mathrm{V} \frac{\Delta \phi}{2 \pi} \mathrm{K}_{\mathrm{y}}
$$


where

$$
\begin{aligned}
& R_{1}=\rho f_{y} d^{2} \frac{\gamma_{s}}{d} \ln \frac{\frac{1}{2} c}{c_{o}}, k g \\
& \mathrm{R}_{2}=A_{s} f_{y} \frac{\gamma_{s}}{d} \frac{d}{c_{0}} \frac{\Delta \phi}{2 \pi}, k g \\
& \mathrm{~V} \quad=\text { ultimate load, } \mathrm{kg} \\
& f(\alpha)=\sin \alpha \cos \alpha(1-\tan \alpha) \leq 0.207 \\
& \alpha=\text { the angle between bottom surface and conical she11, radians } \\
& \mathrm{d}=\text { effective depth of slab, cm } \\
& \text { B = diameter of column, } \mathrm{cm} \\
& \text { h = effective depth of slab } \\
& \mathrm{y} \quad=\text { depth of inclined crack, } \mathrm{cm} \\
& \sigma_{t}=\text { stress in the conical shell, } \mathrm{kg} / \mathrm{cm}^{2} \\
& \mathrm{f}_{\text {cube }}=\text { cube strength of concrete, } \mathrm{kg} / \mathrm{cm}^{2} \\
& R_{1}=\text { resultant tangential force in the reinforcement at right } \\
& \text { angles to the radial crack, } \mathrm{kg} \\
& \mathrm{R}_{2} \quad=\text { resultant radial force in the reinforcement cutting across } \\
& \text { the crack, } \mathrm{kg} \\
& \Delta \phi \quad=\text { angle between the binding radial crack, radians } \\
& k_{y}=\frac{\frac{1}{2} c-\frac{B}{2}}{d-\frac{y}{3}} \\
& \rho \quad=\text { steel ratio } \\
& \mathrm{f}_{\mathrm{y}}=\text { yield stress of steel, } \mathrm{kg} / \mathrm{cm}^{2} \\
& \gamma_{s}=d \frac{E_{s}}{f_{y}} \psi\left(1-\frac{y}{h}\right), c m \\
& \psi \quad=\text { angle of rotation of slab portion outside the shear crack at } \\
& \text { failure, radians }
\end{aligned}
$$


$c_{0}=$ distance in the plane of reinforcement from column center to the concentric shear crack at failure, $\mathrm{cm}$

$\mathrm{c} \quad=$ span length (diameter), $\mathrm{cm}$

The dowel effect was claimed to be about 15 to 20 percent of theoretical total load value obtained from above by comparing this value and experimental results. This model was modified later by Kinnunen (4) for orthogonal two-way reinforced slabs and extended to slabs with shear reinforcement by Anderson (5). They also stated that "If the ratio of reinforcement is small, then failure is primarily initiated when the yield stress is reached in the whole flexural reinforcement over the column." and "at high ratios of reinforcement, $f_{y}$ is reached only in an inner part of the flexural reinforcement." However, no further experimental work has been done to justify Kinnunen and Nylander's model nor to see if the assumed failure surface was correct. In addition, the column-slab system could be different from a flat slab because of the restraint and stress concentration at the junction of slab and column.

\subsubsection{Yitzhaki}

Yitzhaki (6) claimed that the punching resistance depends mainly on the reinforcement. He made theoretical analyses and the derived equation was substantiated by test data. He suggested

$$
v_{u}=8\left(1-\frac{\rho f_{y}}{2 f_{c}^{T}}\right) d^{2}\left(149.3+0.164 \rho f_{y}\right)\left(1+\frac{c}{2 d}\right) \quad 2.6
$$

where $V_{u}=$ ultimate punching load, $1 \mathrm{bs}$.

$$
\begin{aligned}
& f_{c}^{\prime}=\text { concrete strength, psi } \\
& d=\text { effective depth, in. } \\
& c=\text { column size, in. } \\
& f_{y}=\text { yield stress of steel, psi }
\end{aligned}
$$


Equation 2.6 includes the parameters such as size of loading, slab depth, steel ratio, yield stress of steel, and concrete strength, but the depth/ span ratio is limited to the value of about $1 / 35$; thus the formula may not be useful for other slabs of depth/span ratio significantly different. The various supporting conditions and shear span were not taken into consideration by Yitzhaki. He also observed that "the reinforcement closest to the column reached yield stress first and with increase of load the yielding spread to the more distant bars. As long as the reinforcement does not exceed a certain quantity, all the reinforcement reaches yield stress before failure."

\subsubsection{Mattock}

Mattock (9) has conducted experiments on a number of initially cracked and uncracked corbel type and standard push-off specimens to determine the interaction between shear strength and tensile stress across the shear plane. From his work, he concluded that the ultimate shear stress which can be transferred is linearly related to the reinforcement ratio and the yield stress of steel, i.e. $\rho f_{y^{*}}$ He stated that in order to be fully effective, the shear transfer reinforcement should be located in the flexural tension zone. However, the stress state was mainly related to tensile strength rather than flexural strength. From his test data, he suggested an empirical equation to estimate the ultimate shear stress

$$
v_{u}=400+0.8\left(\rho f_{y}+\sigma_{n}\right)
$$

where $\sigma_{n}=$ externally applied normal stress on crack surface (positive for compression), psi., and $v_{u}=u l t i m a t e$ shear stress, psi. 


\subsection{Expressions Dependent Mainly on Concrete Strength}

\subsubsection{Long and Bond}

Long and Bond (7) derived an expression for the compressive stresses near the column by use of elastic thin-plate theory and utilized the octahedral shear stress criterion to determine failure loads. In their derivation, they assumed a linear stress variation in concrete due to bending at the region of most critical section, which is at the column edge. In order to calculate the theoretical ultimate load of a slab, a complex iterative procedure is required. Therefore, Long published another paper (8) and presented the much simplified equations as follows:

$$
\begin{aligned}
& v_{u}=\frac{\rho f_{y d^{2}(1-0.59)}^{\rho f_{y} / f_{c}^{\prime}}}{\left(0.2-0.90 \frac{c}{L}\right)} \\
& \text { or }=\frac{20(c+d) d(100 \rho)^{0.25} \sqrt{f_{c}^{\prime}}}{\left(0.75+4 \frac{c}{L}\right)} \text { whichever is smaller }
\end{aligned}
$$

where $L$ is the span between the centers of two adjacent columns and other parameters are as defined earlier.

Very valuable observations and conclusions can be drawn from Long's papers. He stated "columns punch through the slab before yield-line patterns have fully developed," and "only the reinforcement in the immediate vicinity of load yields before punching, no evidence of yielding was found in locations slightly removed from the load." The author also pointed out that the load at failure depended on the combined effect of the shear force and bending moment, and found that if the steel yields before the concrete fails, then the punching shear strength is influenced strongly by flexural strength; if concrete fails before steel yields, 
then the punching shear strength dominates, as stated by many other papers.

It is easy to calculate the desired ultimate load from Eq. 2.8, and the results are quite consistent with test results. Long found from the data in the literature that the $\frac{\mathrm{P} \text { test }}{\mathrm{P} \text { calculate }}$ ratio is 1.02 with standard deviation 0.075 from Eq. 2.8, and discovered that other methods proposed by Herzog, Moe, Yitzhaki, CP 110, and ACI 318-71 will give larger averages and deviations, thus proving the superiority of Eq. 2.8. However, correlation is relatively bad when low values of $\frac{\rho f}{f_{c}^{\prime}}$, high values of $f_{c}^{\prime}$ ', or extreme values of $\frac{L}{c}$ are encountered. Long suggested $\left(f_{c}^{\prime}\right)^{0.4}$ to be used in Eq. 2.8 instead of $\left(f_{c}^{\prime}\right)^{0.5}$ when the $f_{c}^{\prime}$ value is high.

\section{$\underline{2.3 .2}$ Moe}

Moe (10) tested 43 specimens and analyzed his test results as we11 as earlier data. He proposed that

$$
V_{u}=b d \frac{15\left(1-0.075 \frac{c}{d}\right) \sqrt{f}_{c}^{\prime}}{1+\frac{5.25 b d \sqrt{f_{c}^{\prime}}}{V_{f l e x}}}
$$

where $V_{f l e x}$ is the shear force at which flexural failure takes place and all the units are as defined in section 2.2.2. Eq. 2.9a was not intended for $\frac{c}{d}$ ratios much larger than 3.0 . After simplification and modification, he suggested

$$
\begin{array}{ll}
v_{u}=\left(9.23-1.12 \frac{c}{d}\right) b_{o} d \cdot \sqrt{f} & \text { for } \frac{c}{d} \leq 3 \\
v_{u}=\left(2.5+10 \frac{d}{c}\right) b_{o} d \sqrt{f} & \text { for } \frac{c}{d} \geq 3
\end{array}
$$

for design, where the units of $b_{0}, c, d$ are inch and $f_{c}^{\prime}$ is psi; $b_{0}$ is the minimum perimeter but no closer than $\frac{d}{2}$ from the edge of the loading area, and $v_{u}, c$, and $d$ are as defined previously in section 2.2 .2 . 
Moe was the first investigator to relate the shear strength to $\sqrt{f}$ ' and $c$. He also stated that for $\frac{c}{d} \geq 3$, the limiting stress should be reduced to $2.5 \sqrt{\mathrm{f}} \mathrm{c}$. An important conclusion made by him is that the shear failure mechanism may not be related physically to the flexural capacity and that most of the reinforcement was yielding locally over the column but not throughout the slab at collapse. Another important discovery of Moe is that the reinforcement concentrated near or under the load was not useful in increasing the shear strength; in fact, a slight reduction in strength with increased degree of concentration of reinforcement was found.. He also observed that cracks occurred first at the top surface of the junction of slab and column. The failure surface proposed by Moe is shown in Fig. 2.2.

\subsubsection{Concrete Plasticity}

Nielsen, et. al, (11) and Braestrup (12) proposed a different approach by using plasticity with modified Coulomb failure criterion, assuming that concrete is rigid-perfectly plastic and that the deformation is governed by the associated flow rule (i.e., normality rule). By equating the rate of external and internal work, the load found will be an upper bound. Braestrup defined the punching shear failure as "only collapse modes characterized by the punching out of a concrete body in the directon of the loading, the remainder of the slab remaining comparatively rigid." Consequently, failure with yielding of reinforcement, which occurs quite of ten for lightly reinforced unrestrained slabs, is not to be considered as punching shear failure. In addition, "crushing of concrete around the load and spalling off at the bottom are a secondary phenomenon related to the rotational capacity in connection with flexural failure mechanism." Braestrup also claimed that for heavily 
reinforced concrete slabs, the failure may occur before yielding of the reinforcement by a mode involving crushing of concrete without forming a direct punch-out cone, and again, is related to the lack of rotational capacity. By these restrictions, edge restraint becomes an important requirement for slabs to have the shear failure mode. These two papers proposed the ultimate load to be

$$
\begin{gathered}
\mathrm{v}_{\mathrm{u}}=\frac{1}{2} \pi \mathrm{f}_{\mathrm{c}}^{\prime}\left[\mathrm{h}_{\mathrm{o}}\left(\mathrm{d}_{\mathrm{o}}+\mathrm{h}_{\mathrm{o}} \tan \psi\right) \frac{1-\sin \psi}{\cos \psi}+1 \mathrm{c}\left(\mathrm{h}-\mathrm{h}_{\mathrm{o}}\right)+\right. \\
\left.\quad 1\left(\frac{\mathrm{d}_{1}}{2} \sqrt{\left.\frac{\mathrm{d}_{1}}{2}\right)^{2}-c^{2}}-\mathrm{ab}\right)-\mathrm{m}\left[\left(\frac{\mathrm{d}_{1}}{2}\right)^{2}-\mathrm{a}^{2}\right]\right\}
\end{gathered}
$$

where $d_{0}, d_{1}, h_{0}, h_{1}, \psi$ are shown in Fig. 2.3. and

$$
\begin{aligned}
& d_{1}=2 a \cosh \left(\frac{h-h_{o}}{c}\right)+b \frac{h-h_{o}}{c} \\
& a=\frac{d_{0}}{2}+h_{0} \tan \psi \\
& b=c \tan \psi \\
& 1=1-(K-1) \frac{f_{t}}{f_{c}^{T}} \\
& m=1-(K+1) \frac{f_{t}}{f_{c}^{r}} \\
& K=\frac{1+\sin \psi}{1-\sin \psi}
\end{aligned}
$$

All the units are the same as those in section 2.2.2. By minimizing the upperbound, the $\mathrm{V}_{\mathrm{u}}$ value obtained is the ultimate load. However, in order to make the solution agree with the test results, they suggested a ratio $\frac{f_{t}}{F_{c}^{T}}=\frac{1}{400}$, which "indicates that the effectiveness of the tensile strength is very smal1." Consequent1y, the author stated, "We sha11 as a rule take the tensile concrete strength to be zero." 
In reality, $f_{t}$ is about $1 / 10$ of $f_{c}^{\prime}$ ', which contradicts with their suggestion. Furthermore, in order to give a good prediction, an empirical factor $\nu$ is introduced to modify the concrete strength.

$$
f_{c}^{*}=v f_{c}^{\prime}
$$

where $\nu=4.22 / \sqrt{f} !$

and therefore,

$$
\mathrm{f}_{\mathrm{c}}^{*}=4 \cdot 22 \sqrt{\mathrm{f}} \mathrm{c}
$$

The failure path, proposed by them, was not influenced by shear or flexural reinforcement. However, the applicability of this theory is reduced due to not including the contribution of steel, which could have an important role in determining the ultimate load of a slab failing in punching shear. In addition, a fully rigid support is not realistic for most structural elements.

\subsection{Effect of Edge Restraint}

\subsubsection{Taylor and Hayes}

Twenty two plain and reinforced square concrete slabs were tested by Taylor and Hayes (13). By comparison between pairs (each pair had one slab rigidly restrained along the edges and the other one free), they concluded that edge restraint increases the strength of punching shear from 0 to $60 \%$, depending on the steel rat1o; the higher the reinforcement ratio, the less the increase. The arching or membrane action due to restraints along the perimeter by external frames had no effect at early load stages. However, it clearly affected the subsequent behavior. Crack widths and deflections were smaller for slabs with restraint than those of simply supported slabs. The ultimate loads were also increased due to the membrane action. They found that radial cracks formed first, then, 
circumferential cracks at failure. The restraint, however, reduced the ductility.

\section{$\underline{2.4 .2}$ Aoki and Seki}

It was reported by Aoki and Seki (14) that slabs supported more rigidly were inclined to fail in shear and the ultimate load was greater than the calculated shear strength. They tested fourteen slabs with integrated edge beams of different dimensions. The increase in shear strength varied from 0 to $67 \%$. They found that the membrane forces, due to edge beams, increased as the strength of concrete increased and as the steel ratio decreased, the same as what was found by Taylor and Hayes. However, the contribution of arch action, which depends on the deflection, the rigidity against the lateral movement of supports and the shape of arch, were difficult to determine. Aoki and Seki proposed a set of seven equations which were to be solved simultaneously to get the values of all the variables, including ultimate load, ultimate moment, arching force, lateral movement and vertical deflection.

In general, the restraint comes from both external frames and the part of slab above the inclined cracks. However, the latter depends partially on the steel ratio. As a result, the reason why the effect of external restraint by frames is smaller for high steel ratio is explained.

\subsection{Predictions Based on Codes}

Generally speaking, all the codes are based on the notion of a control surface at a distance from the loading area, and some measure of concrete strength. Parameters such as effective depth, steel ratio, and empirical factors are introduced. They are discussed below. 
2.5.1 ACI $318-77$

The ACI Code (15) suggests that

$v_{u}=\frac{v_{u}}{0.85 b_{0} d}$

where $b_{o}$ is the minimum perimeter but no closer than $\frac{d}{2}$ from the edge of the loading area; $v_{u}$ should not be larger than the shear strength of concrete, taken as $4 \overline{\mathrm{f}}_{\mathrm{c}}^{\prime}$.

$\underline{2.5 .2}$ CP 110

CP 110 (16) has

$v_{u}=\frac{v_{u}}{\xi b_{0} d}$

where $b_{0}$ is the smallest perimeter at $1.5 \mathrm{~d}$ from the loaded area. $\xi$ depends on the slab depth and is larger than or equal to 1.0 ; and $v_{u}$ is not supposed to be greater than the shear strength of concrete, which depends on the compressive strength and the ratio of reinforcement, and can be obtained from tables in the code.

\subsubsection{CEB-FIP}

The CEB-FIP (17) Model Code presents

$$
v_{u}=\frac{v_{u}}{k(1+500) b_{o} d}
$$

for reinforced and prestressed concrete, where $b_{0}$ is the perimeter at $0.5 \mathrm{~d}$ from the loaded area, $\kappa=1.5-\mathrm{d}$, with $\mathrm{d}$ in meters. The term $1+50 p$ is to consider the contribution from reinforcement, with $\rho<0.008$.

\section{5 .4 ACI $349-76$}

The ACI 349-76 Code (18) proposed

*ACI 318-71 and ACI 318-77 have identical provisions for punching shear for square loaded areas. 


$$
v_{u}=4 \sqrt{f_{c}^{\prime}} \sqrt{1+\frac{f_{m}}{4 \sqrt{f}}}
$$

This expression includes biaxial tension by assuming the punching force and tension is uniformly distributed over the control surface, which is $\frac{d}{2}$ from the loading area, and $f_{m}$ is the applied tension stress and $v_{u}$ is the shear stress. However, during the derivation, the material is assumed to be isotropic and continuous, which is evidently far from the real situation. Moreover, the ultimate shear strength of concrete is Iimited to $4 \sqrt{f_{c}^{\prime}}$, disregarding the triaxial stress state and the contribution from reinforcement.

\subsubsection{CEB Code}

Nielsen (19) developed the CEB Code and suggested

$$
\mathrm{V}_{\mathrm{u}}=\mathrm{b}_{\mathrm{o}} \mathrm{d} \mathrm{f}_{\mathrm{ct}}
$$

where $f_{c t}$ is the tensile strength of concrete, $d$ is the effective depth of the critical periphery which is so located that its length is a minimum but approaching no closer to the loaded area than $\frac{d}{2}$. Thus the ultimate shear capacity may be expressed very simply as

$$
\mathbf{v}_{\mathbf{u}}=\mathbf{f}_{\mathrm{ct}}
$$

where in design the tensile strength is replaced by the design value $\mathrm{f}_{\text {ctd }}^{\prime}$, which in turn is defined as the characteristic tensile strength $f_{c t k}$ divided by a safety factor $r=1.5$, where $f_{c t k}$ is a function of the characteristic value of concrete cylinder strength and is tabulated in the CEB Model Code. This equation is similar to ACI equation 2.11 when shear strength is taken as $4 \sqrt{f_{c}^{\prime}}$ on an effective shear area nearly the same as specified by the CEB Code. 
2.5.6 A Comparison between ACI 318-71 and CP 110

A comparison between these two codes has been made by Regan (20), in which he reported that the British Code, using much lower shear stress and much larger control perimeter, takes account of dowel action, stress concentration at corners, and geometry of a slab/column connection. He also concluded, after a comparison between the two codes and existing test data, that CP 110 gives better prediction on influence of column positions of slabs (such as exterior column) on punching strength.

2.5.7 Discussion of CEB Model Code

Nielsen (19) discussed the CEB Model Code, and the physical mechanism of the punching shear rupture. He found that punching shear failure is essentially a sliding failure for two reasons; first because the rupture surface has the same character as the sliding failure observed In ordinary compression tests for the part near the column, and secondly because relative displacement along the rupture surface is not perpendicular to the surface as it should be in pure tension rupture. Based on this observation, he concluded that the load carrying capacity is not sensitive to residual stresses from shrinkage, and the rupture surface can cross existing tensile bending cracks and sti11 contribute substantially to the load carrying capacity, which implies that the existence of cracks produced by membrane tension in the slab will not serfously degrade the punching shear capacity.

Equation 2.15 can be expected to give rather conservative values, since the load capacity seems to be governed by the tensile splitting strength, which is about 1.5 times greater than the unfaxial tensile stress. 


\subsection{Fundamentals of Analysis}

Criswell and Hawkins (21) made a summary of methods of analysis and theories for prediction of the punching shear strength of concentrated loaded slabs without moment transfer and shear reinforcement. They realized the deficiency in the "mechanism of fallure and the limitations imposed on that mechanism by general principles governing the behavior of slabs." They tried to explain the sequence of formation of cracks by judgment and not by observation from test.

They stated that it is 1ikely that inclined cracking develops first in regions of high shear stress such as the areas adjacent to the corners of a column. This cracking then probably extends laterally in the plane of the slab with increasing load and may not penetrate through to the tension surface until collapse. The author stated that "Accurate threedimensional constitutive relationship for concrete is needed before the shear stress carried by the concrete can be satisfactorily qualified." Once this is done, an accurate and simple design equation probably could be developed.

Hawkins, Criswell and Roll (22), included more parameters such as the scale factor, tensile reinforcement pattern, concentration of reinforcement, compression reinforcement, column shape, and rate of loading. Lightweight concrete slabs, prestressed concrete slabs, perforated slabs, and slab systems are also considered. These two papers supplied a comprehensive but brief review of previous work in the punching shear area. Because most of those two papers are not related to the effect of biaxial tension on punching shear strength, they are not discussed in detail here. 


\subsection{Slabs with Biaxial Tension}

2.7.1 Abrams

Abrams (1) made twenty six punching tests to determine the interaction between the punching shear strength and the biaxial tension of 6 inch thick precracked slabs, the geometry of which is shown in Fig. 3.1, and proposed

$$
v_{u}=\left(6-1.5 \frac{f_{s}}{f_{y}}\right) \sqrt{f_{c}^{\prime}} \quad f_{s} \leq 0.9 f_{y} \quad 2.16
$$

where $f_{s}$ is tensile stress (psi) of reinforcing bars, and $v_{u}$ and $f_{c}^{\prime}$ in psi. Equation 2.16 is conservative compared to test data as shown in Fig. 4.9. He reported a bilinear relationship between load and deflection, but did not attempt to explain this behavior. Analysis of his results shows that the stiffness decreases as the biaxial tension increases. Also, the failure surfaces in his tests were along the existing tension cracks. His results are included in Appendix A. 2.7.2 Johnson and Arnouti

Three 3.54 inch thick slabs with the steel ratio $(0.009,0.0052)$, $(0.0089,0.0052)$, and $(0.0089,0.0053)$ were tested at $0.0 f_{y}, 0.43 f_{y}$ and $0.86 \mathrm{f}_{\mathrm{y}}$ blaxial tension level by Johnson and Arnouti (2). The nondimensionalized stress was $8.13,8.08$, and 8.03 respectively, which showed little reduction in punching shear strength due to biaxial tension. No equation was recommended.

\subsection{Summary}

Different behavioral mechanisms were demonstrated and several methods of analysis have been developed to explain the behavior and predict the ultimate load of slabs under punching shear load, but none have been fully successful in explaining the real behavior. In general, 
punching shear strength comes from 1) shear strength of uncracked concrete, 2) friction between cracked surfaces, 3) aggregate interlock, 4) dowel action, 5) membrane action, and 6) shear reinforcement, and flexural reinforcing bars do affect the failure load by supplying components 4) and 5). An equation which could take into account all of these factors, the aspect ratios, and the loading conditions is needed to give the best approximation to punching shear capacity. 
CHAPTER 3

EXPERIMENTAL INVESTIGATIONS

\subsection{General}

This chapter outlines the experimental investigations performed to determine the effect of various parameters on the punching shear strength of reinforced concrete slabs. The parameters are 1) biaxial tension level, 2) shear span, 3) loading area, and 4) steel ratio, as compared to previous tests accomplished by Abrams (1). The specimens, shown in Fig. 3.1 , were independently loaded by simultaneous punching shear and biaxial tension. Six of the seven specimens were precracked. The last one was neither precracked nor biaxially tensioned so that it could provide as a tie with untensioned and uncracked slabs of other investigations.

The tension was applied to the slabs through the protruding reinforcement with the help of tensioning frames as illustrated in Fig. 3.3. A separate overhead reaction frame was used to support the punching shear loading system, as shown in Fig. 3.4 .

\subsection{Test Specimen}

The test specimen in this investigation modeled a region of a containment vessel which is cracked by internal pressurization. The specimen, shown in Fig. 3.1, was not a scaled version of the containment wall, however, it displayed several similarities to the containment vessel. The specimen was designed to have a minimum cover of $3 / 4$ inch. Each slab was $4^{\prime} \times 4^{\prime} \times 6^{\prime \prime}$ in dimension, with two layers of orthogonal reinforcement in each face. Each layer had eight bars at equal spacing (6 in.) except exterior bars, which had 3 in. between centroid of rebar and free surface. There were two sets of steel used for slabs. One set was composed of \#6 
and $\$ 4$ rebars, which had steel ratios of 0.0317 and 0.0144 in the two perpendicular directions. The other set consisted of $\# 4$ and $\# 3$ rebars, which gave the steel ratios to be 0.0136 and 0.0076 , respectively. All the steel was commercially available $10^{\prime}$ long Grade 60 deformed bars. These bars protruded $3^{\prime}$ from each edge of the slab in order to apply the precracking and membrane tension to the specimen. This phenomenon could be observed when a containment vessel is internally pressurized, which produces cracks in meridional and hoop directions; then the transfer of membrane tension across cracks from one wall section to the next will be solely through the reinforcement, if the force in the liner is neglected.

The specimens were cast using concrete prepared on site by a local manufacturer with a concrete design strength of 3500 psi and a specified maximum slump of $4 "$. The mixture was composed of Type III high early strength Portland cement, sand with a maximum size of 0.125 inches, and locally available crushed gravel aggregate with a maximum size of 1.5 inches. The aggregate consisted of one part of N.Y. 非 type with a gradation of $3 / 8$ to $1 / 2$ inches and five parts of N.Y. 非 type aggregate with a gradation of $5 / 8$ to $11 / 2$ inches. A representive gradation of sand and aggregate used is shown in Table 3.1 . One cubic yard of this mix contained 1340 lbs. of sand, 300 lbs. of N.Y. No. 1 aggregate, $16801 \mathrm{bs}$. of N.Y. No. 2 aggregate and six bags of Type III Portland cement. The uniaxial compressive strength of the concrete was determined from tests of 6 " $\mathrm{x} 12$ " cylinders cast and cured alongside with each specimen.

Reusable plywood forms were used to cast the slabs. Drilled holes accurately positioned the reinforcement while allowing the bars to go through the form. An external wooden frame restricted the deformation of the sides of the form to within reasonable limits, held the rebars at 
their positions, and kept the form square. The form was coated with a light layer of oil to facilitate stripping.

The concrete was placed in the form and compacted with a hand vibrator to eliminate voids. The depth of the slab was accurately held to 6" by screeding the surface of the concrete using the form as a guide. Then the surface was smoothed with a trowel. The specimen and cylinders were kept moist for 7 days, then the form was stripped and the specimen was stored until it was tested.

\subsection{Loading, Test Setup, and Instrumentation}

Only one punch test was performed on each specimen. There were two different sizes of loading area used: $4^{\prime \prime} \times 4^{\prime \prime}$ and $8 " \times 8^{\prime \prime}$ and the slab was loaded at the center in both cases. The specimen rested on twelve concrete blocks with three along each edge. The dimensions of the blocks were $4 " \times 8 " \times 16^{\prime \prime}$. Between the blocks and the slab were $1 / 2 "$ thick support pads of plywood and another 1/2" thick plywood loading pad was placed between the punching shear load and the slab. The pads minimized the effect due to local surface irregularities and reduced the lateral restraint. They also reduced the stress concentrations at the corners and edges of the rigid square load ram which extended from the actuator to the slab. Also, the plywood took care of the local bending effect of the loading pad, especially for larger loading area. Thus the load could be assumed to be uniform over the loaded area. From the setup, the shear span was 18" and 16" respectively for the two loading pads, as shown in Fig. 3.2.

Although the support system directly supported only half of the total length of the perimeter, the support condition approximated a simple support condition, with corner uplift possible on this simply supported slab. 
Two independent reaction frames were employed to apply the tensile and punching shear stress to the specimens. The first reaction frame, shown in Fig. 3.3, consisted of eight separate frames which tensioned the reinforcing bars of the specimens. Each unit tensioned the four bars immediately adjacent to it by means of a steel block with transverse holes. The force was transmitted through nuts welded to the bar ends. One end piece per unit was directly acted upon by a hydraulic jack while the other was loaded by a vertical beam. The load was carried above and below the specimen by the system of pipes and vertical beams.

In order to stress all bars equally, the four jacks on each face had to apply the same force and this force had to be applied through the centroid of the bar group on which it acted. The jack forces were held constant in each direction by employing four identical jacks supplied with hydraulic pressure from a common manifold. Four 60-ton hollow core jacks were used for the heavily reinforced direction with four 30-ton similar jacks for the lightly reinforced direction.

The force from each jack was applied through the centroid of the bar group by careful alignment of each reaction frame unit. First, a pipe stub was welded to each vertical beam which accepted a jack. This stub was located at the height corresponding to the vertical centroid of the reinforcement. Thus once the hollow core jacks fit around the stub, it was automatically held at the correct height. Secondly, in order to accomplish the horizontal alignment, the positions of the reaction frame units on the floor were adjusted. In this way, the bars were uniformly tensioned.

In order to measure the tensioning loads, strain gages were attached to the rebars. One randomly selected bar in each direction was filed and 
smoothed on opposite sides to provide sufficient surface for strain gages. The gages were carefully applied at these prepared locations which were 12" from the slab. During the test, the load level in each direction was determined by monitoring the instrumented bars and was double checked by the readings of the pressure gages from the hydraulic jacks serving each of the two directions.

The second overhead reaction frame was used to apply the punching load. A 100-kip capacity hydraulic actuator was positioned in the vertical direction underneath a cross beam of the overhead frame as shown in Fig. 3.4. A 4" $\times$ 4" tubular ram with a solid, flat bearing surface was placed on the nose of the actuator to apply load to the specimen. The rest of the equipment was positioned relative to the actuator.

The data gathered included the bar tension, load, and corresponding deflection. The load was monitored directly from the actuator system and it was applied by the stroke control with $0.002 "$ increment so that postpeak data could be obtained. This procedure also gave adequate time for observation even during failure. Deflections were measured at five points (see Fig.3.2). Points 1 and 5 were right above the inner edge of concrete block. The deflections of these two points were used to determine the rigid body motion of the slab due to compression of the plywood and thus served as a baseline. Points 2 and 4 were located $4^{\prime \prime}$ from the edge of loading pad and served to determine the curvature near the load when the slab was loaded. Point 3 , at the center of the slab, was used to obtain the deflection. The dial gage was placed below the slab at this point while the other 4 gages were on the top surface. The net deflections at point 2 and 3 were obtained by subtracting the average of the deflections 
at points 2, 4 and the center from the average deflection of the base points. That is

$$
\begin{aligned}
& \Delta_{2}=\frac{\mathrm{D}_{2}+\mathrm{D}_{4}}{2}-\frac{\mathrm{D}_{1}+\mathrm{D}_{5}}{2} \\
& \Delta_{3}=\mathrm{D}_{3}-\frac{\mathrm{D}_{1}+\mathrm{D}_{5}}{2}
\end{aligned}
$$

where $D_{1}, D_{2}, D_{3}, D_{4}$, and $D_{5}$ were measured deflections and $\Delta_{2}, \Delta_{3}$ were net deflections. Al1 deflection measurements were made using 0.001 " dial gages.

\subsection{Test Procedure}

The slabs were marked along the reinforcement locations in both directions and the points of deflection measurement were also located before any load was applied to the specimen. The $4 " \times 4 "$ or $8 " \times 8$ " loading area was also marked on the slab. Once the slab was correctly positioned, the tensioning frames were constructed and aligned and the nuts were welded to the bars.

With all apparatus in place, the specimen was precracked. Each direction was stressed to produce cracking while the other direction was free from load. A bar stress of $0.6 \mathrm{f}$ was required to crack the specimens with \#6 and $\$ 4$ bars while $0.9 \mathrm{f}$ was needed for 3 bars. In general, the cracks formed perpendicular to the applied tension and along the transverse bars in the other direction. However, due to insufficient development length, cracks seldom formed along the reinforcement closest to the slab edges. The precrack pattern of the top face of the specimen was recorded for each test. They are shown in Fig. 3.5 for all specimens.

After the specimen was precracked, the tension leve1 was either released or set to the specified tension value and then held constant. 
The tubular ram and loading pad were positioned and small load of about 100 lbs. was applied to hold them in position. Initial readings were taken at this point. Load was then applied monotonically in increments. After each $0.002 "$ displacement increment of the load cell, the punching load level and readings of dial gages were recorded. The strain gages were checked and adjustments were made as necessary. In general, about 40 Increments were needed to reach failure.

When the slab reached the ultimate load, circumferential cracks mainly along the support and radial cracks toward the edge were found at bottom surface. The failure surface on the top face followed closely along the edges of the loading pad. Only minor spall-off at the bottom surface was observed. The failure surfaces are shown in Fig. 3.6 and Fig. 3.7

Upon the completion of the test, the reinforcing bars outside the slab were cut such that the slab could be removed from the tension frames. Both faces of the slab were photographed and then the concrete was chiseled off to help define the failure surface. Details of the results will be discussed in Chapter 4. 
CHAPTER 4

DISCUSSION OF EXPERIMENTAL RESULTS

\subsection{General}

Seven specimens in four series were tested, with each series having one main parameter to investigate. Series A, B, and C had two specimens each; both were precracked and one was tested with zero biaxial tension and the other with $0.8 \mathrm{f}$ biaxial tension. Series A dealt with shear span, which was increased from 6 inches (used by Abrams) to 18 inches as already shown in Fig. 3.2. Series B investigated the effect of increasing the loading area. A 8" $\times$ 8" square loading pad was used rather than a 4" $x$ 4" pad. Series $C$ was conducted to study the effect of steel ratio on the punching shear strength, with the large shear span and the 4 " $\times 4^{\prime \prime}$ loading pad. Finally, a single specimen in series D was done without precracking and with no biaxial tension, but with $8^{\prime \prime}$ x 8 " loading area to serve as baseline for series $B$. The load-displacement curves are plotted in Fig. 4.1, where 4.1 a) and 4.1 b) are from reference (1); 4.1 c) to 4.1 j) are from the present study.

Individual tests of this program were identified by a code which consists of two numbers and one letter. The first number, a decimal between 0 and 1 , designates the biaxial tension level applied during test, relative to the yield stress of steel. The second number is used to specify the size of loading pad, i.e. either 4 or 8 . The letter indicates the series to which the test belongs. For example, $0.8 \mathrm{~B} 8$ means one test of series $B$, with biaxial tension level $0.8 \mathrm{f}_{\mathrm{y}}$ and $8 " \mathrm{x} 8$ " loading pad. As observed from tests, the initial behavior under low load was nearly linear as was the curvature near the load. When the load reached a critical value, which varied from specimen to specimen, nonlinear 
relationships between both load-displacement and load-curvature began. This phenomenon held true until ultimate load was reached, which was accompanied by a sudden and brittle failure. The failure surface reached the bottom surface first, then, after extensive displacement, formed on the upper surface. The upper failure surface, as shown in Fig. 3.6, remained square along the loading pad but the bottom failure surface extended close to the supports in the circumferential direction, as shown in Fig. 3.7. At failure, cracks formed from A to D successively due to tension from the change of curvature as shown in Fig. 4.2. The upper surface above the inclined crack and the bottom surface of the punched plug were both relatively flat. As the slab was failing in punching shear, the load decreased and the concrete outside the failure surface moved upward while the plug moved downward in a rigid body mode, as shown in Fig 4.3. Greater displacements would cause radial cracks, mainly outside the fallure surface. The post-peak stiffness came largely from steel which might have yielded already due to a sharp change of slope at the fallure surface, which can be seen in Fig. 4.3. The load capacity remained constant in this range. Relatively little spall-off of the bottom surface and permanent out-of-plane deformation were found.

In general, ductility was increased for specimens with higher biaxial tension level, larger loading area, and lower steel ratio. The ultimate load capacity increased with larger loading pad and decreased with lower steel ratio. Higher biaxial tension level decreased the load-carrying capacity to different degrees, depending on loading condition and steel ratio.

Ultimate shear stresses were calculated according to ACI design equation, which evaluates the stress at a perimeter $b_{0}$, where $b_{0}$ is at a 
distance of $d / 2$ from the edge of the loading pad. The shear stress was then normalized by $\sqrt{f_{c}^{\prime}}$ to account for the effect of concrete strength. The average slab depth $d, 45 / 8 "$ and 4 13/16" for different steel ratios, was used in the calculations. These results are presented in Table 4.1. Because the behavior of slabs with biaxial tension differed from those without the membrane force, they are to be introduced briefly and separately in this section. More details are included in subsequent parts of this chapter.

4.1.1 General Behavior of Specimens without Biaxial Tension In general, the load-deflection curve was quite linear up to $90 \%$ of the ultimate load for specimen $0.0 \mathrm{~A} 4$, and up to $50 \%$ of the ultimate load for specimens $0.0 \mathrm{~B} 8$ and $0.0 \mathrm{C} 4$, which can be seen from Fig. 4.1c, 4.1e, and $4.1 \mathrm{~g}$ respectively. The initial slopes of the load-deflection curves of specimens $0.0 \mathrm{~A} 4$ and $0.0 \mathrm{~B} 8$ were about the same. The nonlinear part of behavior occurred earlier as the size of loading pad increased and as the steel ratio decreased. Horizontal splitting along the lower layer of reinforcement was observed in specimen $0.0 \mathrm{~B} 8$. The pre-existing cracks seem not to influence the $v_{u}$ at all if the slabs are of same steel ratio, which implies that the friction and aggregate interlock between crack surfaces is very effective in resisting shear force without failure.

4.1.2 General Behavior of Specimens with Biaxial Tension

Tests with biaxial tension showed less regularity among one another. However, the linear behavior was observed only at the beginning part of specimen $0.8 \mathrm{~A} 4$, and $0.8 \mathrm{C} 4$. A bilinear characteristic was found in specimen $0.8 \mathrm{~B} 8$, which can be seen in Fig. 4.1f. The reason for this bilinear behavior is that splitting occurred at that point and the slab was separated into two layers, thus reducing the rigidity of the specimen. 
A typical pre-formed crack is shown in Fig. 4.4. The crack width was a function of tensile force level. When the crack was widened by the tensile membrane forces, the aggregates on both sides of cracks did not bear on each other, while on the contrary, the aggregates were in contact for specimens without biaxial tension. Hence the shear transfer mechanisms were different at low load levels for these two categories.

At the time the slabs were loaded in punching shear, a small out-ofplane deformation was required to close the crack in order to mobilize membrane stresses to resist the applied load, as shown in Fig. 4.5. The neutral planes of these slabs were higher than those of specimens without biaxial tension, and the neutral planes kept on rising as load was increased. The biaxial tension can contribute to resisting the punching shear by its vertical component, as shown in Fig. 4.6, hence the slabs with tension should show a higher stiffness than the slabs without the tension. However, the vertical component is very small due to very small out-of-plane displacements compared to the shear span. Also, the local stresses near the load could be high enough to cause ylelding of steel bars, especially for bars in the tension zone, as shown in Fig. 4.7. In addition, "free" displacement is necessary for the two opposite faces to contact each other in order to transmit compression and shear stresses. Thus these reasons explain why the slabs with biaxial tension exhibited less stiff behavior. Ductility characteristic and lower ultimate strength can also be partly explained by the latter phenomena.

\subsection{Series A}

The primary parameter of this series was the shear span. This series contained two tests, one with a biaxial tension level of $0.0 \mathrm{f}_{y}$, and a second with $\mathrm{f}_{\mathrm{s}}=0.8 \mathrm{f}_{\mathrm{y}}$. Specimen $0.0 \mathrm{~A} 4$ had an ultimate strength of $72.4 \mathrm{kips}$ and a deflection of 0.159 in. at fallure. The load-deflection curve was 
linear up to $90 \%$ of ultimate load. The effective depth d was $45 / 8$ ", thus, $b_{o}$ equaled $34.5 \mathrm{in}$, which gave $b_{0} d=159.56 \mathrm{in}^{2}$. With $\mathrm{f}_{c}^{\prime}$ being equal to $4353 \mathrm{psi}$, the non-dimensionalized stress parameter $\frac{\mathrm{V}_{\mathrm{u}}}{\mathrm{b}_{\mathrm{o}} \mathrm{d}_{\mathrm{f}_{\mathrm{c}}^{\prime}}}$ equaled 6.88 . For specimen $0.8 \mathrm{~A} 4$, the ultimate strength was $65.8 \mathrm{kips}$, or $5.5 \%$ below that of test $0.0 \mathrm{~A} 4$, and the deflection at the center of the slab at failure was 0.232 in., a $46 \%$ increase over specimen $0.0 \mathrm{~A} 4$. The non-dimensionalized stress was 6.50, with $f_{c}^{\prime}$ being 4020 psi. A 1inear variation between biaxial tension and non-dimensionalized stress was assumed and a straight line was drawn by connecting these two points. This result confirmed Abrams' finding that the level of biaxial tension has only minor influence on strength. Ductility was increased when biaxial tension was applied without significantly reducing the shear capacity. By comparing the data from this series and the data from Abrams', it is obvious that as shear span increased from 6" to $18 "$, the non-dimensionalized stress also increased. This behavior demonstrates the role of shear span in determining the load-carrying capacity. The larger the shear span, the larger the membrane forces which serve as restraining forces, thus the larger the ultimate strength. The failure surfaces were approximately the same for these two tests, and are shown in Fig. $4.8 \mathrm{a}$ and $\mathrm{b}$.

\subsection{Series B}

The specimens were the same as in Series A, with the size of loading pad being the main parameter to be investigated, which was increased from $4 " \times 4 "$ to $8 " \times 8 "$. Since the dimensions of the slabs were not changed, the shear span was decreased to $16^{\prime \prime}$, instead of $18^{\prime \prime}$ in Series A and $b_{0}$ was increased to $50.5 \mathrm{in}$, which in turn changed $b_{0} d$ to $233.56 \mathrm{in.}{ }^{2}$. The spacing of adjacent rebars was 6", thus the 8" square loading pad extended over the reinforcements, as shown in Fig. 3.2. This geometry allowed 
a better assessment of the contribution of the steel bars to the punching shear strength of the slab. Specimen 0.0B8 gave an ultimate load of 90.1

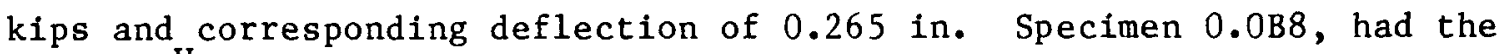
ratio $\frac{V_{u}}{b_{o} d \sqrt{f_{c}^{\prime}}}$ equal to 6.78 , which is very close to the value of 6.88 for specimen 0.044 . However, the deflection at failure was increased by $67 \%$. The linear behavior was observed up to $50 \%$ of the ultimate $10 a d$, and the initial slope was very close to that of specimen $0.0 \mathrm{~A} 4$, which implied that the behavior of initial stage of these two specimen was very similar. Horizontal splitting along the lower layer of reinforcements was found in specimen $0.0 \mathrm{~B} 8$ but not in specimen $0.0 \mathrm{~A} 4$. Splitting was accentuated because of higher stresses and larger deformation of reinforcements. In test $0.8 \mathrm{~B} 8$, the ultimate load was $68.8 \mathrm{kips}$ and corresponding deflection was $0.355 \mathrm{in.}$. In a comparison of the results of this specimen and specimen $0.0 B 8$, the ultimate strength dropped $23.6 \%$, and the displacement increased $34 \%$. If compared to specimen $0.8 \mathrm{~A} 4$, ( small loading pad) the ultimate load increased $4.5 \%$ and deflection at fallure increased 53\%. From these comparisons, it can be concluded that the larger the size of loading area, the higher the ultimate loads and the larger the deflections under the same biaxial tension level. However, after being normalized by $\sqrt{f}_{c}^{\prime}$, the non-dimensionalized stress was only $5.18,23.6 \%$ lower than specimen $0.0 \mathrm{~B} 8$ and $20.3 \%$ lower than specimen 0.8A4. This phenomenon suggests that biaxial tension does affect the ultimate unit punching shear stress under this special loading condition, i.e., load applied over the rebars. One reason for this behavior is that it has been acknowledged by Long (see Chapter 2) that only the steel in the immediate vicinity of load was effective in resisting the punching shear. Thus for specimen $0.8 \mathrm{~B} 8$ these effective bars (under the loading 
pad) yielded at much lower load because $0.8 \mathrm{f}$ stress had been applied prior to the application of punching load as compared to specimen $0.0 \mathrm{~B} 8$, and hence were not able to contribute to the punching shear strength. As for specimen $0.8 \mathrm{~A} 4$, although $0.8 \mathrm{f}$ biaxial tension level was applied also, the rebars were not right under the loading pad such that they were less stressed at the same punching load when compared to specimen $0.8 \mathrm{~B} 8$. Thus lower non-dimensionalized stress of specimen $0.8 \mathrm{~B} 8$ can be anticipated.

Another possible reason is that the definition of $b_{0}$ is not a good parameter to determine the punching shear stress. The bilinear characteristic of test $0.8 \mathrm{~B} 8$ was due to horizontal splitting, which in turn decreased the rigidity of the slab, and thus the stiffness. The discontinuity occurred at about $60 \%$ of ultimate load. The failure surface was along the periphery of loading pad on the top and was along the support on the bottom, as shown in Fig. $4.8 \mathrm{~d}$.

\subsection{Series C}

The steel ratio, which was the main parameter investigated in this series, was changed from $(0.0317,0.0144)$ to $(0.0136,0.0076)$ by using \#4 and $\# 3$ bars instead of $\# 6$ and $\# 4$ bars. This change helps determine the effectiveness of reinforcement in punching shear strength. As before, two specimens were tested at $0.0 \mathrm{f}_{\mathrm{y}}$ and $0.8 \mathrm{f}$ y biaxial tension levels with a 4 in. by 4 in. loading pad.

The ultimate shear strength was significantly reduced to 50.2 kips for specimen $0.0 \mathrm{C} 4$ and $41.6 \mathrm{kips}$ for $0.8 \mathrm{C} 4$, with displacements at failure 0.257 and 0.381 inches. For specimen $0.0 \mathrm{C} 4$, the load-carrying capacity was reduced by $30.7 \%$ and the deflection was increased by $62 \%$ as compared to specimen 0.0A4. The compressive strength of concrete $f_{c}^{\prime}$ was $3155 \mathrm{psi}$, and the non-dimensionalized ratio was 5.73 , a drop of $16.7 \%$ compared to 
test $0.0 \mathrm{~A} 4$. This drop agreed well with Long's approach to computing the punching shear strength of reinforced concrete slabs (Eq. 2.8 in Chapter 2). The load-deflection curve (F1g. 4.1g) showed a tri-1inear behavior, which could be reasoned as follows: at point $A$, cracks inside the slab began to form because more load were carried by concrete when compared to Series A. At point B, yield of reinforcements started, because of the smaller bars.

For specimen $0.8 \mathrm{C} 4$, the ultimate punching shear strength was reduced to 41.6 kips, a $36.8 \%$ drop and the corresponding displacement 0.381 in., an increase of $64 \%$ as compared to specimen $0.8 \mathrm{~A} 4$. Comparison between tests 0.004 and $0.8 \mathrm{C} 4$ showed $17.1 \%$ drop in strength and $48 \%$ increase in displacement as tension was increased from $0.0 \mathrm{f}_{\mathrm{y}}$ to $0.8 \mathrm{f}_{\mathrm{y}}$. The conclusion can be drawn that a lower steel ratio will decrease the flexural strength and dowel action which in turn reduce the punching shear strength and that the membrane tension will decrease the punching capacity for the specimens of less reinforcement. The non-dimensionalized stress was 4.49 for specimen $0.8 \mathrm{C} 4$, which showed a drop of $30.9 \%$ with respect to specimen $0.8 \mathrm{~A} 4$ and a drop of $21.6 \%$ relative to specimen 0.0C4. Because the diameters of reinforcement were changed, the effective depth also changed somewhat from $45 / 8$ " to $413 / 16 "$, thus $b_{0}$ was $35.25 \mathrm{in}$. and $\mathrm{b} \mathrm{d}$ was $169.64 \mathrm{in}^{2}$.

The load-deflection curve of specimen $0.8 \mathrm{C} 4$ (Fig. $4.1 \mathrm{~h}$ ) was rather complex. It is supposed that at point A, yield of steel and crack formation interior of concrete began; at point B, strain hardening took place, and at point $\mathrm{C}$, horizontal splitting along the lower layer of reinforcement occurred. Explanation of this behavior is similar to that of test $0.0 \mathrm{C} 4$, except yielding is even earlier because of the existence of biaxial tension and thus the subsequent strain hardening. 
Although the loading pad was not directly over the rebars in Series C, yielding of reinforcement, as described in the paragraph above, was found and was confirmed by the larger permanent out-of-plane deformation. This can be explained as follows: When the punching force was applied, the load was carried by both the concrete and the steel bars, since the areas of $\# 4$ and $\# 3$ bars were smaller than those of $\# 6$ and $\# 4$ bars, the stresses in the bars of Series $C$ must be higher under the same load. Thus these smaller bars reached $f_{y}$ at lower load levels and consequently reduced the punching shear capacity by reducing the normal stiffness across the crack and the dowel action. The failure surfaces of this series were approximately the same and are shown in Fig. 4.8 e and $\mathrm{f}$. 4.5 Series D

One slab with no precracking and zero biaxial tension was tested. The geometry and steel ratio were the same in Series A and B, with a 8" $\times$ 8" square loading pad. The main purpose of this test was to determine a baseline strength for uncracked untensioned slabs. This test, however, yielded even a slightly lower punching shear strength than 0.0B8, where the specimen was precracked. This phenomenon can be explained by the scattered properties of concrete. More tests are necessary to reach a reasonable average value. The ultimate strength was 84.3 kips with the displacement at failure being 0.228 in., and the $\frac{v_{u}}{b_{o} d_{c}}$ ratio was 6.26 .

Referring to the load-displacement curve, the initial slope was larger than those of $0.0 \mathrm{~A} 4$ and $0.0 \mathrm{~B} 8$, because specimen $\mathrm{D}$ was not precracked. Linear behavior followed this initial stage and showed a slope close to those of slab $0.0 \mathrm{~A} 4$ and $0.0 \mathrm{~B} 8$, as shown in Fig. $4.1 \mathrm{j}$, thus implying a similar interior shear transfer mechanism in all the three slabs. 
The failure deflection was smaller than that of test $0.0 \mathrm{~B} 8$, but larger than that of $0.0 \mathrm{~A} 4$.

From this test result, it is suggested that cracks have only a minor effect on punching shear capacity and they affect only the initial stiffness of the slab.

4.6 Summary

The ultimate load was normalized and non-dimensionalized by $b_{0} d \sqrt{f_{c}^{r}}$, according to the ACI approach, and is tabulated in Table 4.1. The relationship between normalized ultimate punching shear stress versus biaxial tension is plotted in Fig. 4.9; where a linear relationship between the normalized stress and biaxial tension was used.

Because the failure surface did not follow the tension-induced cracks, it is obvious that the force from friction and aggregate interlock between the faces of the cracks is very effective and transfers the punching shear force without failure, and thus new cracking and the tensile strength of concrete dominate. The effect of the four parameters investigated in this program may be summarized as follows:

$\underline{4.6 .1}$ Shear Span

Two shear spans were compared, $h$ and $3 h$, where $h$ is the total thickness of specimen, by using Abrams' data and Series A. It is found that specimens with larger shear span were about $10 \%$ stronger than the shorter span specimens at $0.0 \mathrm{f}_{\mathrm{y}}$ biaxial tension and were about $38 \%$ stronger at $0.8 f_{y}$ level.

\subsubsection{Steel Ratio}

Two sets of steel ratios were used: $(0.0317,0.0144)$ and $(0.0136$, $0.0076)$. Since the flexural stiffness does contribute to the punching shear strength, which was acknowledged in Chapter 2, it follows that by 
reducing the steel ratio, the punching shear strength should be also reduced. The lower values of $\rho$ led to a reduction of $16.7 \%$ in normalized stress at $0.0 \mathrm{f}_{\mathrm{y}}$ and $30.9 \%$ at $0.8 \mathrm{f}_{\mathrm{y}}$ biaxial tension level, when compared to specimens $0.0 \mathrm{~A} 4$ and $0.8 \mathrm{~A} 4$.

\subsubsection{Loading Area}

Two different loading areas were employed, 4" $\times 4 "$ and $8 "$ × 8". The total ultimate load capacity was increased with increased loading area. With zero biaxial tension the loading area had little effect on the normalized shear strength. However, the existence of biaxial tension decreased the $\frac{v_{u}}{b_{0} d \sqrt{f_{c}^{T}}}$ ratio by about $20 \%$.

4.6.4 Biaxial Tension Leve1

$0.0 \mathrm{f}_{\mathrm{y}}$ and $0.8 \mathrm{f}_{\mathrm{y}}$ biaxial tension levels were used throughout. From Fig. 4.9, it is seen that biaxial tension affects the stress to different degrees, under different conditions. Linear variations were assumed in drawing this figure as Abrams' specimens showed this type of relationship to be valid. 
CHAPTER 5

COMPARISON BETWEEN TEST DATA

AND PREDICTIONS BY VARIOUS FORMULAS

\subsection{General}

In this chapter the equations derived by different investigators (reviewed in Chapter 2) are used to predict the punching shear strength. These values are then compared with test data obtained in the present study. Discussions will be included for each of the equations on their relative advantages and deficiencies. Because only Abrams' and Mattock's equations included membrane tension, they are used for all seven slabs. The equations derived by others are applied only to specimens without biaxial tension because these expressions do not account for the effect of tension.

\subsection{Yitzhaki's Equation}

His equation, based mainly on the strength of reinforcement, predicts the normalized shear strength parameter of $7.37,7.10,6.28,7.06$ for specimens $0.0 \mathrm{~A} 4,0.0 \mathrm{~B} 8,0.0 \mathrm{C} 4$ and $0.0 \mathrm{D} 8$, respectively. These values are larger than the test results by $7.1 \%, 4.8 \%, 19.1 \%$ and $12.8 \%$. The largest deviation $(19.1 \%)$ for specimen $0.0 \mathrm{C} 4$ is due to the terms containing $\rho$ may not entirely appropriate, because $\rho$ is the only variable between specimen $0.0 \mathrm{~A} 4$ and specimen $0.0 \mathrm{C} 4$. But the deviations for specimens $0.0 \mathrm{~A} 4,0.0 \mathrm{~B} 8$ and $0.0 \mathrm{D} 8$ are relatively smaller, which implies that

the term $\left(1+\frac{c}{2 d}\right)$, which includes the size of loading area, may be a good approach. This term gave 1.43 and 1.86 for the two different loading conditions. 


\subsection{Long's Equation}

Equation 2.7 predicts $5.36,3.97,4.41$ and 4.02 for the critical stress of specimens $0.0 \mathrm{~A} 4,0.0 \mathrm{~B} 8,0.0 \mathrm{C} 4$, and $0.0 \mathrm{D} 8$. These values are a11 lower than the test results, by percentages of $22.1,41.4,16.3$, and 35.6. By further investigation into his equation, it can be found that the term $(100 \rho)^{0.25}$ is a good approximation to the effectiveness and contribution of reinforcement to punching shear strength, because after substituting $\rho=(0.0317,0.0144)$ and $(0.0136,0.0076)$ into $(100 \rho)^{0.25}$, it gives 1.232 and 1.015 respectively. These values in turn yield a $17.7 \%$ drop which is quite consistent with the test data where a $16.7 \%$ drop was found $(6.88$ and 5.73$)$. From his derivation of Eq. 2.8, it can be found that steel bars are assumed to be in elastic range at failure, which is not guaranteed under most cases. As discussed in chapter 2, reinforcement near the load or in the tension zone may yield at failure; thus failures generally fall between pure flexural and pure shear type. It may be expected that Long's equation could yield a better result if the yielding of steel bars does not occur anywhere at anytime. However, the location of first crack formation, which was at the junction of column and slab in Long's test, was not observed until failure in the present test; stress concentration could be important in explaining this phenomenon.

\subsection{Moe's Equation}

Equation $2.9 \mathrm{~b}$ predicted the "normalized stress" of $4.05,7.50,4.05$ and 7.60 for specimens $0.0 \mathrm{~A} 4,0.0 \mathrm{~B} 8,0.0 \mathrm{C} 4$, and $0.0 \mathrm{D} 8$. The differences in percentage are $-41.1,10.6,-23.2$, and 21.5 respective1y, taking test data as base, where minus sign means the predicted value is less than the test result. The deficiency of Moe's equation is that the steel ratio as 
well as shear span is not included. Also, $v_{u}$ was underestimated for the specimens with small loading pad and was overestimated for larger loading area cases, which implies the constants of the general form $\left[k_{1}+k_{2}\left(\frac{c}{d}\right)\right.$ or $\left(\frac{d}{c}\right)$ ] need improvement. However, Moe found that most of the reinforcement was yielding locally over the colum but not throughout the slab at failure, which agreed with the present tests. On the contrary, the failure surface of Moe's model presented in Fig. 2.2 was different from what was found in the present study which was shown in Fig. 4.8. A possible reason is the stress concentration at the junction of column and slab. Moreover, the locations of crack initiation were different just as explained in section 5.3 .

\subsection{Concrete P1asticity}

By using the concrete plasticity approach, the normalized punching shear stress was found to be $7.34,8.31,7.21$ and 8.42 for specimens 0.0 $\mathrm{A} 4,0.0 \mathrm{~B} 8,0.0 \mathrm{C} 4$, and $0.0 \mathrm{D} 8$. These values overestimated the strength of the slabs by $6.7 \%, 22.6 \%, 25.8 \%$ and $34.5 \%$. Because the derivation of this theory required edge restraint and non-yielding of the bars (both of which were not satisfied in the present study) it became clear why higher values were predicted. For test $0.0 A 4$, the deviation is smallest, because yielding of reinforcement was only very local and the other rebars which remained elastic supplied an edge-restraint force. Thus, in the general case, if the two requirements (edge-restraint and non-yielding) can be fulfilled, the plasticity theory may be expected to give good results. The failure paths predicted by this theory agreed with those observed here and did not change much from slab to slab. 
5.6 Mattock's Method

His equation can be rewritten as $v_{u}=400+0.8 \rho f_{y}\left(1-\frac{f_{s}}{f_{y}}\right)$ by

using $\sigma_{n}=\rho f_{y} \frac{f_{s}}{f_{y}}$, negative for tension. In order to use this equation, $\rho$ is halved because only half of the steel was in tension zone during

test. The predicted non-dimensionalized stress parameters were tabulated in Table 5.1. These values were much higher than the test data, because first, 400 psi was assumed as the shear friction stress for all kinds of concrete, and secondly, all the steel was assumed to yield. Furthermore, since the failure surfaces did not follow the pre-existing cracks, it is obvious that the friction force between crack surfaces can be very large without the failure of the concrete, thus the high predicted value can be anticipated. An important reason for the inappropriateness of Mattock's equation is that his equation was derived and used for corbel type and standard push-off test, not to be used for punching shear analysis, although some similarities in stresses existed between these two type of tests.

\subsection{Abrams' Equation}

Equation 2.16 in Chapter 2 was based on his test data, where a smaller shear span ( 6 in.) was used. This equation underestimates the normalized stress parameters of the seven tests, shown in Table 5.1, because the shear span was different from those in the present tests and the size of loading pad was not included. But the effect of biaxial tension observed by him and by the recent work was in agreement, i.e., a weak relationship between normalized punching shear stress and biaxial tension. 
CHAPTER 6

ANALYTICAL APPROACHES TO PUNCHING SHEAR

AND DESIGN IMPLICATIONS

\subsection{General}

Punching shear action in a flat slab is basically a three-dimensional problem. However, for an isotropically reinforced circular slab of constant depth, it may be reduced to a two-dimensional problem because of the axisymmetric characteristics. Hence a three-dimensional computer code using the finite element method is not necessary. A two-way orthogonally reinforced concrete slab can be transformed to an equivalent circular, axisymmetrically reinforced slab with little error; thus a twodimensional finite element computer program is adequate to simulate the punching shear problems. Since the precracking did not affect the behavior at linear range and the ultimate capacity, the slabs were assumed to be linear elastic and no cracks were included. Victor Saouma, a former graduate student of Cornell, developed a finite element analysis program (FEFAP), which was used to analyze the behavior of an axisymmetric slab subjected to external punching load.

\subsection{Effect of Edge Restraint on Homogeneous Circular Slab Behavior}

In Chapter 2 it was pointed out that edge restraint would increase the punching load capacity, reduce the deflection and the width of cracks. In order to examine this effect, six slabs were analyzed with different $h / L$ ratios: $1 / 4,1 / 8$, and $1 / 16$, where $h$ is the thickness and L the diameter of the slab with $L$ unchanged for these three pairs of slabs. Two slabs were studied for each $h / L$ ratio with the difference between the two models being the stiffness of the outer ring which surrounded the circular slab and supplied the restraining forces; the 
Young's modulus of the outer ring material was $E_{c}$ or $10 E_{c}$, where $E_{c}$ is the Young's modulus of concrete. The $d / h$ ratio, ( $d$ is the diameter of loading area) was maintained at 1.0 for the three pairs. The outer ring had the same thickness as the slab and a width of $\mathrm{L} / 16$. The maximum deflection and stresses are tabulated in Table 6.1.

From Table 6.1 it is apparent that when E' (Young's modulus of ring) was increased by a factor of ten, the maximum deflection and maximum principal tensile stresses decreased, and the maximum tensile stress in the ring increased. However, the effectiveness of the edge restraint varied from one slab to another. In terms of maximum deflection, if the slab is thick enough, then the slab itself supplies sufficient restraint force and thus the external restraining force is not important, which is the case for slabs $1 \mathrm{a}$ and $1 \mathrm{~b}$. On the other hand, if the slab is very thin, then the edge restraint cannot help much because the slab itself is so flexible and the ring is also less stiff because it is reduced in $h$ too, which is the case for slabs $3 a$ and $3 b$. As for the effect of the edge restraint on maximum principal tensile stress, it is seen from Table 6.1 that the thinner the slab, the less effective the edge restraint under the condition studied. However, the percentage change of maximum tensile stress in the ring continuously increases as the slabs become thinner. But all these changes are smaller than the factor of ten used for $E^{\prime}$, which implies the edge restraint is not an efficient means to increase the strength of a slab subjected to punching shear. Although the outer ring is not efficient in supplying the restraining forces, the confining stresses always make the stresses in the slab smaller, which is helpful in increasing the load capacity. This behavior also makes the location of crack formation and propagation shift toward 
the axis of symmetry. But, the thinner the slab, the less is the shift, which again coincides with the previous conclusion that edge restraint has relatively little effect on thin slabs.

6.3 Elastic Analysis of Axisymmetrically Reinforced Slab under Concentrical Punching Shear Force

A $24 "$ radius and 6" thick axisymmetrically reinforced concrete slab was used for finite element analysis in order to simulate the slabs in the present study. Three cases were analyzed to examine the correlation between the finite element model and test results. As recommended by Long (8), the radius of the equivalent circular loading area was 0.6 times the side of square loading pad, which became $2.4^{\prime \prime}, 4.8^{\prime \prime}$, and $2.4 "$ respectively for specimen $0.0 \mathrm{~A} 4,0.0 \mathrm{~B} 8$, and $0.0 \mathrm{C} 4$. The mesh is shown in Fig. 6.2

Since the failure was sudden and brittle, it is postulated that when any point within the concrete reaches its tensile strength $\left(9.5 \sqrt{f_{C}^{r}}\right.$ modulus of rupture), the slab is assumed to fail, i.e., the maximum principal tensile stress criterion governs. According to this assumption, the ultimate load was calulated and compared with test data, the results are shown in Table 6.2. From the comparisons, it is obvious that the calculated ultimate 1 oad was about $70 \%$ of the load from test, which indicates that the initiation of cracking does not mean the fallure of the slab. 6.4 Design Implications

In contrast to ACI Codes $359 \& 349$, true punching shear strength is only slightly related to biaxial tension level. The present study confirms Abrams' equation to be a reasonable and conservative representation of both his data and the present study. However, in order to conform with ACI value of $4 \sqrt{\mathrm{f}}$ c for zero tension, Abrams' equation was divided by $3 / 2$ to give the following equation: 


$$
v_{u}=\left(4-\frac{f_{s}}{f_{y}}\right) \sqrt{f}_{c}^{\prime} \quad f_{s} \leq 0.9 f_{y}
$$

where $v_{u}$ is the shear stress capacity on an area $b_{0} d b_{0}=$ perimeter of section at $\frac{d}{2}$ from the face of loaded area) as the best current estimate for design purposes. Equation 2.16 a may eventually be refined to include more factors such as steel ratio, size of loading area, shear span, support condition, and thickness of slabs for better prediction.

In order to take the effect of steel ratio on punching strength into account, Eq. 2.16a is modified as follows:

$$
\begin{array}{lll}
v_{u}=\left(4-\frac{f_{s}}{f_{y}}\right)(43 \rho)^{0.25} \sqrt{f_{c}^{\prime}} & \rho \leq 0.023 & 2.17 a \\
v_{u}=\left(4-\frac{f_{s}}{f_{y}}\right) \sqrt{f_{c}^{\prime}} & \rho>0.023 & 2.17 b
\end{array}
$$

and $\rho$ is taken as the average value of the steel ratio in the two orthogonal directions.

other factors may need more attention, such as (a) punching action at penetrations that run completely through the containment wall, (b) difference in punching shear strength of curved wall vs. flat slab, (c) cyclic loading, and (d) when steel is stressed to yield in tension. 
CHAPTER 7

SUMMARY, CONCLUSIONS AND RECOMMENDATIONS

FOR FUTURE RESEARCH

\subsection{Summary}

This research was designed to study the effect of 1) shear span, 2) steel ratio, 3) loading area, and 4) biaxial tension level on punching shear strength of reinforced concrete slabs. Seven $4 \mathrm{ft}$. square, 6 in. thick specimens with various values of steel ratio, loading area, and biaxial tension level have been tested to failure. The square slab was designed to simulate a cracked section of containment vessel. The test data were compared to previous research results for a better understanding of the punching shear behavior of slabs and the prediction of their ultimate strength. Comparisons were also made with current provisions of the ACI Code and European codes.

The experimental puching shear strength results showed only slight dependence on the level of the biaxial tension applied to slabs. The equation

$$
v_{u}=\left(4-\frac{f_{s}}{f_{y}}\right) \sqrt{f_{c}^{\prime}} \quad \text { for } f_{s} \leq 0.9 f_{y}
$$

is suggested for design.

\subsection{Conclusions}

Tension-induced precracking affects the behavior of slabs without biaxial tension only at early load stages, and has little effect at subsequent stages and on the ultimate strength. The failure was always sudden and brittle without warning. The failure path did not follow the pre-formed orthogonal tension cracks, instead, it was along the edge of loading pad on the top and extended within the slab to near the supports 
at the bottom. From this observation, it is concluded that aggregate interlock is so strong that it can transfer the punching shear force between crack faces without failing and consequently the tensile strength dominates the ultimate capacity.

The factors investigated at the present studies and their effects can be concluded as follows.

\subsubsection{Effect of Biaxial Tension on Punching Shear Strength}

Punching shear strength is only slightly related to biaxial tension

level, as also concluded by Abrams. More flexible behavior was also observed for slabs under higher biaxial tension level.

7.2.2 Effect of Size of Loading Area on Overall Behavior

Larger loading area always yields larger ultimate load, but not necessarily larger non-dimensionalized stress calculated on a section $\frac{d}{2}$ from the face of the loaded area. Out-of-plane deformation also increased with increased loading pad size.

\subsubsection{Effect of Shear Span on Load Capacity}

Larger shear span can increase the ultimate load-carring capacity by supplying more membrane forces which serve as restraining forces. This factor can also changes the failure path. 7.2.4 Effect of Reinforcement Ratio on Ultimate Punching Shear Strength

Reinforcements contribute to resisting punching load by dowel action, membrane action, and kinking action, thus it becomes obvious that the higher the steel ratio, the higher the punching shear strength. 


\subsection{Recommendations for Future Study}

\subsubsection{Experimental Work}

Although the data from both Abrams and the present study showed only a slight correlation between punching shear stress and biaxial tension, a comprehensive understanding of the true behavior and mechanism of the slab under punching force is still not available. Two major variables needing more studies are:

i) loading on a penetration through the slab, and

ii) loading on much thicker slabs for better simulation of the containment vessel.

Other factors include curved specimen, shear span (shear span/thickness ratio), steel ratio, as well as distribution and effectiveness of reinforcement. Other loading conditions that need attention include steel stresses up to $f_{y}$, slab subjected to simultaneous membrane shear and punching load, and uniaxial tension plus punching load.

\subsubsection{Numerical Analysis}

Numerical methods based on finite element and fracture mechanics may form a good approach for understanding and predicting the punching shear problem. 


\begin{tabular}{|c|c|c|c|}
\hline Sieve Size & Sand & N.Y. 非 & N.Y. \#2 \\
\hline $11 / 2$ in. & & & 100 \\
\hline 1 & & & 99 \\
\hline $3 / 4$ & & 100 & 87 \\
\hline $1 / 2$ & & 98 & 7 \\
\hline $3 / 8$ & 100 & 70 & 1 \\
\hline$\$ 4$ & 99 & 2 & \\
\hline \# 8 & 90 & 1 & \\
\hline \#16 & 65 & & \\
\hline$\# 30$ & 25 & & \\
\hline$\$ 50$ & 9 & & \\
\hline$\# 100$ & 2 & & \\
\hline$\# 200$ & 1 & & \\
\hline
\end{tabular}

Table 3.1 Gradation of Aggregates 


\begin{tabular}{|c|c|c|c|c|c|c|c|c|c|c|c|}
\hline $\begin{array}{l}\text { s lab } \\
\text { code }\end{array}$ & Bar & Size & $\begin{array}{c}\text { Steel } \\
\text { Ratio } \\
\rho\end{array}$ & $b_{0}$ in. & d in. & $b_{o} d, \ln .^{2}$ & $f_{c}^{\prime}, p s i$ & $\frac{f_{s}}{f_{y}}$ & $\begin{array}{l}v_{u,} \\
\text { kips }\end{array}$ & $\begin{array}{r}v_{u}, \\
\text { psi }\end{array}$ & $\frac{v_{u}}{\sqrt{f^{r}}}$ \\
\hline $0.0 \mathrm{A4}$ & $\# 6$ & $\# 4$ & $\begin{array}{l}(0.0317) \\
(0.0144)\end{array}$ & 34.5 & $45 / 8$ & 159.56 & 4353 & 0.0 & 72.4 & 454 & 6.88 \\
\hline $0.8 \mathrm{~A} 4$ & $\$ 6$ & $\# 4$ & $(" n)$ & $"$ & •• & $"$ & 4020 & 0.8 & 65.8 & 412 & 6.50 \\
\hline $0.0 \mathrm{~B} 8$ & $\# 6$ & $\$ 4$ & $(")$ & 50.5 & $"$ & 233.56 & 3235 & 0.0 & 90.1 & 386 & 6.78 \\
\hline $0.8 \mathrm{~B} 8$ & \#6 & $\$ 4$ & $(")$ & $"$ & $"$ & $"$ & 3229 & 0.8 & 68.8 & 295 & 5.18 \\
\hline $0.0 \mathrm{C4}$ & $\$ 4$ & \#3 & $\begin{array}{l}(0.0136) \\
(0.0076)\end{array}$ & 35.3 & $413 / 16$ & 169.64 & 3155 & 0.0 & 50.2 & 322 & 5.73 \\
\hline $0.8 \mathrm{C4}$ & \#4 & $\# 3$ & $(")$ & $"$ & $"$ & ". & 3396 & 0.8 & 41.6 & 262 & 4.49 \\
\hline $0.0 \mathrm{D} 8$ & 非 6 & 非 4 & $\begin{array}{l}(0.0317) \\
(0.0144)\end{array}$ & 50.5 & $45 / 8$ & 233.56 & 3325 & 0.0 & 84.3 & 361 & 6.26 \\
\hline
\end{tabular}

Table 4.1 Test Results 


\begin{tabular}{|c|c|c|c|c|c|c|c|c|c|c|c|c|c|}
\hline $\begin{array}{l}\text { slab } \\
\text { code }\end{array}$ & Test & Yitzhaki & $\%$ & Moe & $\%$ & Long & $\%$ & Plasticity & $\%$ & Mattock & $\%$ & Abrams & $\%$ \\
\hline $0.0 \mathrm{~A} 4$ & 6.88 & 7.37 & 7.1 & 4.05 & -41.1 & 5.36 & -22.1 & 7.34 & 6.7 & 14.45 & 110.0 & 6.0 & 12.8 \\
\hline $0.8 \mathrm{~A} 4$ & 6.50 & & & & & & & & & 8.05 & 23.8 & 4.8 & 26.2 \\
\hline $0.0 \mathrm{~B} 8$ & 6.78 & 7.10 & 4.8 & 7.50 & 10.6 & 3.97 & -41.4 & 8.31 & 22.6 & 16.76 & 147.2 & 6.0 & 11.5 \\
\hline $0.8 \mathrm{~B} 8$ & 5.18 & & & & & & & & & 8.99 & 73.6 & 4.8 & 7.3 \\
\hline $0.0 \mathrm{C} 4$ & 5.73 & 6.28 & 19.1 & 4.05 & -23.2 & 4.41 & $-16 \cdot 3$ & 7.21 & 25.8 & 12.78 & 142.5 & 6.0 & 13.9 \\
\hline $0.8 \mathrm{C} 4$ & 4.49 & & & & & & & & & 7.96 & 89.1 & 4.8 & 14.0 \\
\hline $0.0 \mathrm{D} 8$ & 6.26 & 7.06 & 12.8 & 7.60 & 21.5 & 4.02 & -35.6 & 8.42 & 34.5 & 16.53 & 164.1 & 6.0 & 4.2 \\
\hline
\end{tabular}

Table 5.1 Normalized Failure Stresses from Test Results and as Predicted by Different Researchers. 


\begin{tabular}{|c|c|c|c|c|c|c|c|c|c|c|c|c|c|}
\hline \multirow[b]{2}{*}{ Palr } & \multirow{2}{*}{$\frac{\mathrm{h}}{\overline{\mathrm{L}}}$} & \multirow{2}{*}{$\frac{d}{h}$} & \multicolumn{2}{|c|}{ Max. Deflection } & \multirow{2}{*}{$\begin{array}{l}\text { percentage } \\
\text { decrease }\end{array}$} & \multicolumn{4}{|c|}{ Max. Stress } & \multirow{2}{*}{$\begin{array}{l}\text { percentage } \\
\text { decrease }\end{array}$} & \multicolumn{2}{|c|}{ Max. Stress at ring } & \multirow[b]{2}{*}{$\%$} \\
\hline & & & $E^{\prime}=E_{c}$ & $E^{\prime}=10 E_{c}$ & & $E^{\prime}=E_{c}$ & $\underset{\#}{\mathrm{e}} \mathrm{lem}$. & $E=10 E_{c}^{\prime}$ & $\underset{f}{e}$ lem. & & $E^{\prime}=E_{c}$ & $E^{\prime}=1 O E_{c}$ & \\
\hline 1 & $1 / 4$ & 1 & $7.02 \times 10^{-6}$ & $5.95 \times 10^{-6}$ & 15.2 & $6.64 \times 10^{-1}$ & 1 & $5.60 \times 10^{-1}$ & 1 & 15.7 & $1.79 \times 10^{-1}$ & 1.01 & 464.2 \\
\hline 2 & $1 / 8$ & 1 & $9.55 \times 10^{-6}$ & $7.62 \times 10^{-6}$ & 20.2 & $8.74 \times 10^{-1}$ & 1 & $7.81 \times 10^{-1}$ & 1 & 10.6 & $1.79 \times 10^{-1}$ & 1.02 & 469.8 \\
\hline 3 & $1 / 16$ & 1 & $1.43 \times 10^{-5}$ & $1.22 \times 10^{-5}$ & 14.7 & 1.04 & 1 & $9.93 \times 10^{-1}$ & 1 & 4.5 & $1.24 \times 10^{-1}$ & $7.93 \times 10^{-1}$ & 539.5 \\
\hline
\end{tabular}

Table 6.1 Finite Element Study of Effects of Edge Restraint 


\begin{tabular}{|c|l|l|c|c|}
\hline slab \# & $f_{c}^{\prime}, \mathrm{ksi}$ & $\mathrm{f}_{\mathrm{t}}, \mathrm{ksi}$ & $\mathrm{P}_{\text {critical, kips }}$ & $\frac{\mathrm{P}_{\text {critical }}}{\mathrm{test}} \%$ \\
\hline $0.0 \mathrm{~A} 4$ & 4.353 & 0.627 & 53.0 & 73.2 \\
\hline $0.0 \mathrm{~B} 8$ & 3.235 & 0.404 & 67.3 & 74.7 \\
\hline $0.0 \mathrm{C} 4$ & 3.155 & 0.534 & 37.3 & 74.3 \\
\hline
\end{tabular}

Table 6.2 Finite Element Analysis of Slabs Simulating the Present Study 


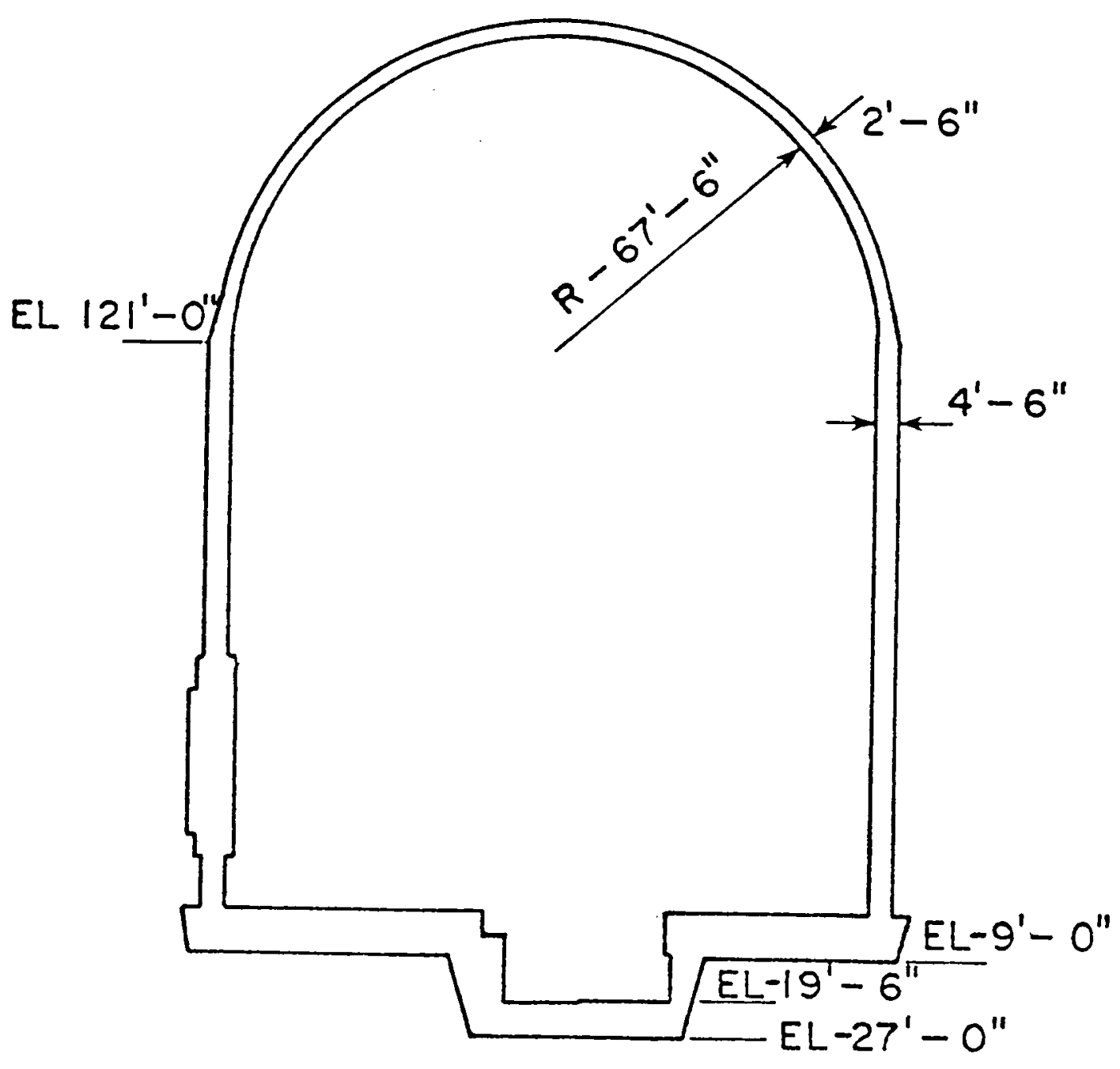

From Reference (1)

Fig. 1.1 Typical Nuclear Containment Vessel 


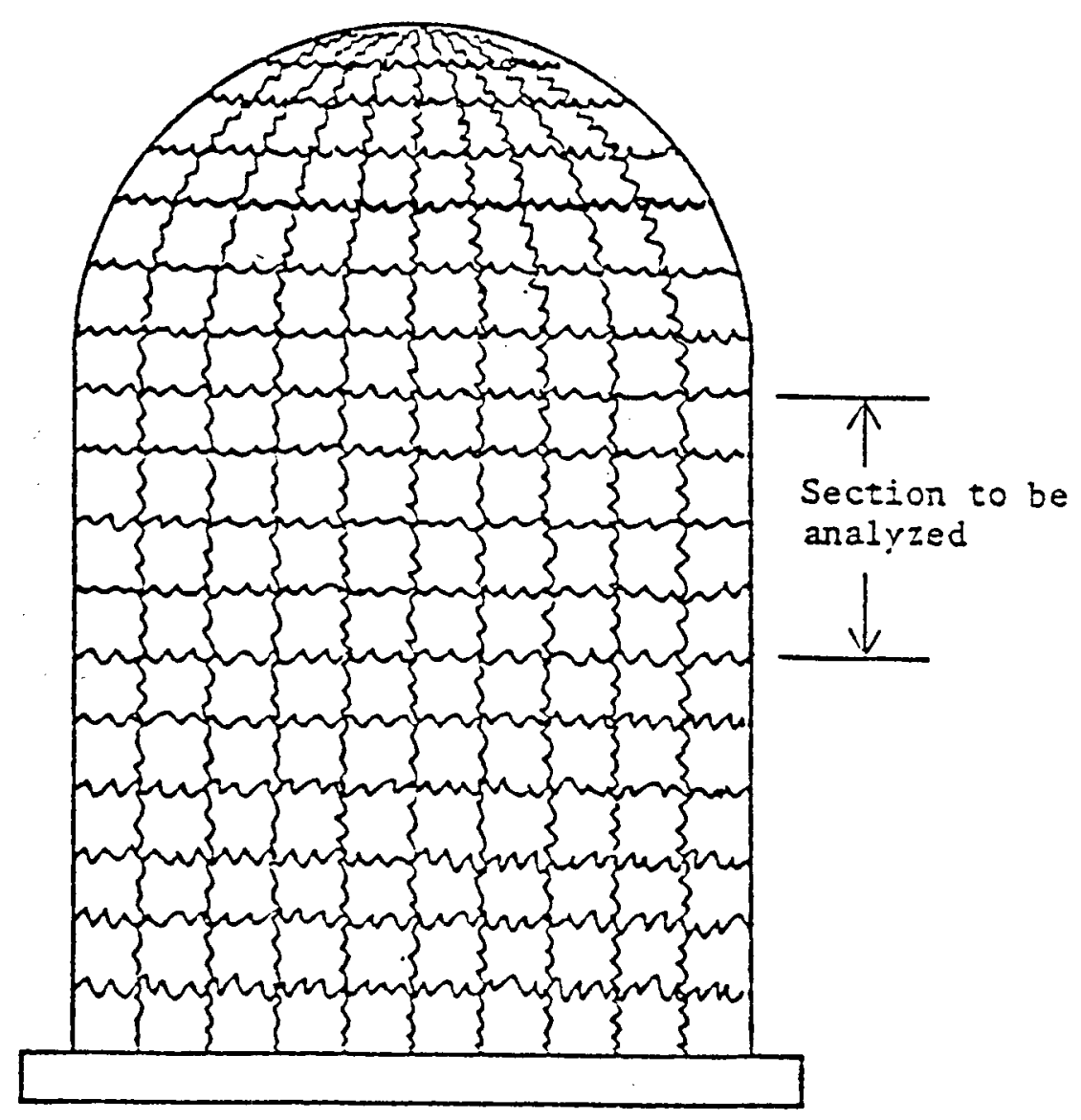

From Reference (1)

Fig. 1.2 Containment with Horizontal and Vertical Cracking 


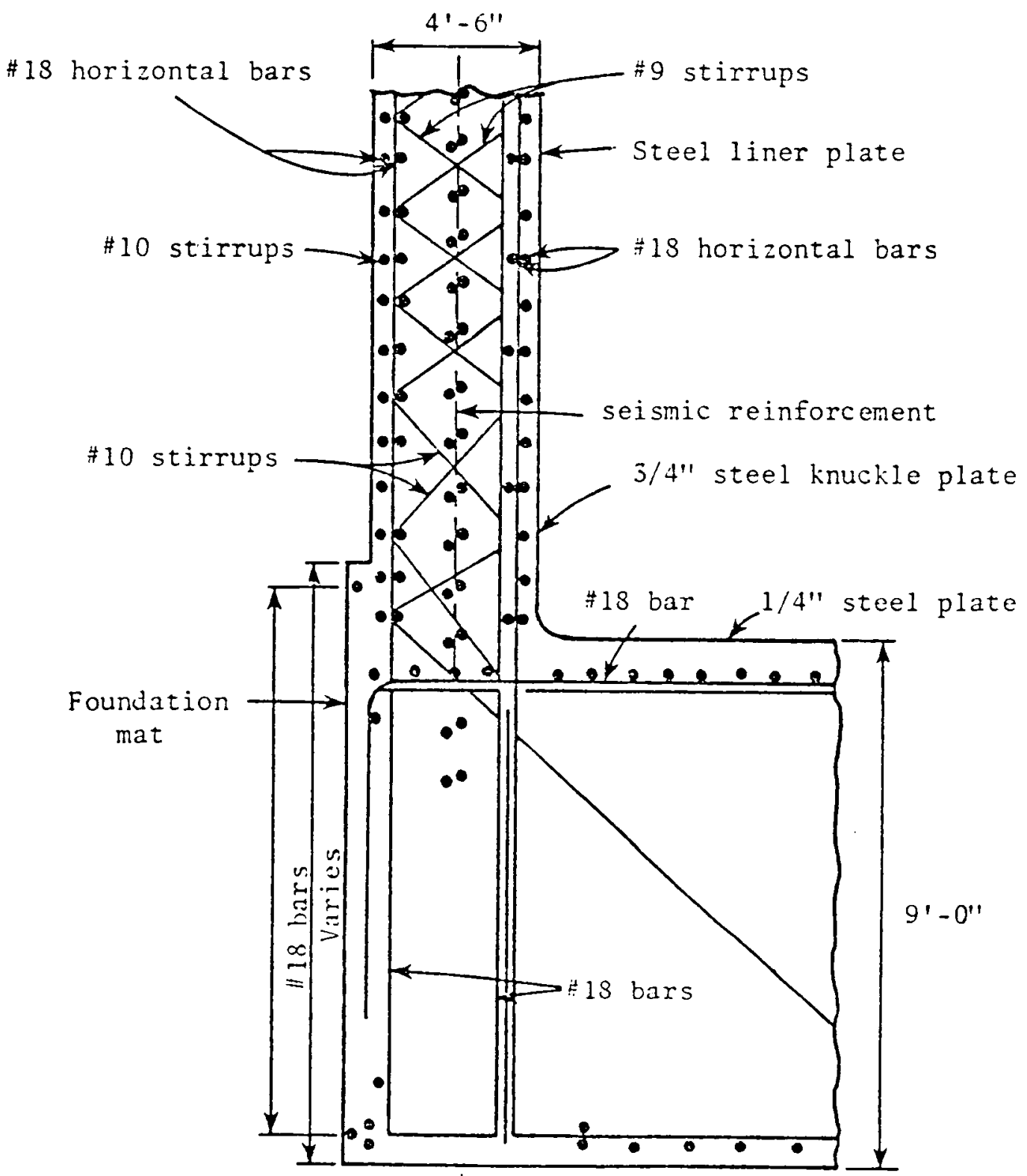

Note: not all reinforcing shown

From Reference (1)

Fig. 1.3 Typical Detall for Vessel Wall 


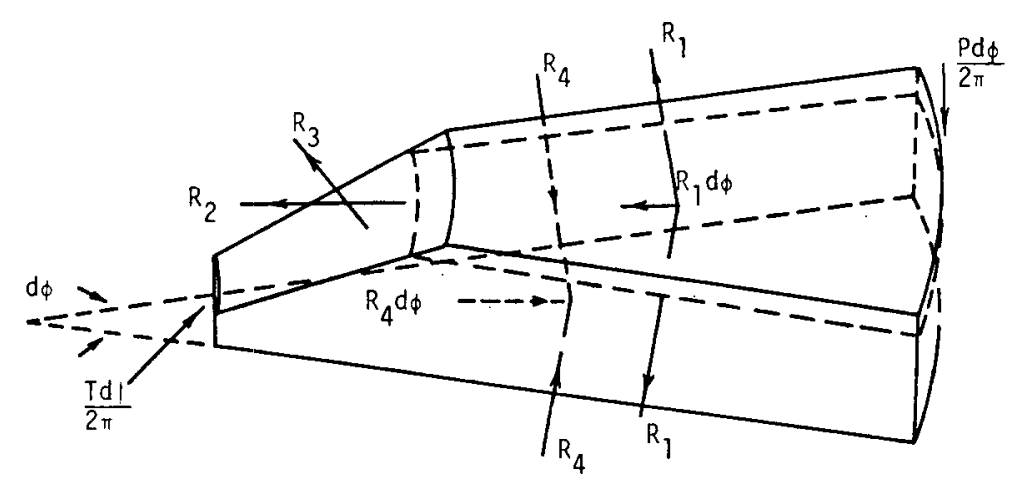

(A) FORCES ACTING ON A SLAB

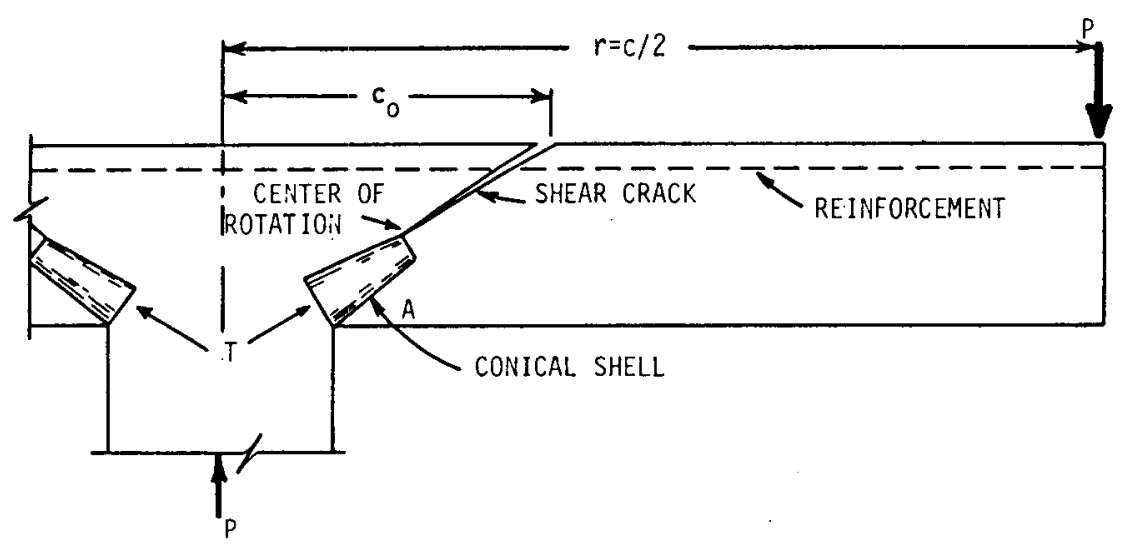

(B) ASSUMED GEOMETRY OF CONNECTION

\section{LEGEND}

$P=$ Applied Load at the Slab Periphery

$T=$ Inclined Compressive Force Acting on the Conical Shell

$R_{1}=$ Resultant Perpendicular to Radial Crack of the Reinforcement

$R_{2}=$ Resultant Perpendicular to Shear Crack of the Reinforcement

$R_{3}=$ Resultant of Shear Reinforcement, If Any

$R_{4}=$ Tangential Resultant of the Concrete Compressive Stresses

From Reference (21)

Fig. 2.1 Mechanical Model from Kinnunen and Nylander 

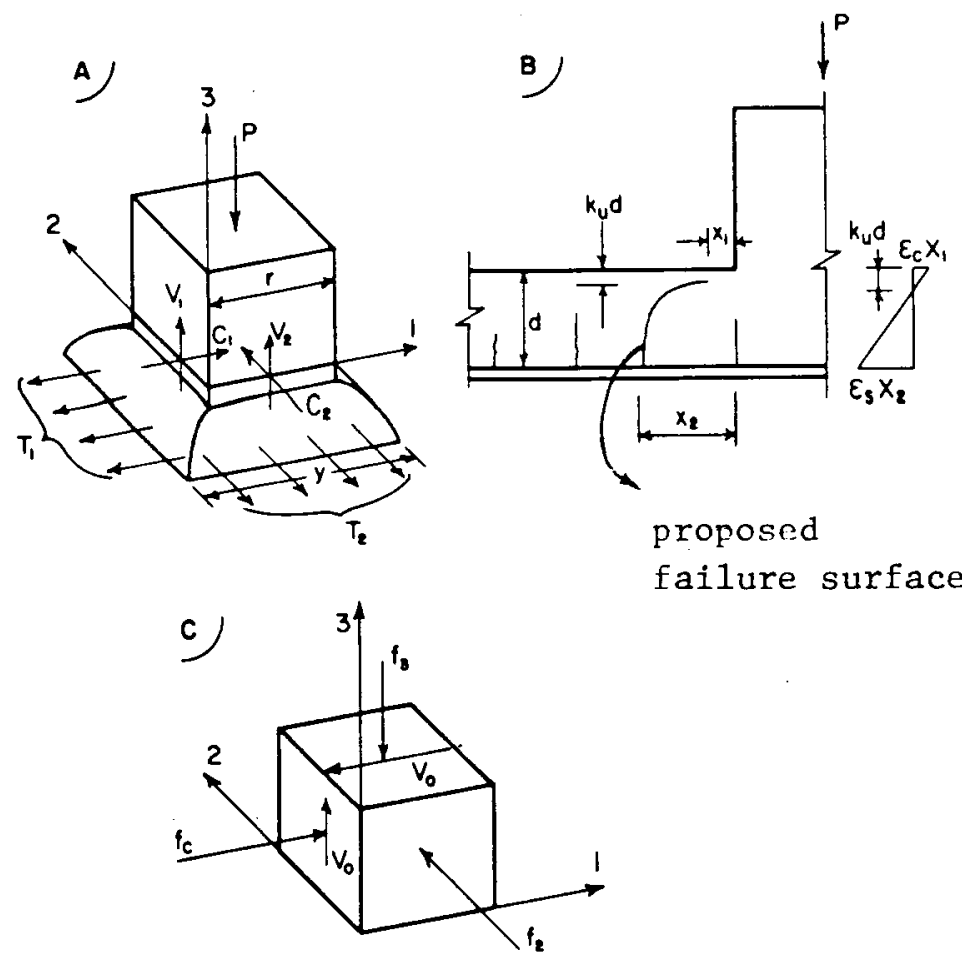

From Reference (10)

Fig. 2.2 - Free-Body Diagrams of Moe's Mode1

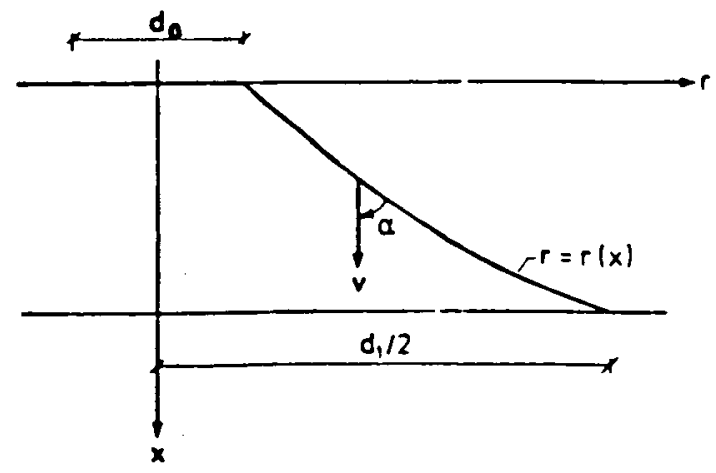

Failure Surface

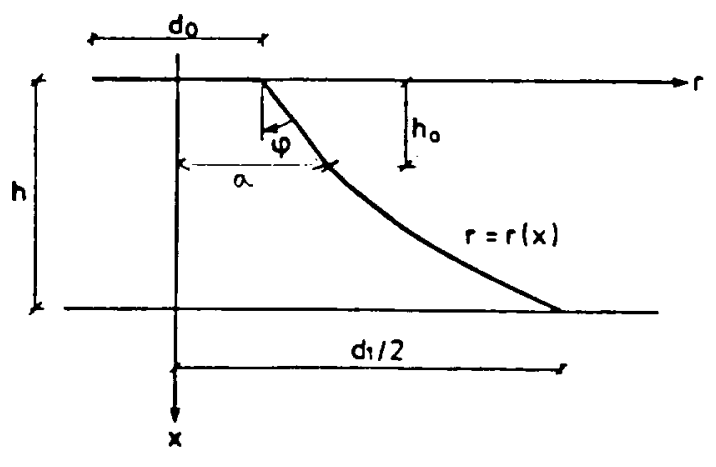

Optimal Generatrix

From Reference (12)

Fig. 2.3 Failure Surface of Concrete Plasticity 


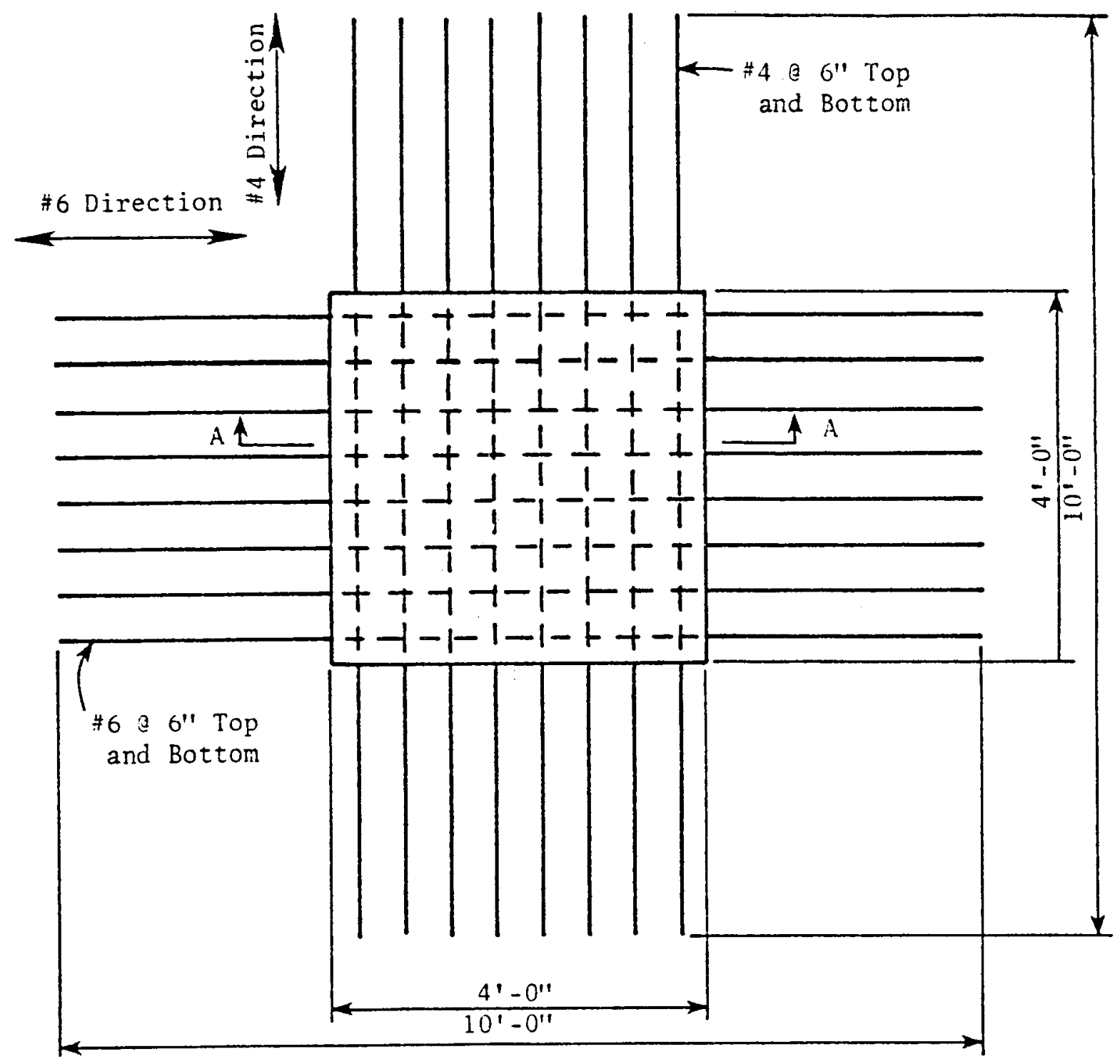

a) Plan

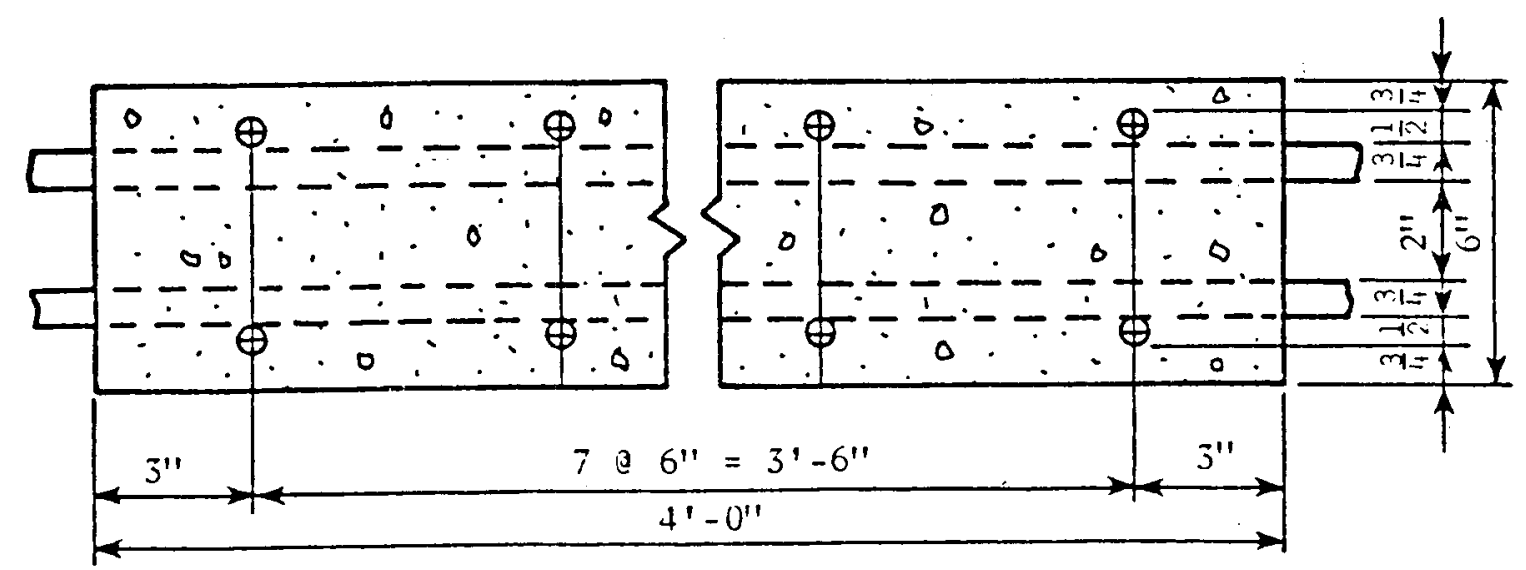

b) Section A-A

From Reference (1)

Fig. 3.1 Test Specimen 


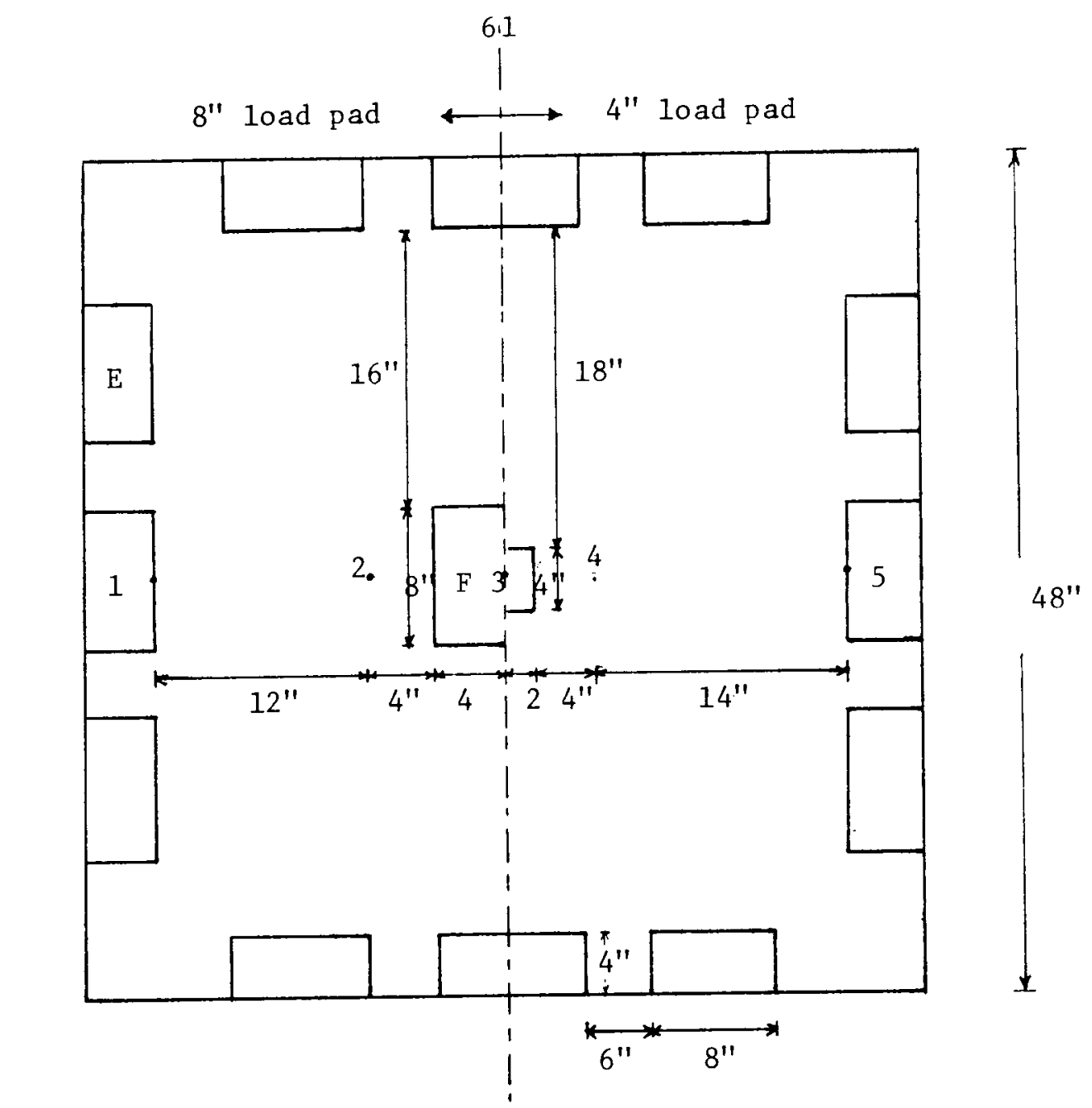

(a) Top View of Specimen

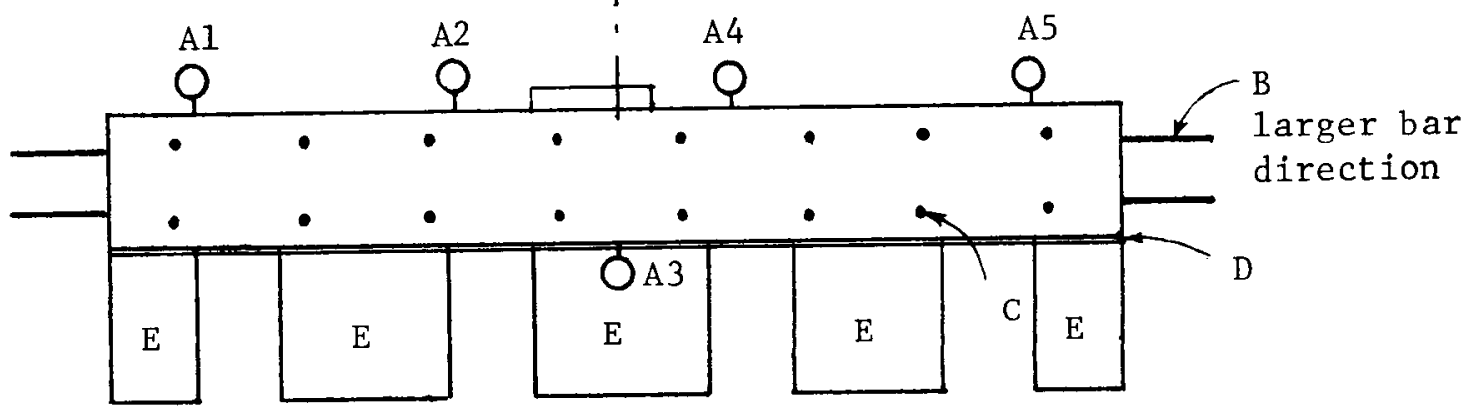

$$
\begin{aligned}
& A=\text { dialgage } \\
& B=\text { larger bar } \\
& C=\text { smaller bar } \\
& D=\text { support pad } \\
& E=\text { concrete block } \\
& F=\text { loading pad }
\end{aligned}
$$

b) Side Views of Specimen

Fig. 3.2. Test Specimen with Loading, Supports and Dial Gage Locations 


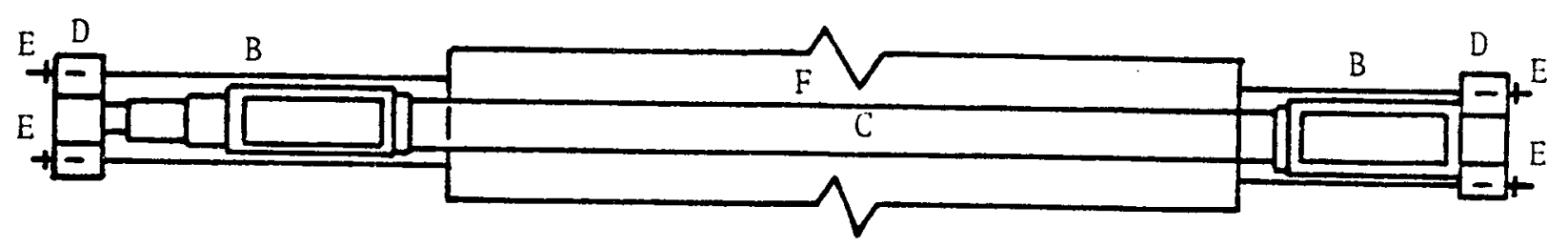

Top View

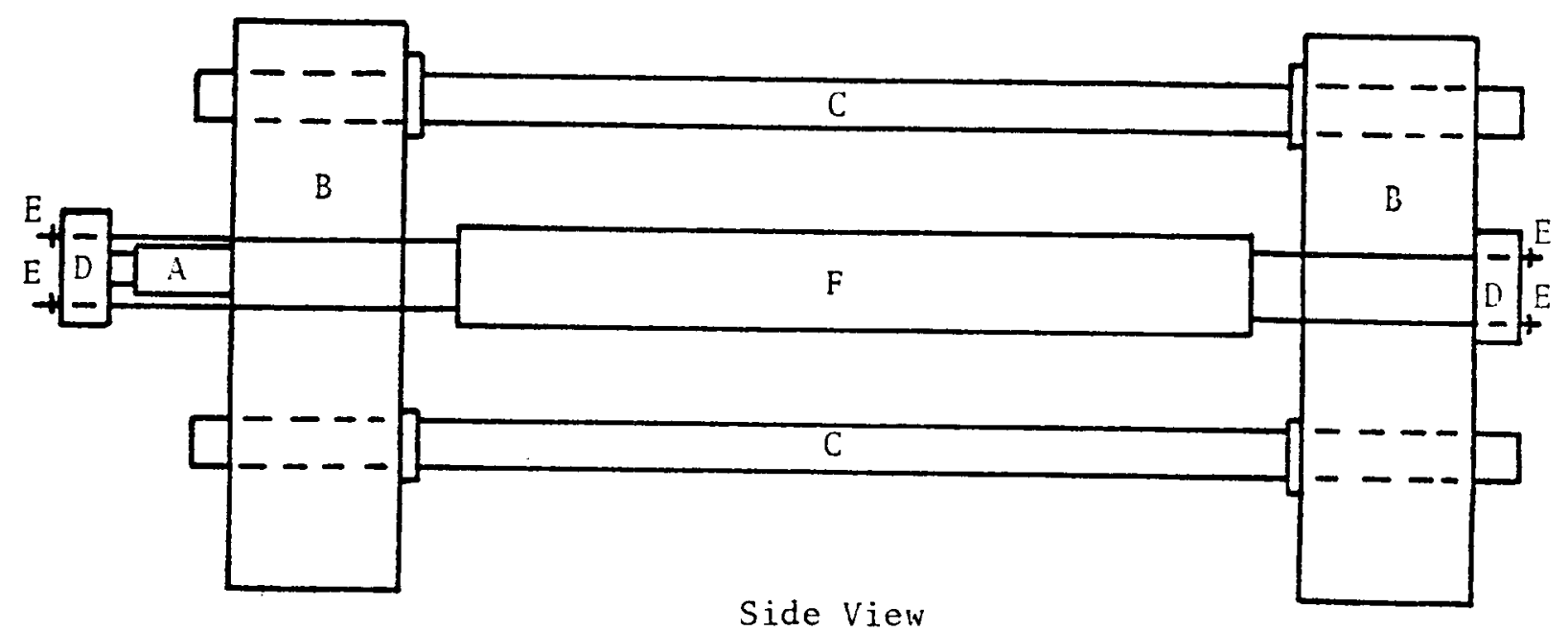
A - Jack
B - Vertical Beam
C - Pipe
D - Cap Piece
E - Nut
F - Test Specimen

Note: Support Blocks Not Shown.

From Reference (1)

Fig. 3.3 Tension Reaction Frame Unit 


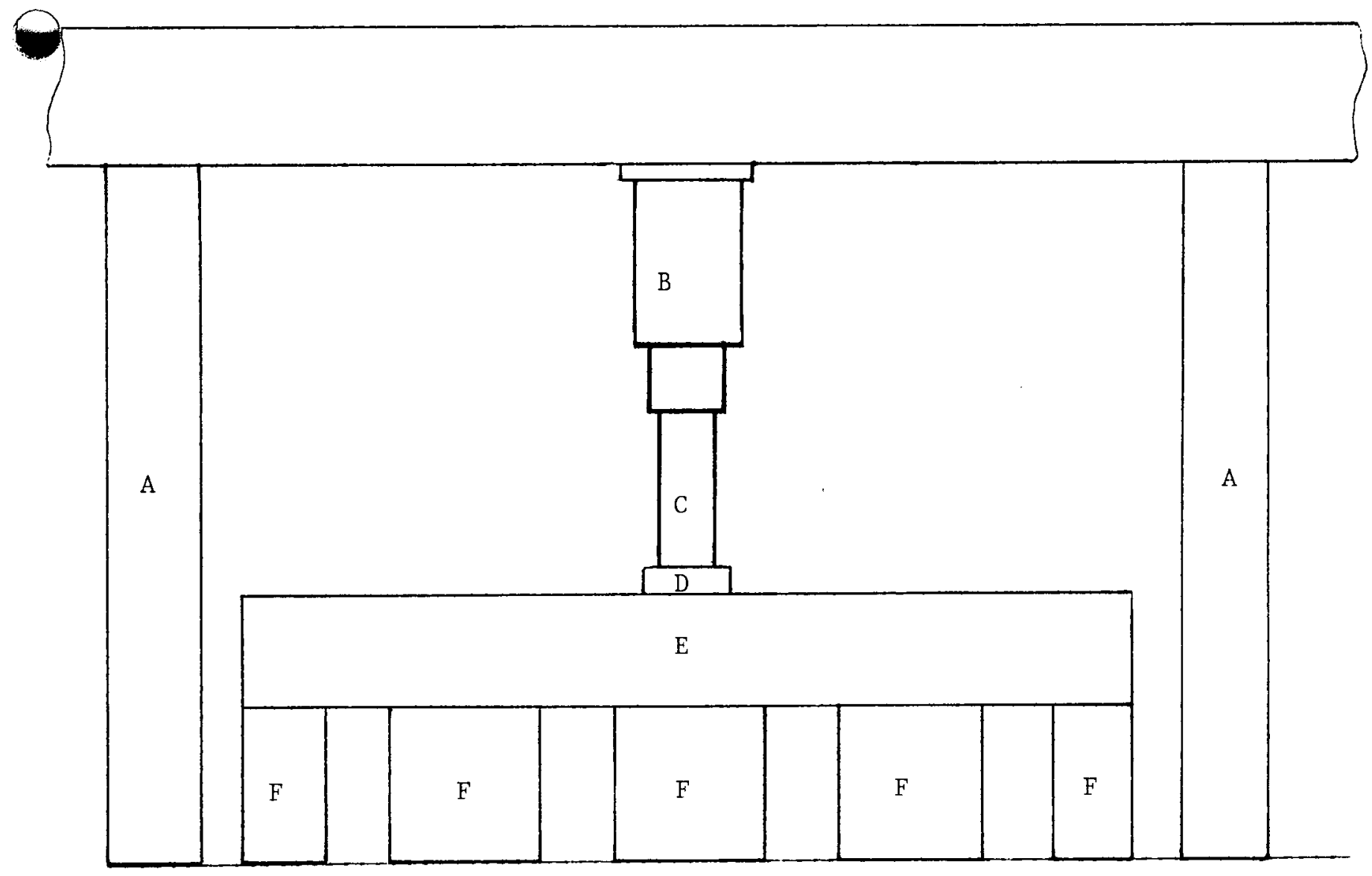

$$
\begin{aligned}
& A=\text { overhead reaction frame } \\
& B=\text { actuator } \\
& C=\text { extension ram } \\
& D=\text { loading pad and plywood } \\
& E=\text { slab } \\
& F=\text { concrete blocks }
\end{aligned}
$$

Fig. 3.4. Side View of Overhead Reaction Frame and Specimen 


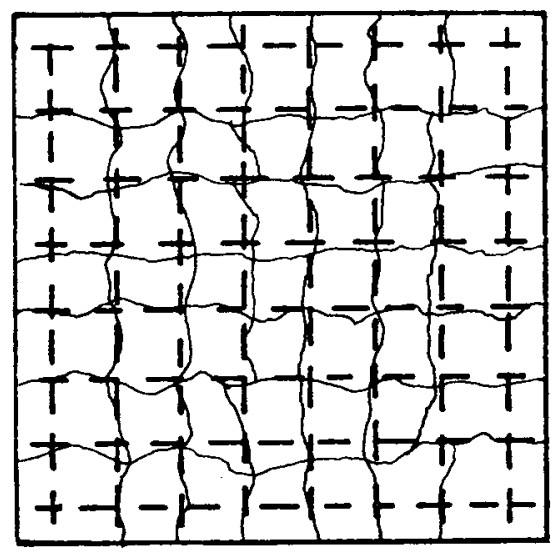

a) specimen $0.0 \mathrm{~A} 4$

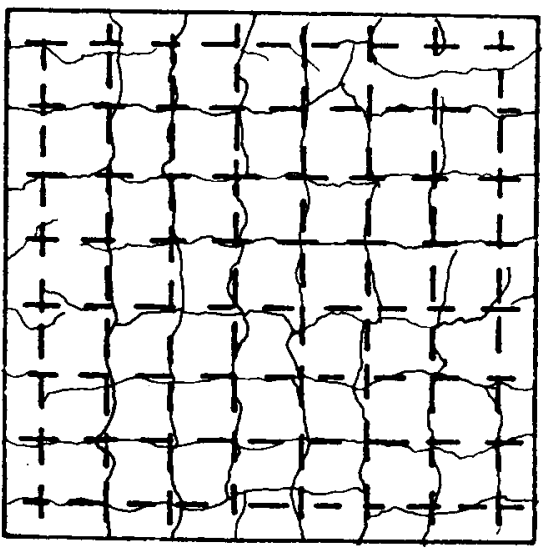

b) specimen $0.8 \mathrm{~A} 4$

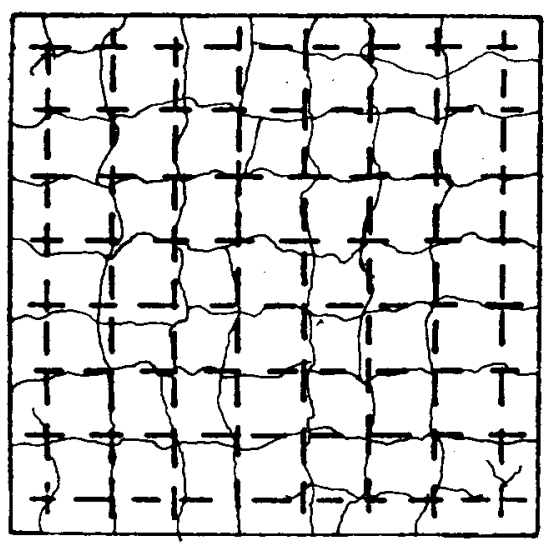

c) specimen $0.0 \mathrm{~B} 8$

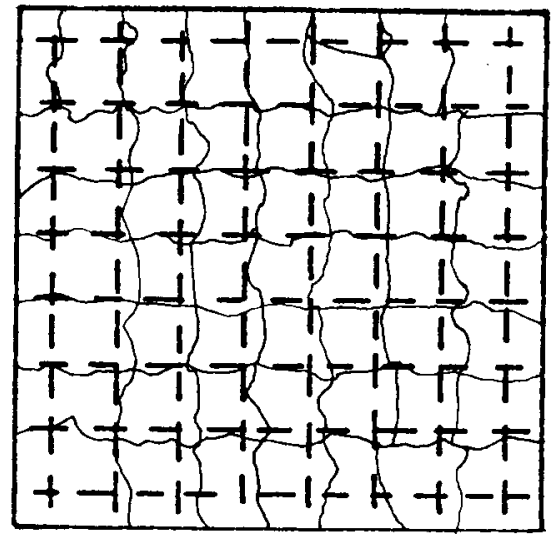

d) specimen $0.8 \mathrm{~B} 8$ 


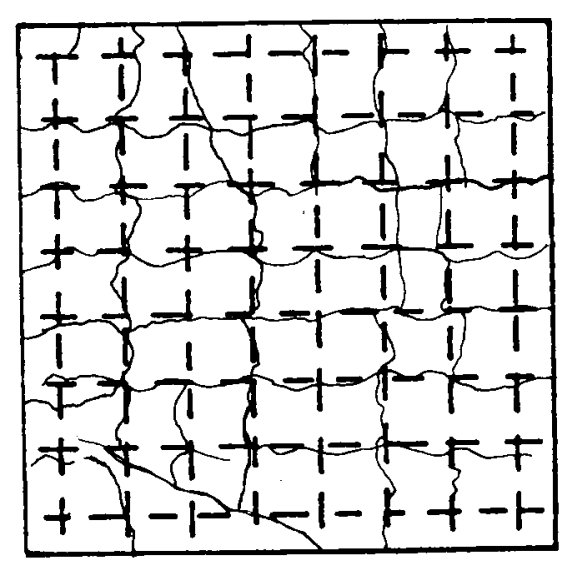

e) specimen $0.0 \mathrm{C} 4$

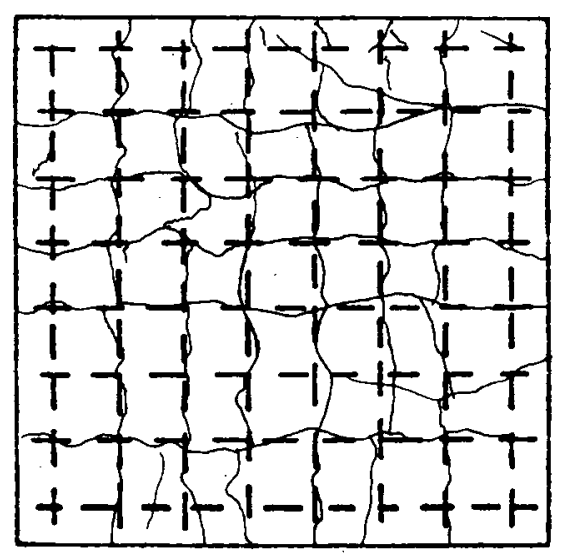

f) specimen $0.8 \mathrm{C} 4$

Fig. 3.5 (cont.) Typical Precracking of Specimens 


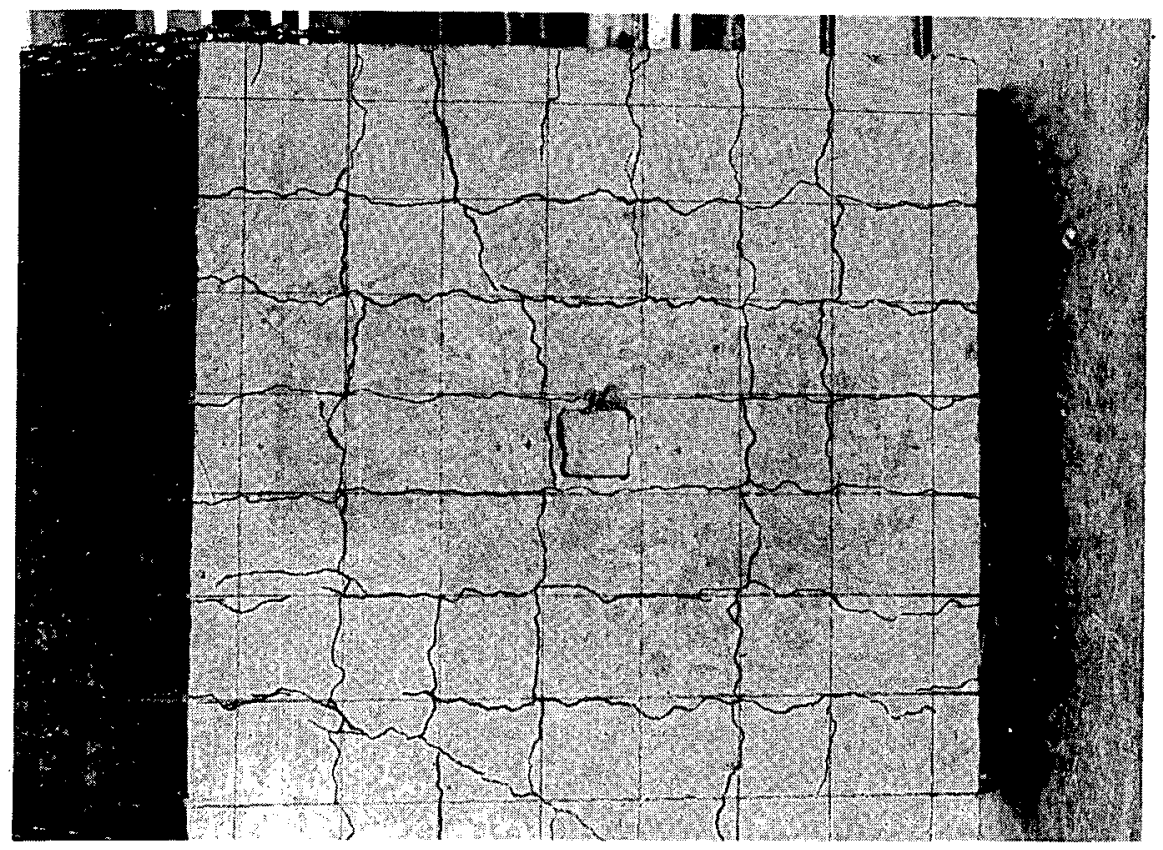

Fig. 3.6 Representative Failure Path on the Top Surface

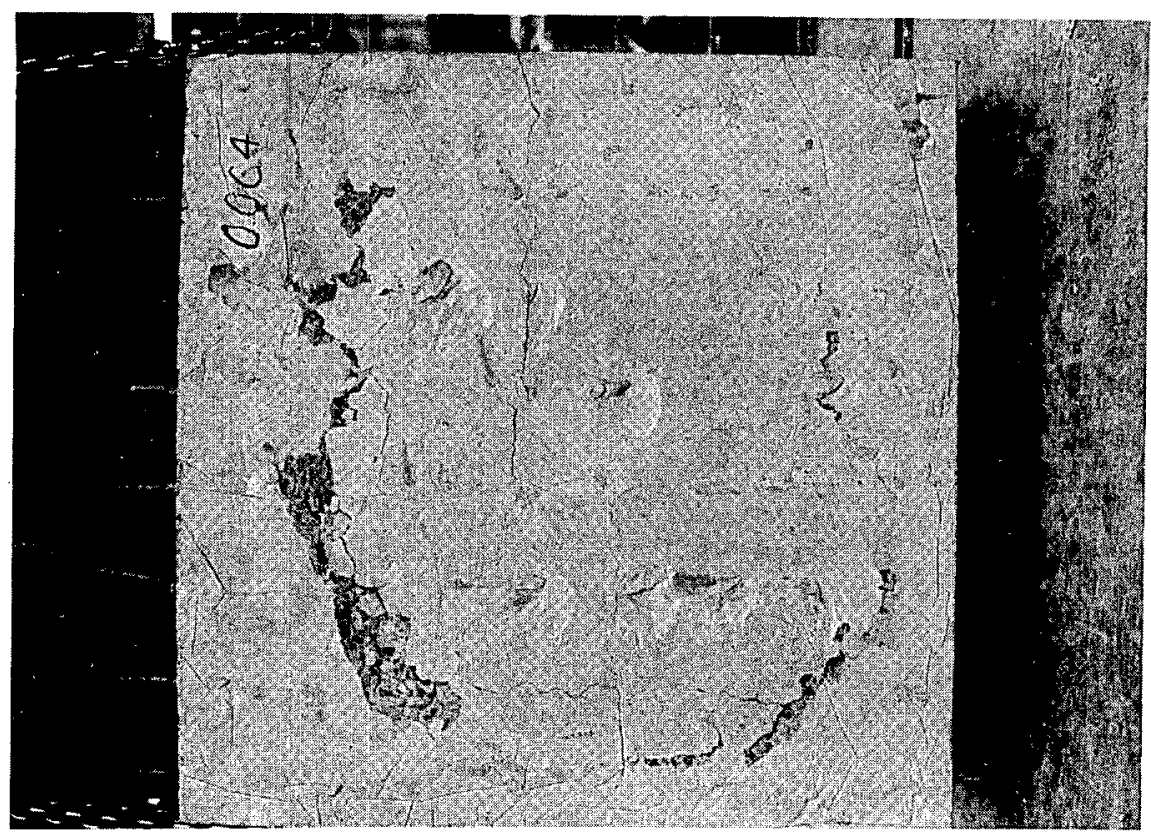

Fig. 3.7 Representative Failure Path on the Bottom Surface 


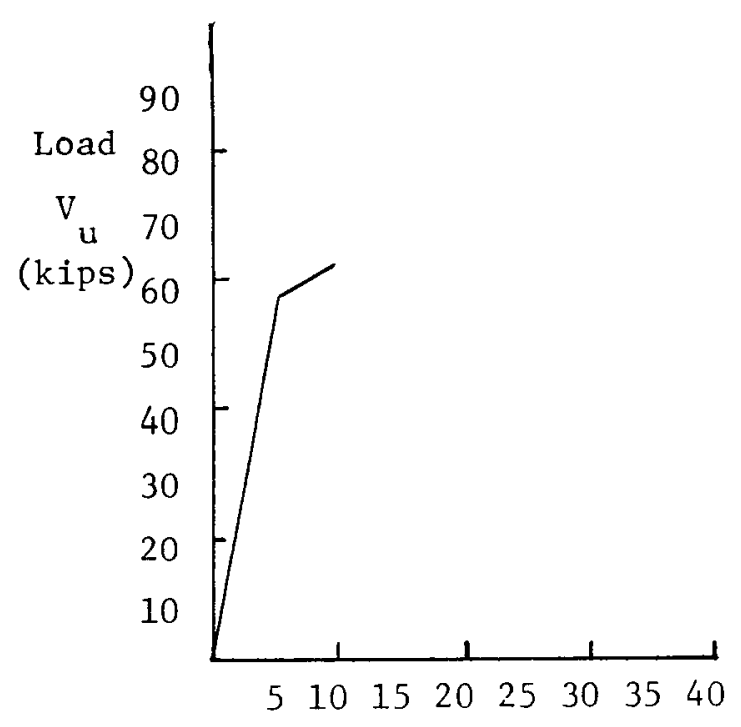

Deflection $\&\left(10^{-2}\right.$ in $)$

a)

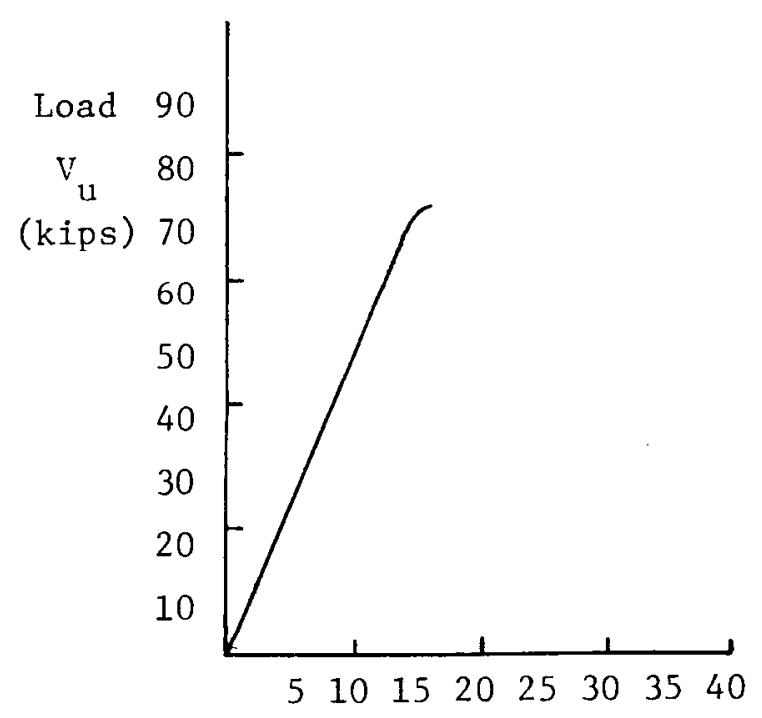

Deflection $\Delta\left(10^{-2}\right.$ in $)$

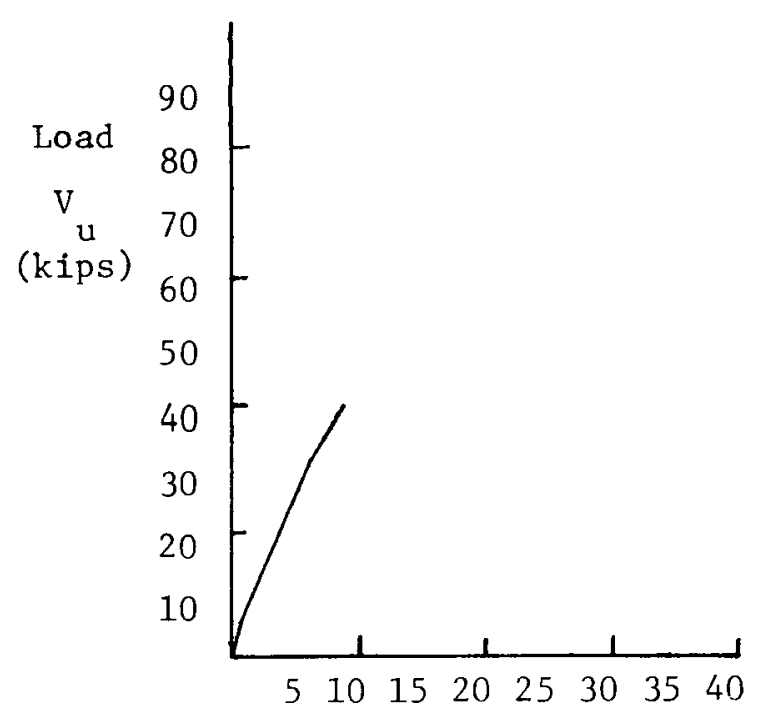

Deflection $\Delta\left(10^{-2}\right.$ in $)$

b)

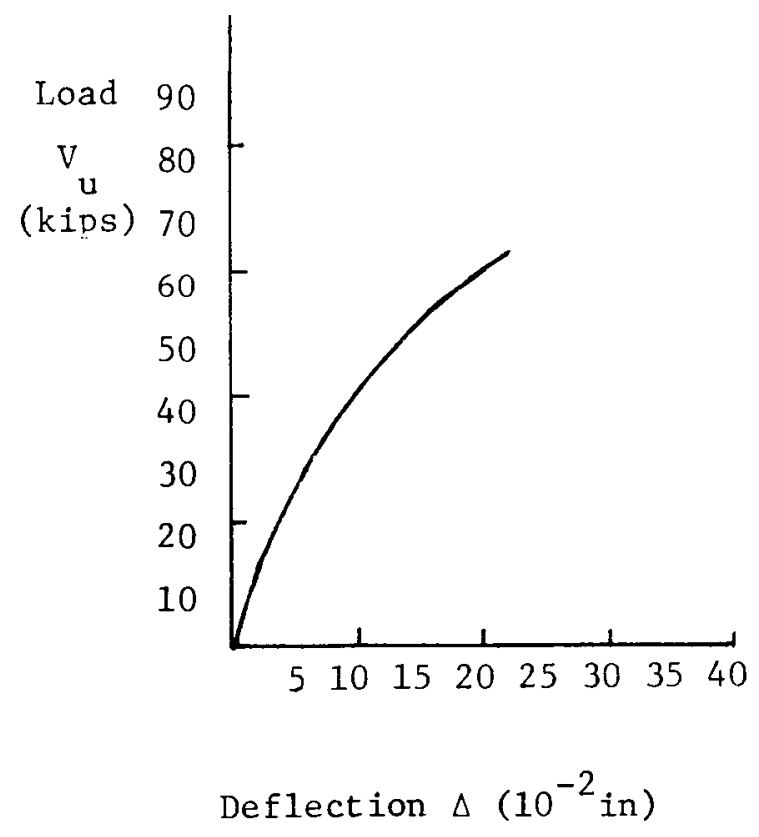

d) Test $0.8 \mathrm{~A} 4$

Fig. 4.1 Load-Deflection Curves 


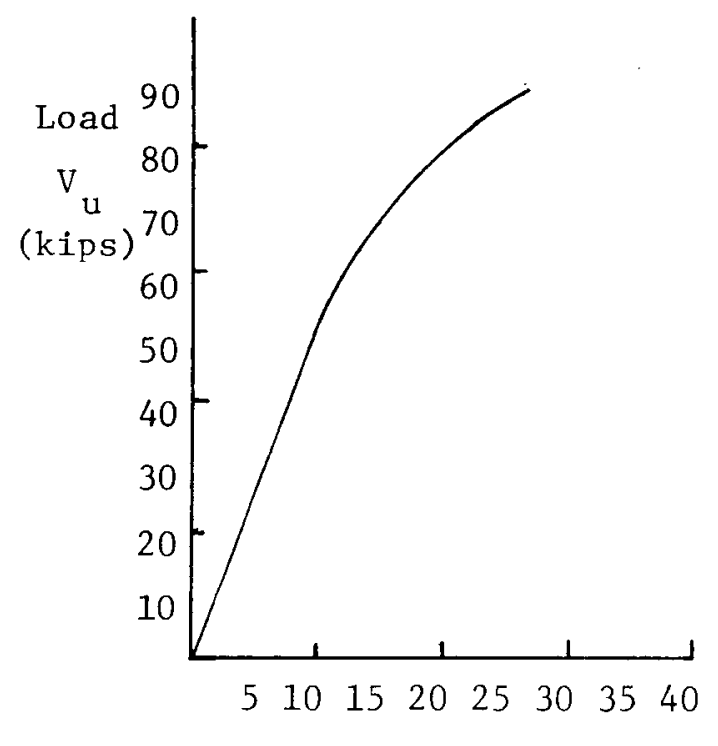

Deflection $\Delta\left(10^{-2}\right.$ in $)$

e) Test $0.0 \mathrm{~B} 8$

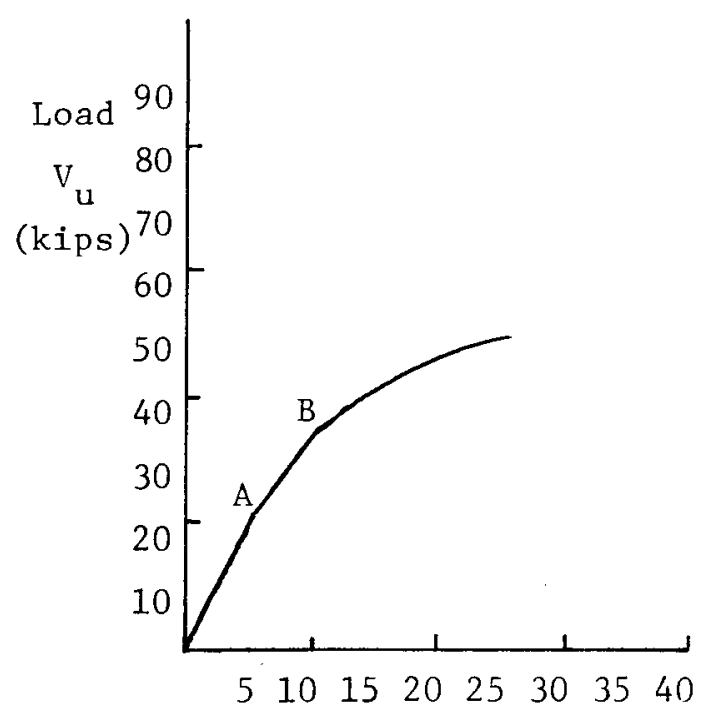

Deflection $\Delta\left(10^{-2}\right.$ in $)$

g) Test $0.0 \mathrm{C} 4$

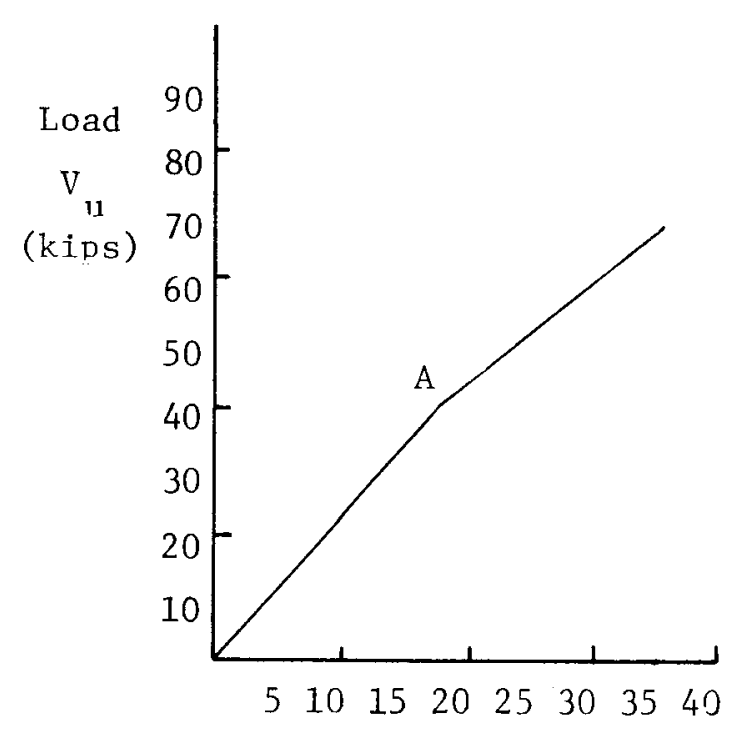

Deflection $\Delta\left(10^{-2}\right.$ in $)$

f) Test $0.8 \mathrm{~B} 8$

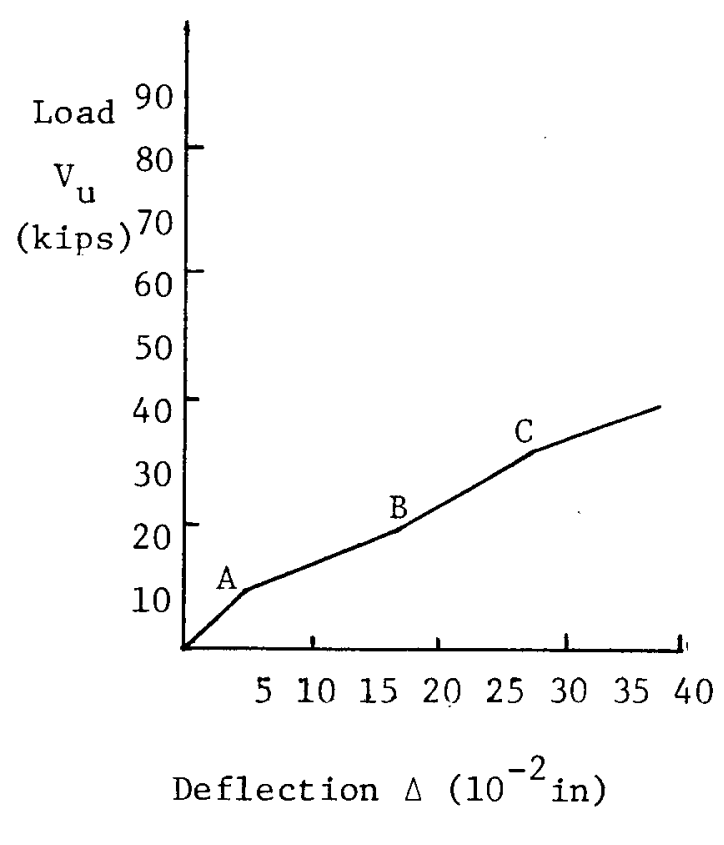

h) Test $0.8 \mathrm{C} 4$

Fig. 4.1 (cont.) Load-Deflection Curves 

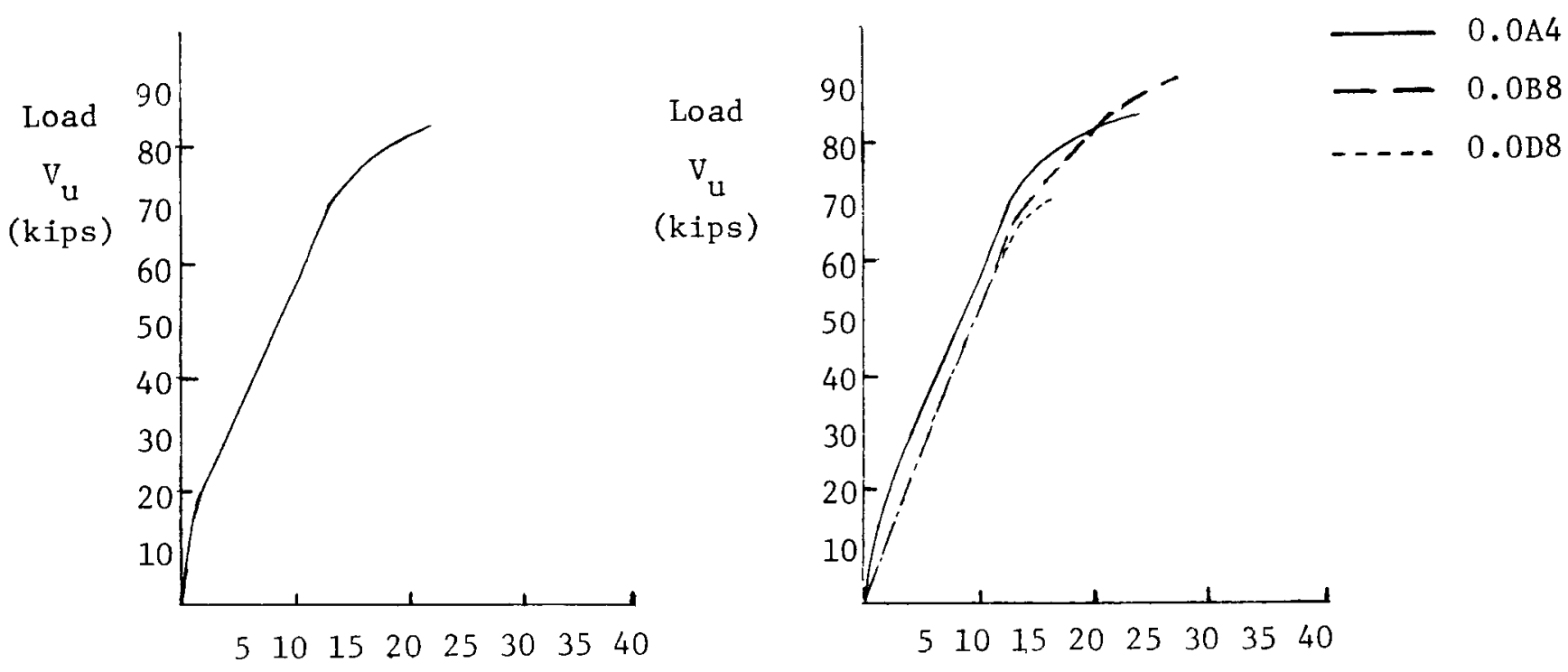

Deflection $\left(10^{-2}\right.$ in $)$

Deflection $\left(10^{-2}\right.$ in $)$

i) Test $0.0 \mathrm{D} 8$

j) Comparison of

Test $0.0 \mathrm{~A} 4,0.0 \mathrm{~B} 8$,

$0.0 \mathrm{D} 8$

Fig. 4.1 (cont.) Load-Deflection Curves 


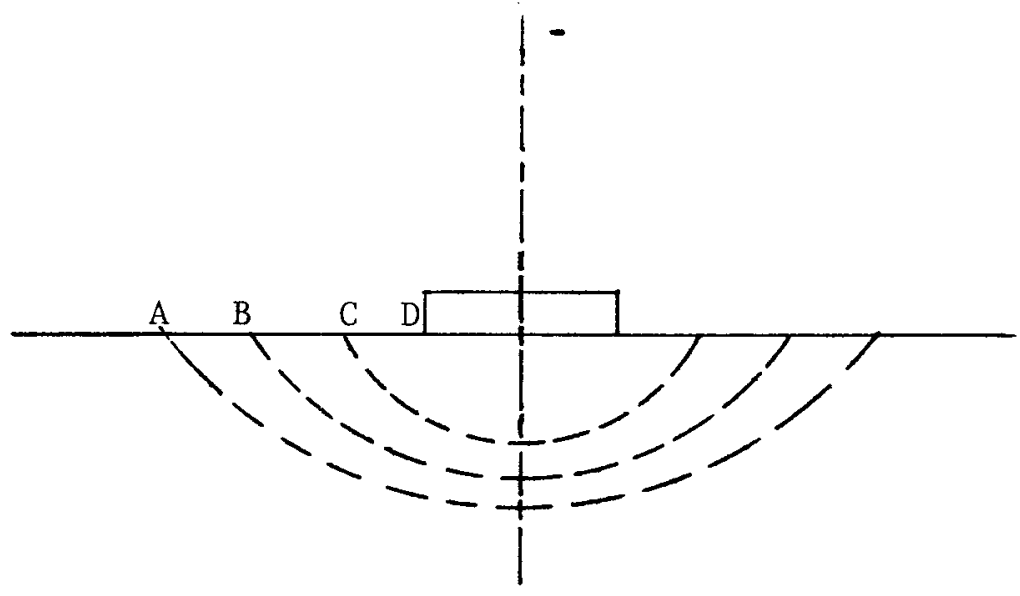

Fig. 4.2 Sequence of Crack Formation near Load

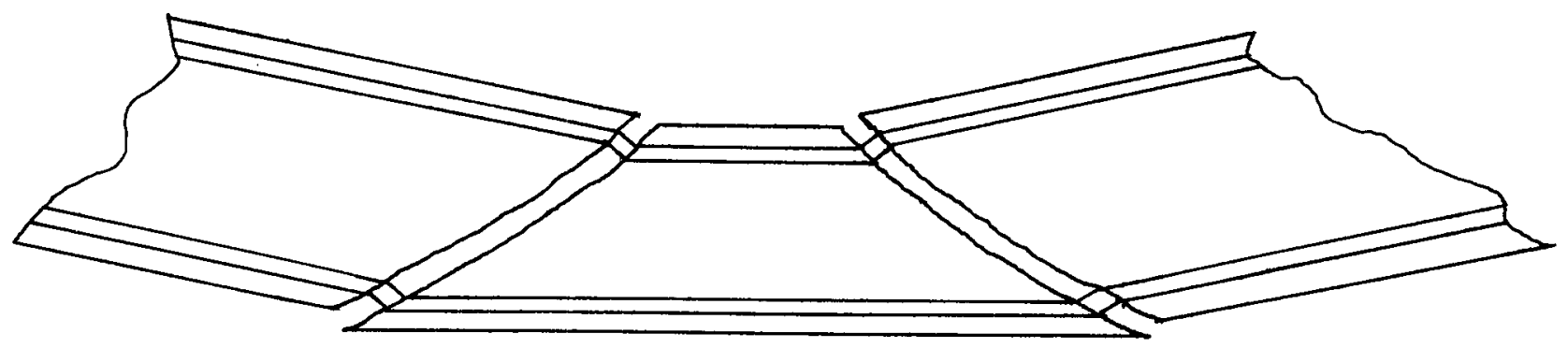

Fig. 4.3 Dowel Displacement (Exaggerated) 


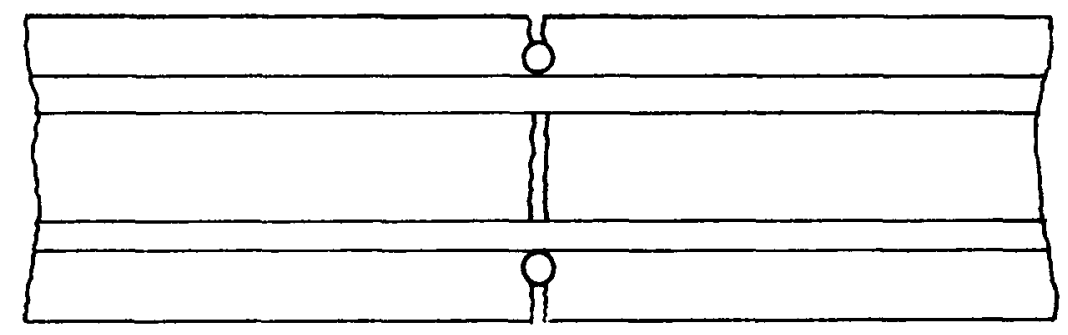

Fig. 4.4. Typical Widened Crack under Biaxial Tension
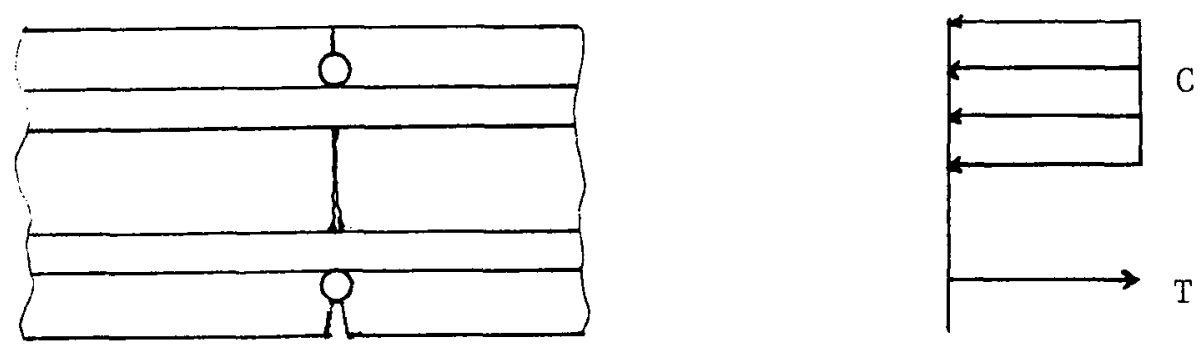

Fig. 4.5 Typical Crack under Punching Load 


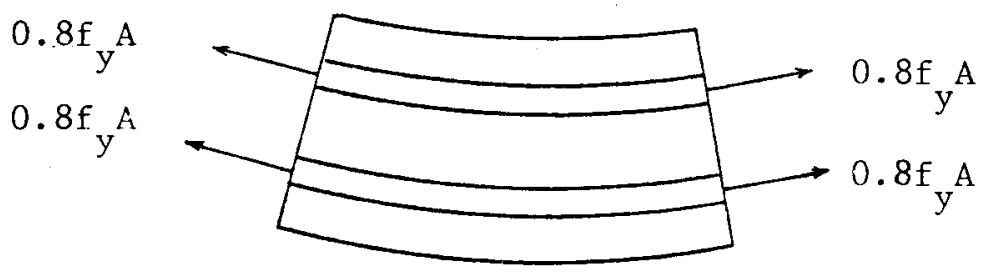

Fig. 4.6 Free-Body Diagram of a Typical Element under Biaxial Tension and Punching Shear Load, Vertical Component
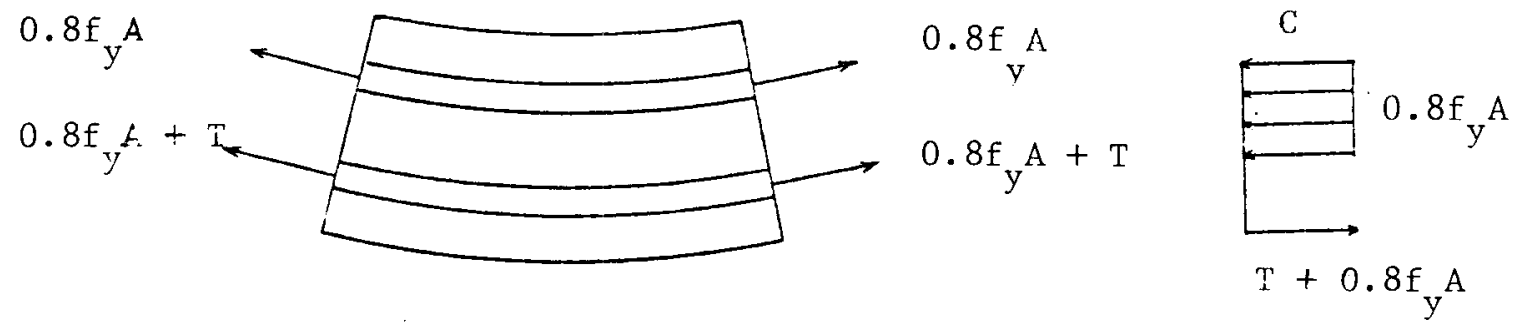

Fig. 4.7 Free-Body Diagram of a Typical Element under Biaxial Tension and Punching Shear Load, Internal Stresses 
smaller bar dir.

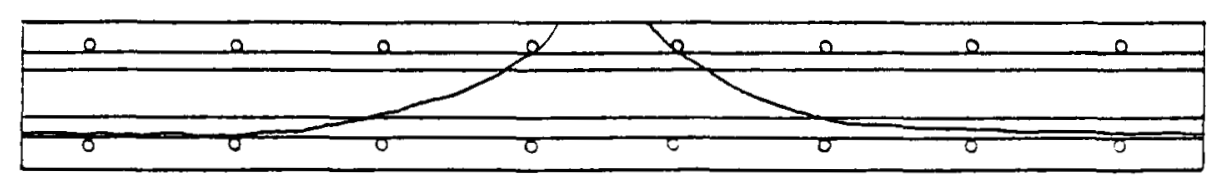

larger bar dir.

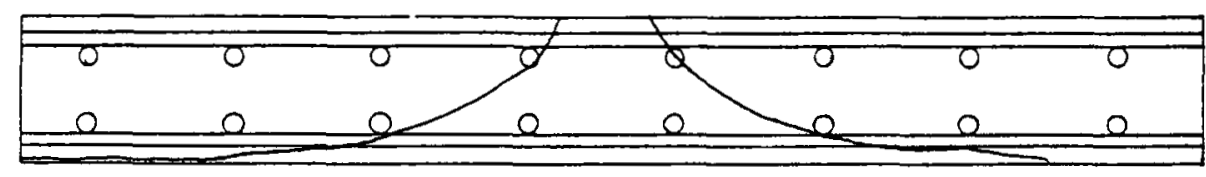

diagonal dir.

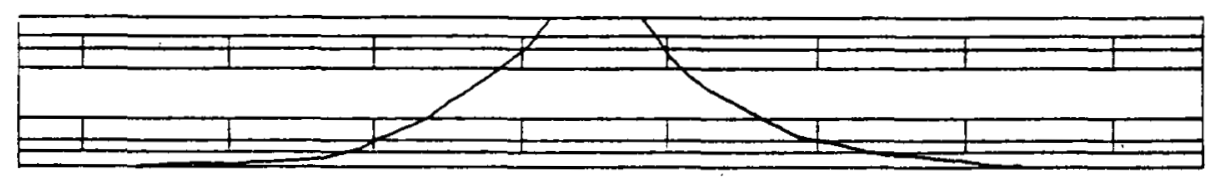

diagonal dir.

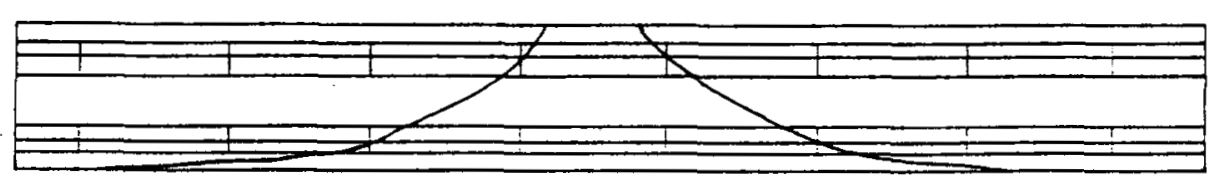

a) $\mathrm{S} 1 \mathrm{ab} 0.0 \mathrm{A4}$

Fig. 4.8 Failure Surface 
smaller bar dir.

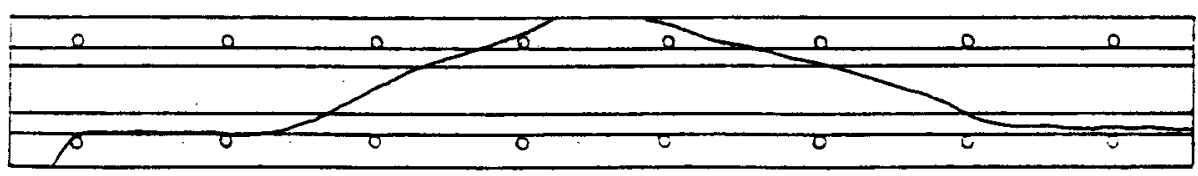

larger bar dir.

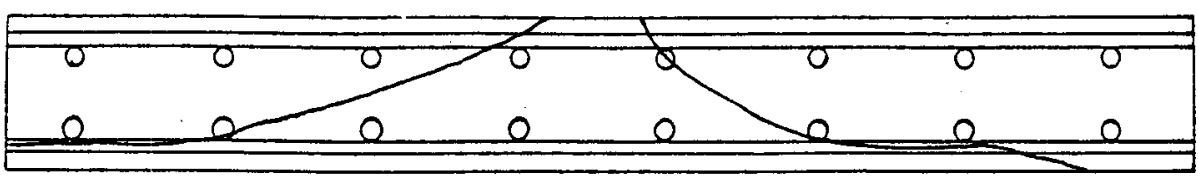

diagonal dir.

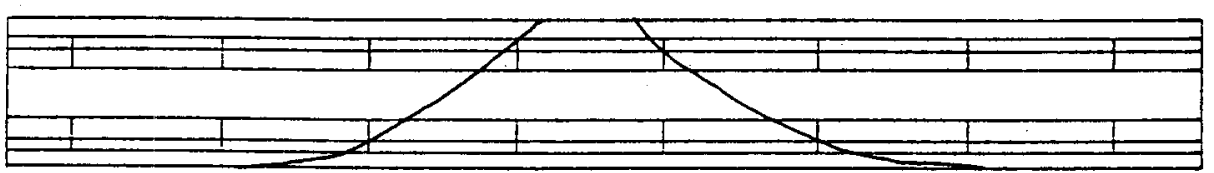

diagonal dfr.

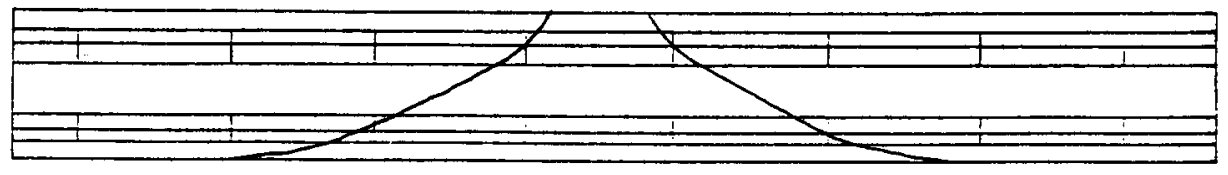

b) Slab $0.8 \mathrm{A4}$

Fig. 4.8 (cont.) Failure Surface 
smaller bar dir.

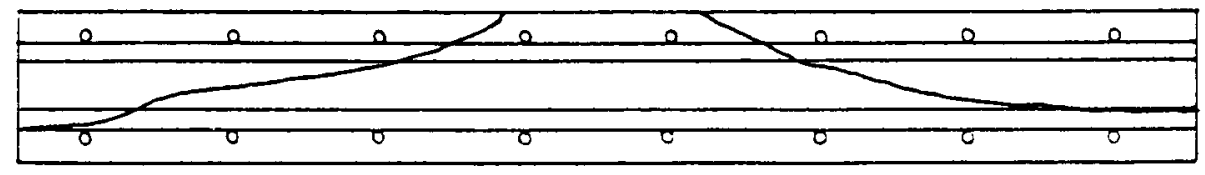

larger bar dir.

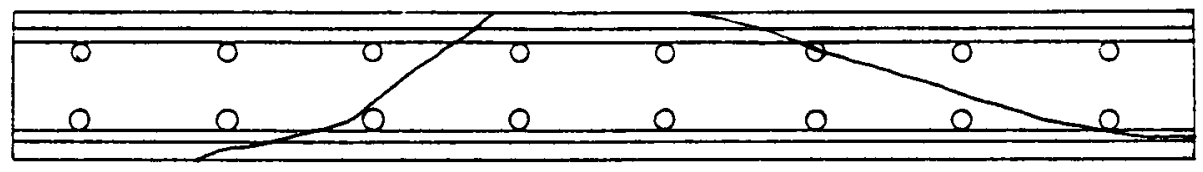

dlagonal dir.

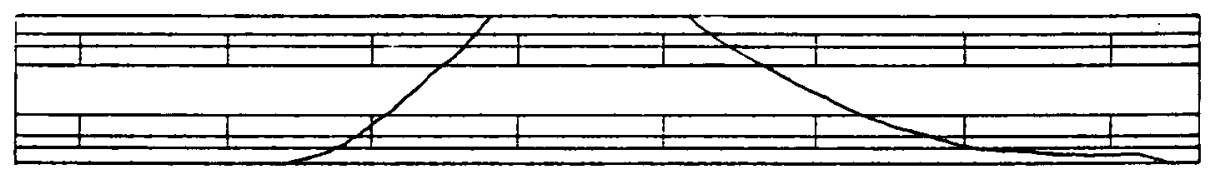

diagonal dir.

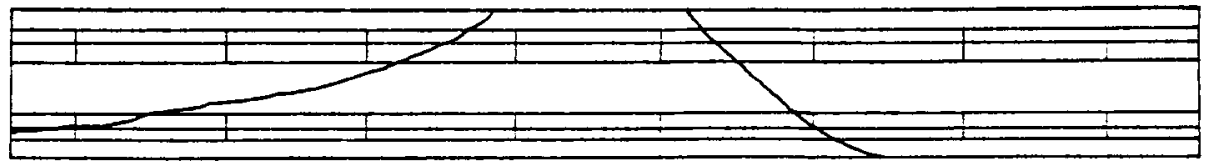

c) S1ab $0.0 \mathrm{~B} 8$

Fig. 4.8 (cont.) Failure Surface 
smaller bar dir.

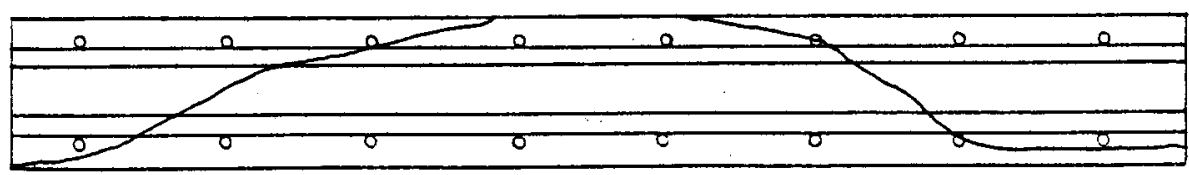

larger bar dir.

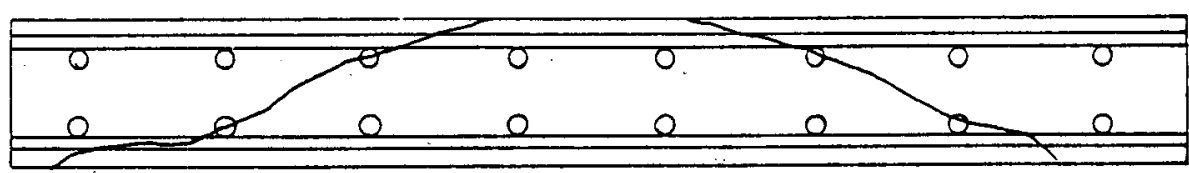

diagonal dir.

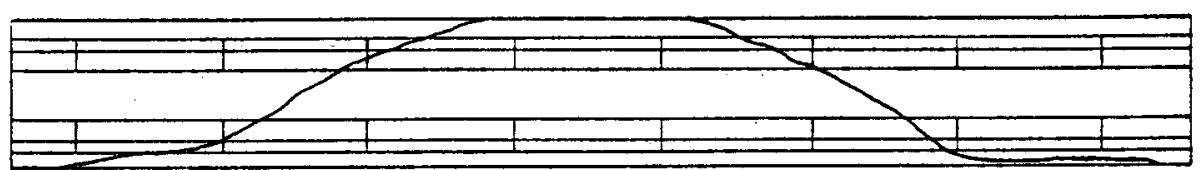

diagonal dir.

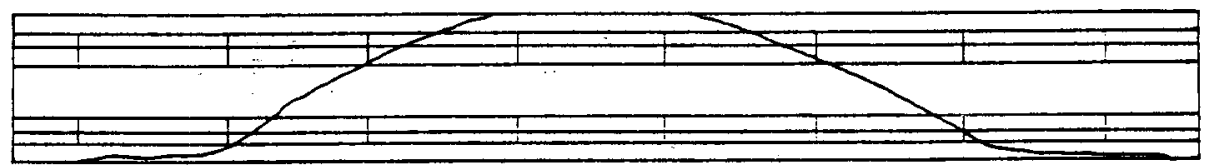

d) Slab $0.8 \mathrm{~B} 8$

Fig. 4.8 (cont.) Failure Surface 
smaller bar dir.

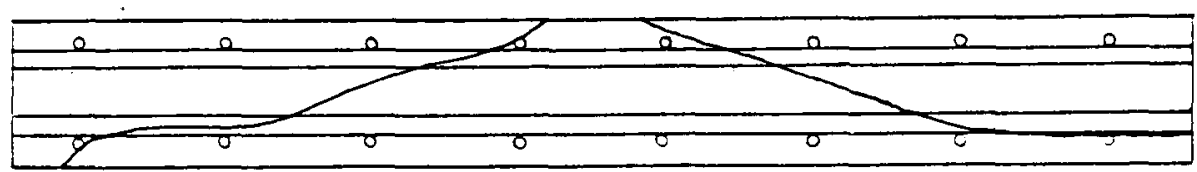

larger bar dir.

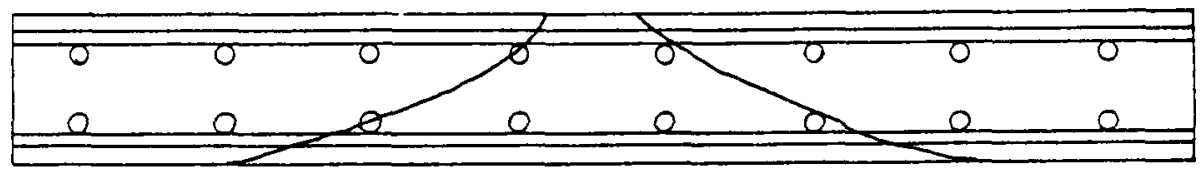

diagonal dir.

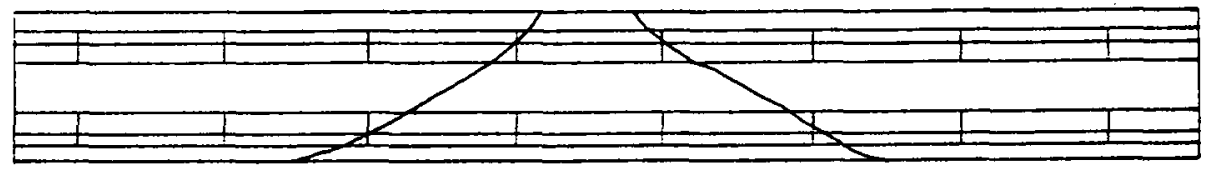

diagonal dir.

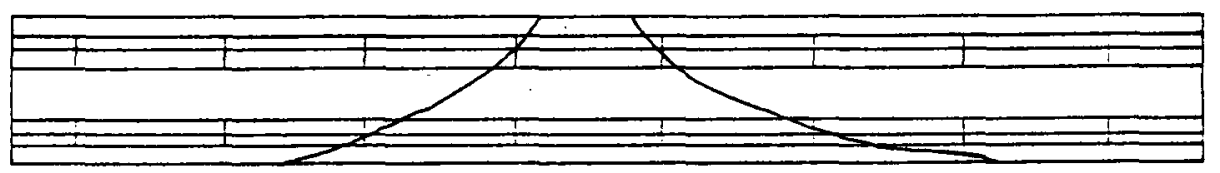

e) S1ab $0.0 \mathrm{C} 4$

Fig. 4.8 (cont.) Failure Surface 
smaller bar dir.

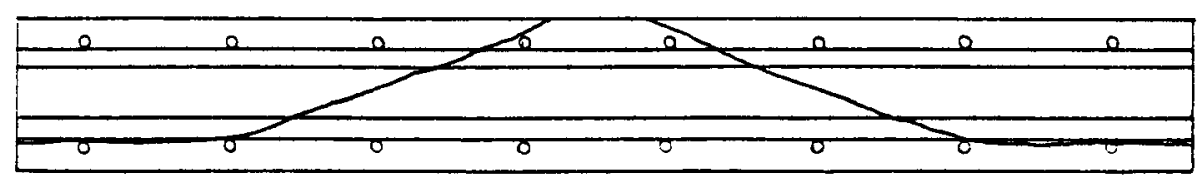

larger bar dir.

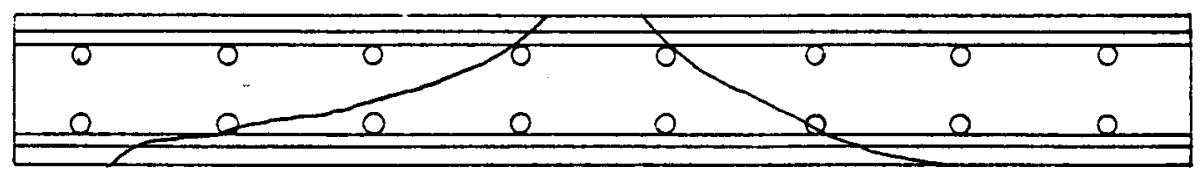

diagonal dir.

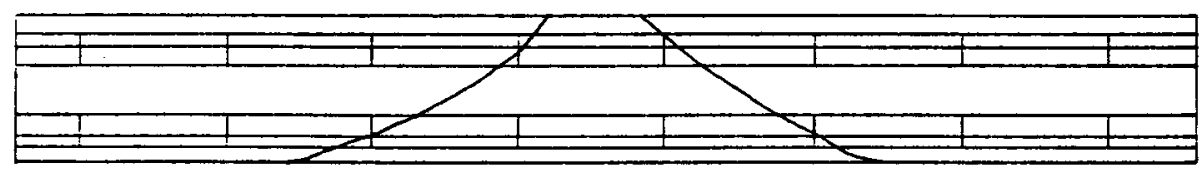

ditarean Atr.

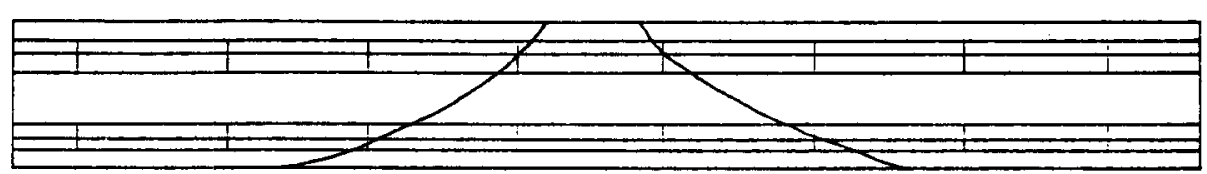

f) $\mathrm{Slab} 0.8 \mathrm{c} 4$

Fig. 4.8 (cont.) Failure Surface 
smaller bar dir.

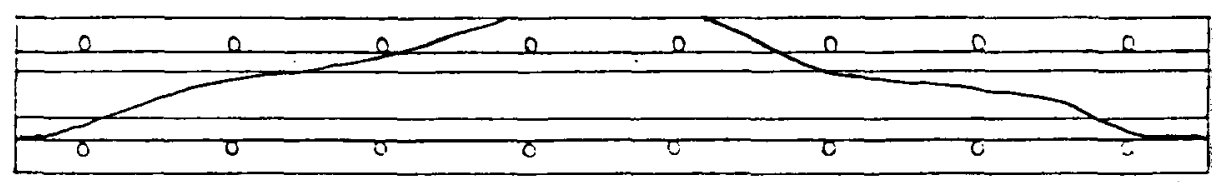

larger bar dir.

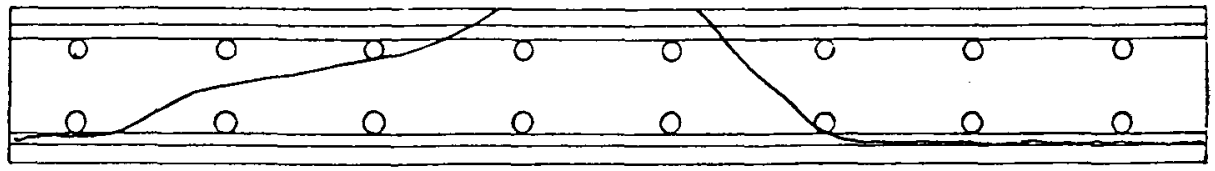

diagonal dir.

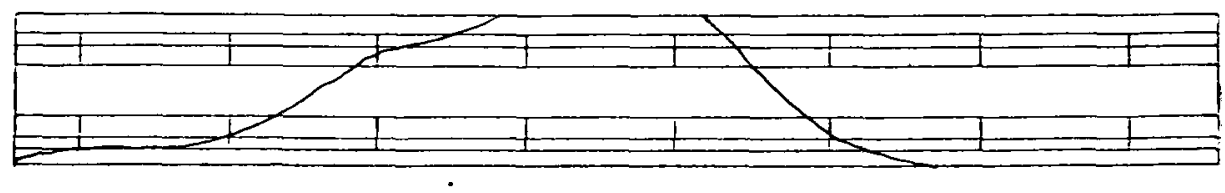

diagonal dir.

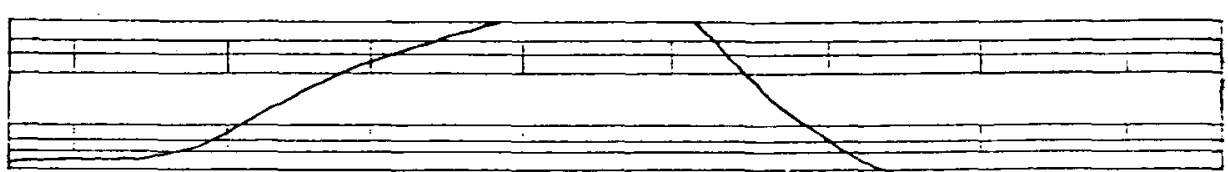

g) $51 \mathrm{ab} 0.008$

Fig. 4.8 (cont.) Failure Surface 

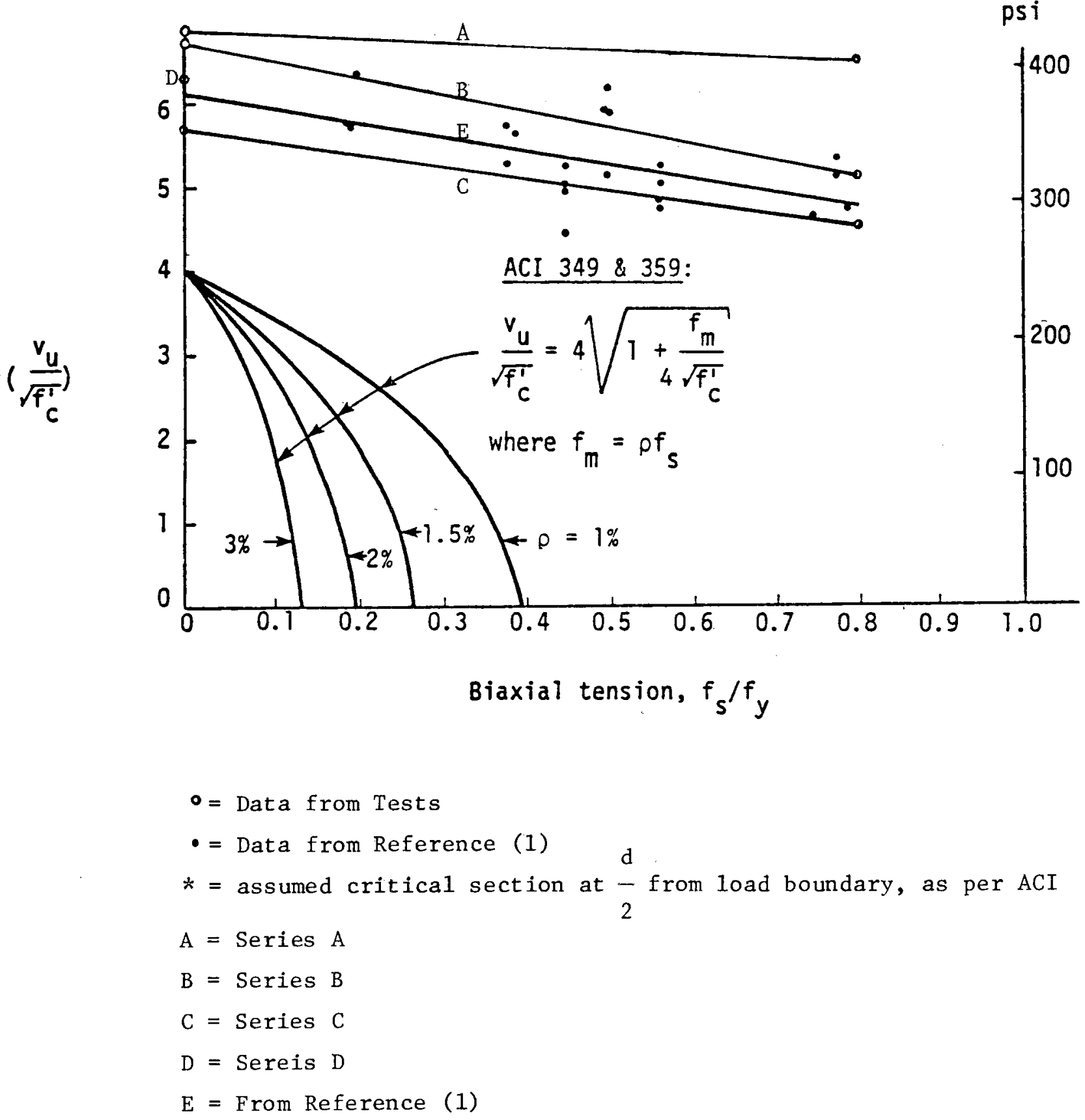

Fig. 4.9 P1ot of Normalized Punching Shearing Stress vs. Biaxial. Tension 


\section{1}

$\mathrm{L}$

$\overline{2}=20^{\prime \prime}$

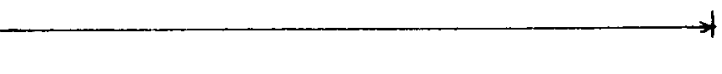

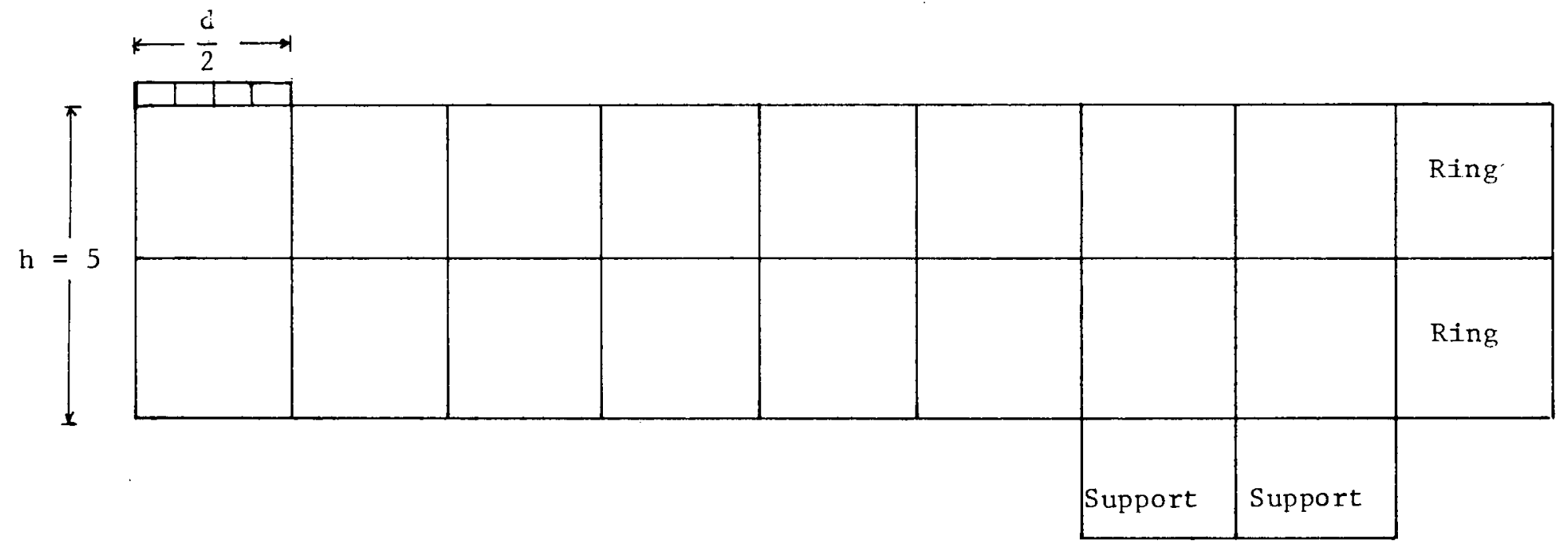

Fig. 6.1 Typical Finite Element Mesh for Studying the Effect of Edge Restraint 


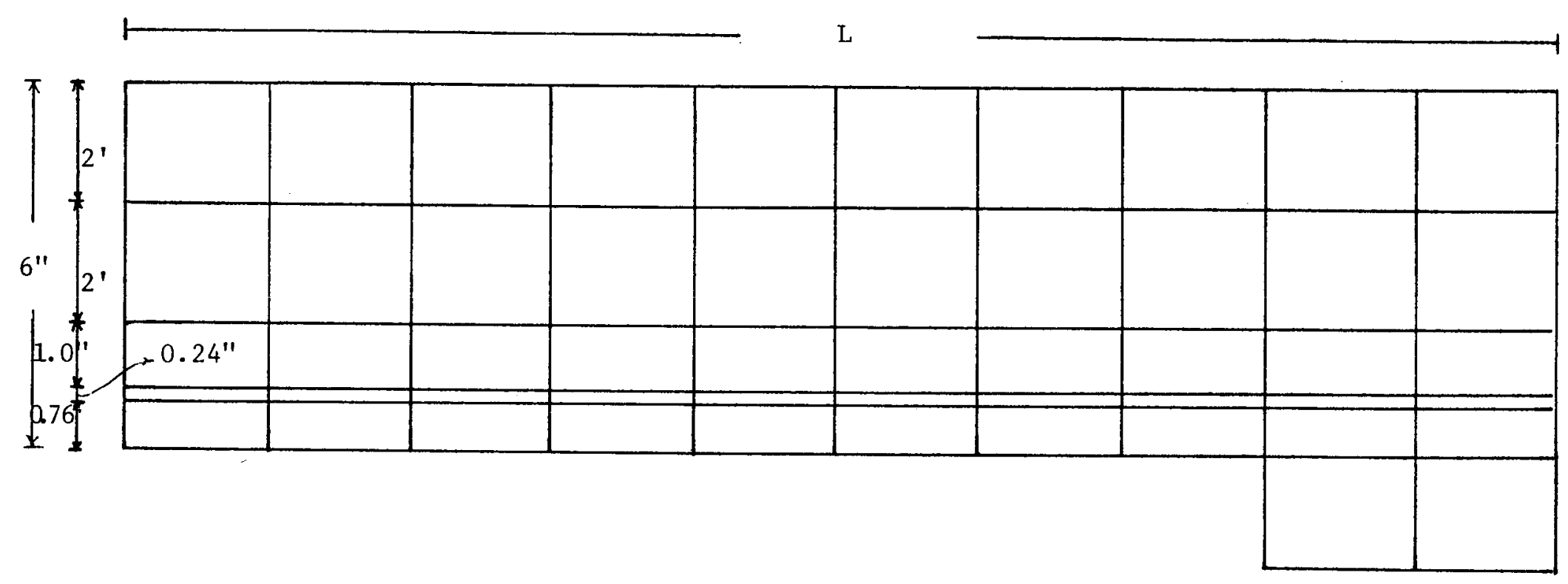

Fig. 6.2 Finite Element Mesh for Simulating

Specimen with Large Shear Span 


\section{REFERENCE}

1. Abrams, J.H., "The Punching Shear Strength of Precracked Reinforced Concrete in Biaxial Tension", M.S. Thesis Cornell University, May 1979.

2. Johnson, R.P. and Arnouti, C., "Punching Shear Strength of Concrete Slabs Subjected to In-Plane Biaxial Tension", Magazine of Concrete Research, Vol. 32, No. 110, March 1980.

3. Kinnunen, and Nylander, "Punching of Concrete Slab without Shear Reinforcement", Stockholm Royal Institute of Technology, Transaction No. 158,1960 pp. 112 .

4. Kinnunen, S. "Punching of Concrete Slabs with Two-Way Reinforcement", Stockholm Royal Institute of Technology, Transaction No. 198, 1963 pp. 109 .

5. Anderson, J.L., "Punching of Concrete Slab with Shear Reinforcement", Stockholm Royal Institute of Technology, Transaction No. 212, 1963 pp. 59 .

6. Yitzhaki, D., "Punching Strength of Reinforced Concrete Slabs", ACI Journa1, Proc., May 1966.

7. Long, A.E. and Bond, D., "Punching Failure of Reinforced Concrete Slabs", Proc., Institute of Civil Engineers, May 1976, pp. 109-136.

8. Long, A.E., "A Two-Phase Approach to the Prediction of Punching Strength of Slabs", ACI Journal, Proc., February 1975.

9. Mattock, A.H., Johal, L., and Chow, H.C., "Shear Transfer in Reinforced Concrete with Moment or Tension Acting across the Shear P1ane", PCI Journa1, Vol. 20, No. 4, July/August 1975.

10. Moe, J., "Shearing Strength of Reinforced Concrete Slabs and Footings under Concentrated Loads", Development Department, Bulletin D47, PCA, April 1961.

11. Nielsen, M.P., et al, "Concrete Plasticity, Beam Shear - Shear in Joints - Punching Shear", Danish Society for Structural Science and Engineering, October 1978 .

12. Braestrup, M.W., "Punching Shear in Concrete Slabs", IABSE Colloquium, Kopenhagen 1979, "Plasticity in Reinforced Concrete, Introductory Reports."

13. Taylor, R. and Hayes, B., "Some Tests on the Effect of Edge Restraint on Punching Shear in Reinforced Concrete Slabs", Magazine of Concrete Research, Vo1. 17, No. 50, March 1965.

14. Aoki, Y. and Seki, H.L., "Shearing Strength and Cracking in Two-Way Slabs Subjected to Concentrated Loads," ACI Special Publication 30-5 pp. 103-126, 1971 . 
15. ACI 318-77, "Building Requirements for Reinforced Concrete", Detroit, 1977.

16. British Standards Institute: CP 110, "The Structural Use of Concrete", Part 1, 1972.

17. CEB-FIP: Code Modele Pour les structures en beton. Paris. Comite' Euro-International du Beton 1978.

18. ACI Committee 349, "Code Requirements for Nuclear Safety Related Concrete Structures", Detroit 1976.

19. Nielsen, M.P., "Punching Shear Resistance According to the CEB Model Code", ACI SP-59, Concrete Design: U.S. and European Practices, ACI-CEB-PCI-FIP Symposium Paper \#11, pp. 193-210.

20. Regan, P.E., "A Comparison of British and ACI 318-71 Treatments of Punching Shear", ACI Special Publication 42-37, pp. 881-903, Detroit 1974.

21. Criswe11, M.E. and Hawkins, N.M., "Shear Strength of Slabs: Basic Principle and Their Relation to Current Method of Analysis", ACI SP 42-29, pp. 641-676, Detroit 1974.

22. Hawkins, N.M., Criswe11, M.E., and Roll, F., "Shear Strength of Slabs without Shear Reinforcement", ACI SP 42-30, pp. 677-720, Detroit 1974 .

23. Anis, N.N., "Shear Strength of Reinforced Concrete Flat Slabs without Shear Reinforcement", Ph.D. Thesis, Imperial College, University of London 1970. 


\section{APPENDIX A}

Seven $4^{\prime} \times 4^{\prime} \times 6^{\prime \prime}$ slabs with $\# 6$ and $\left.\right|_{4}$ bars in the two orthogonal directions were tested by Abrams. Four punching tests were performed on each slab, with each at the center of a quadrant. Therefore, the shear span was only 6", with 4" 4 4" loading pad. The tabulated results are shown on the next page, and the load-displacement curves for the tests are given in Figure A.1. 


\section{6}

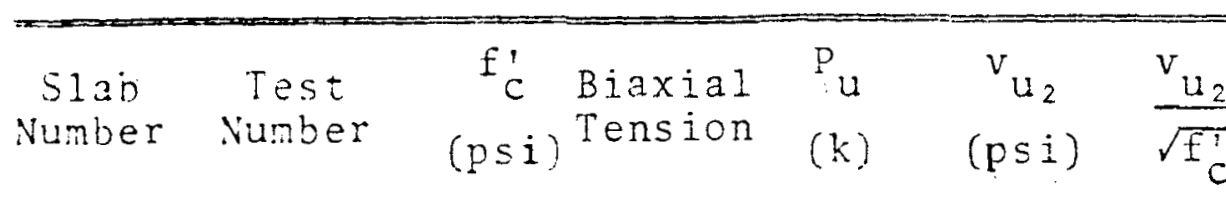

\begin{tabular}{|c|c|c|c|c|c|c|}
\hline 1 & $\begin{array}{l}0.9 A \\
0.9 B \\
0.9 C \\
0.9 D\end{array}$ & 4100 & $\begin{array}{l}0.5 f_{y} \\
0.5 f y \\
0.5 f_{y} \\
0.5 f_{y}\end{array}$ & $\begin{array}{l}62.8 \\
60.1 \\
60.2 \\
52.5\end{array}$ & $\begin{array}{l}394 \\
377 \\
377 \\
329\end{array}$ & $\begin{array}{l}6.15 \\
5.88 \\
5.89 \\
5.14\end{array}$ \\
\hline 2 & $\begin{array}{l}0.6 \mathrm{~A} \\
0.6 \mathrm{~B} \\
0.6 \mathrm{C} \\
0.6 \mathrm{D}\end{array}$ & 3200 & $\begin{array}{l}0.45 f_{y} \\
0.45 f_{y} \\
0.45 f_{y} \\
0.45 \mathrm{f}^{2}\end{array}$ & $\begin{array}{l}45.1 \\
47.5 \\
40.1 \\
44.9\end{array}$ & $\begin{array}{l}283 \\
298 \\
251 \\
281\end{array}$ & $\begin{array}{l}5.00 \\
5.26 \\
4.44 \\
4.97\end{array}$ \\
\hline$j$ & $\begin{array}{l}0.6 \mathrm{E} \\
0.6 \mathrm{~F}\end{array}$ & 3500 & $\begin{array}{l}0.57 f_{y} \\
0.57 f_{y}\end{array}$ & $\begin{array}{l}44.9 \\
47.6\end{array}$ & $\begin{array}{l}281 \\
298\end{array}$ & $\begin{array}{l}4.76 \\
5.04\end{array}$ \\
\hline 4 & $\begin{array}{l}0.0 \mathrm{~A} \\
0.0 \mathrm{~B} \\
0.9 \mathrm{E} \\
0.9 \mathrm{E}\end{array}$ & 4500 & $\begin{array}{l}0.00 f y \\
0.00 f_{y} \\
0.78 f_{y} \\
0.78 f_{y}\end{array}$ & $\begin{array}{l}66.7 \\
69.7 \\
55.1 \\
57.6\end{array}$ & $\begin{array}{l}418 \\
437 \\
345 \\
361\end{array}$ & $\begin{array}{l}6.23 \\
6.51 \\
5.15 \\
5.38\end{array}$ \\
\hline 5 & $\begin{array}{l}0.0 C \\
0.2 A \\
0.4 A \\
0.6 G\end{array}$ & 4100 & $\begin{array}{l}0.00 f y \\
0.20 f y \\
0.39 f y \\
0.57 f y\end{array}$ & $\begin{array}{l}67.0 \\
65.0 \\
57.5 \\
49.0\end{array}$ & $\begin{array}{l}420 \\
407 \\
360 \\
307\end{array}$ & $\begin{array}{l}6.56 \\
6.36 \\
5.63 \\
4.80\end{array}$ \\
\hline 6 & $\begin{array}{l}0.0 \mathrm{D} \\
0.2 \mathrm{~B} \\
0.4 \mathrm{~B} \\
0.6 \mathrm{H}\end{array}$ & 4300 & $\begin{array}{l}0.00 f_{y} \\
0.19 f_{y} \\
0.38 f_{y} \\
0.57 f_{y}\end{array}$ & $\begin{array}{l}64.1 \\
60.1 \\
55.1 \\
54.7\end{array}$ & $\begin{array}{l}402 \\
377 \\
345 \\
343\end{array}$ & $\begin{array}{l}6.13 \\
5.74 \\
5.27 \\
5.23\end{array}$ \\
\hline$T$ & $\begin{array}{l}0.2 \mathrm{C} \\
0.4 \mathrm{C} \\
0.8 \mathrm{~A} \\
0.8 \mathrm{~B}\end{array}$ & 3300 & $\begin{array}{l}0.19 f y \\
0.38 f y \\
0.75 f y \\
0.79 f y\end{array}$ & $\begin{array}{l}52.5 \\
52.4 \\
42.5 \\
43.6\end{array}$ & $\begin{array}{l}329 \\
328 \\
265 \\
273\end{array}$ & $\begin{array}{l}5.73 \\
5.72 \\
4.64 \\
4.76\end{array}$ \\
\hline
\end{tabular}

$d=45 / 8^{\prime \prime} \quad b_{\mathrm{O}_{2}}=34.5^{\prime \prime} \quad \mathrm{b}_{\mathrm{O}_{2}} \mathrm{~d}=1599 / 16 \mathrm{in}^{2} \quad v_{\mathrm{u}_{2}}=\mathrm{P}_{\mathrm{u}} / \mathrm{b}_{\mathrm{O}_{2}} \mathrm{~d}$

Table A. 1

UTtimate Punching Shearing Stresses 
e

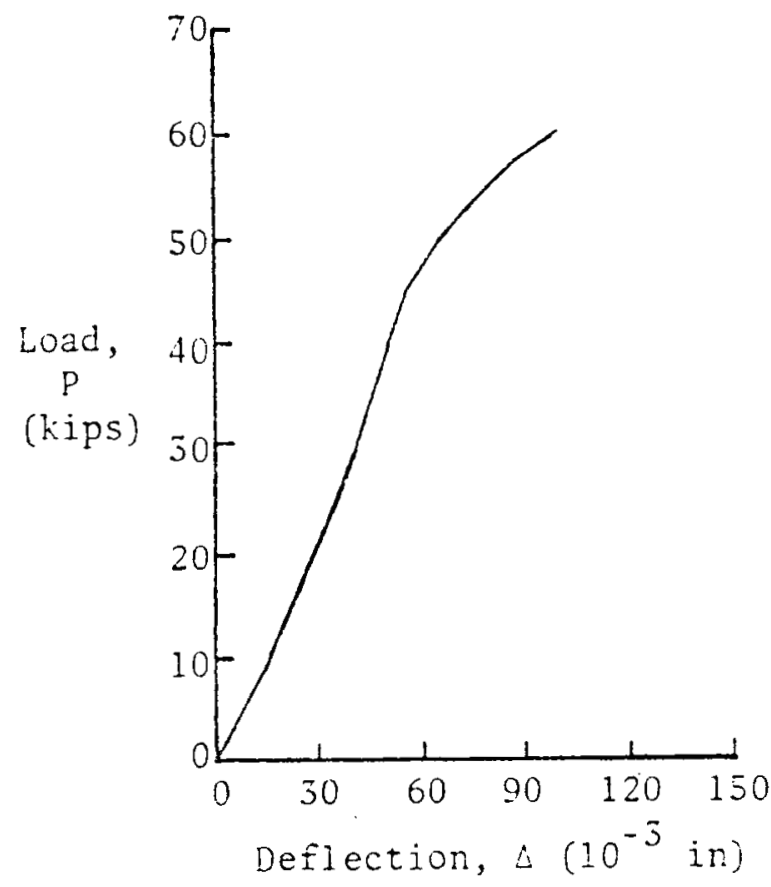

a) Test 0.9A

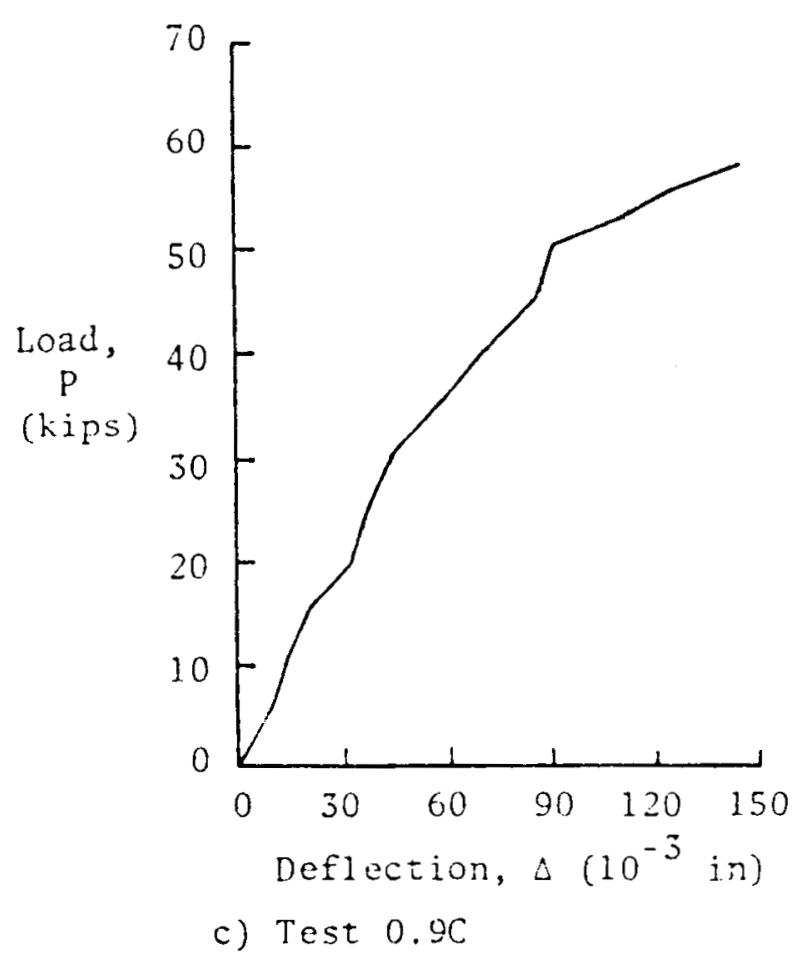

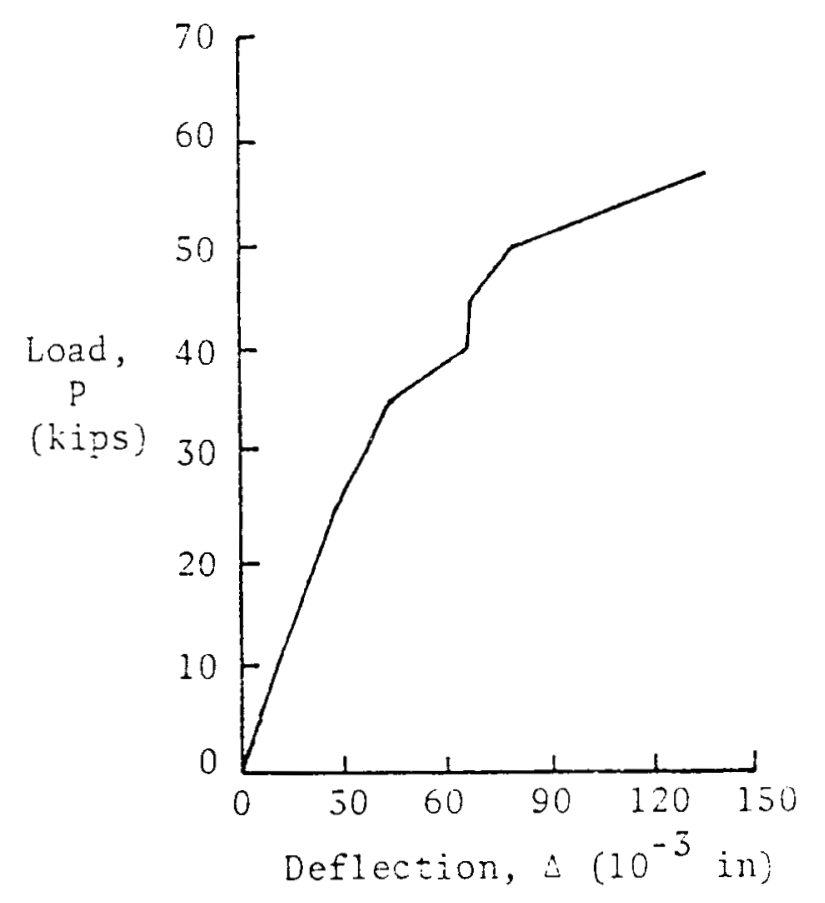

b) Test 0.98

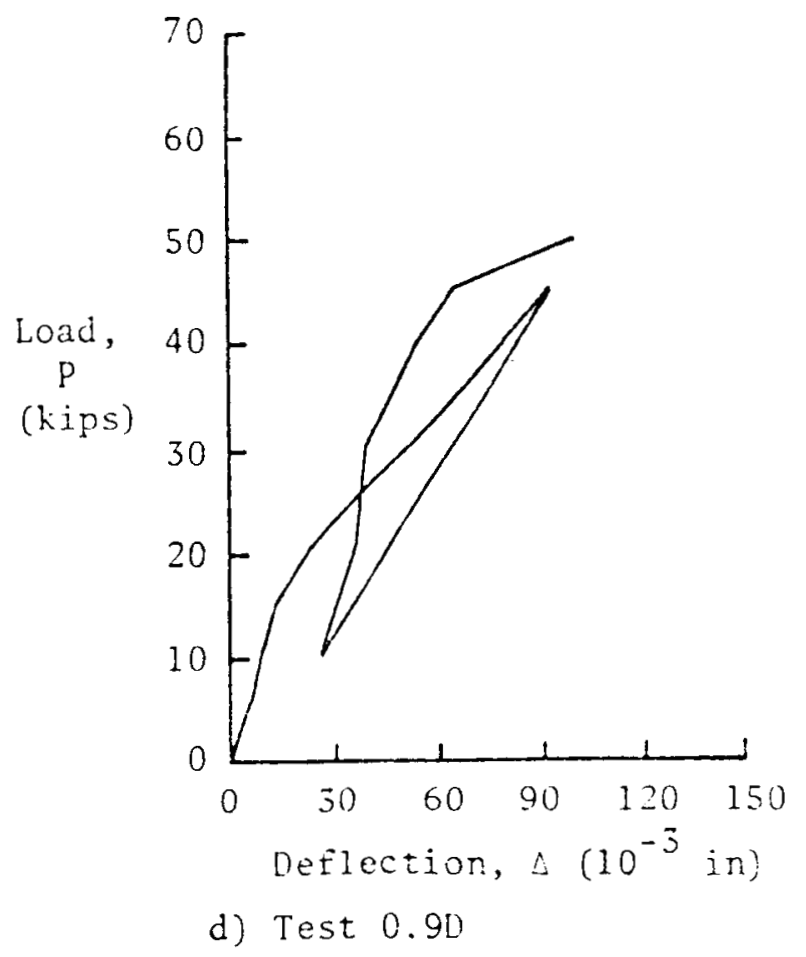

Fig. A.1. Load-Deflection Response Slab $=1$ 

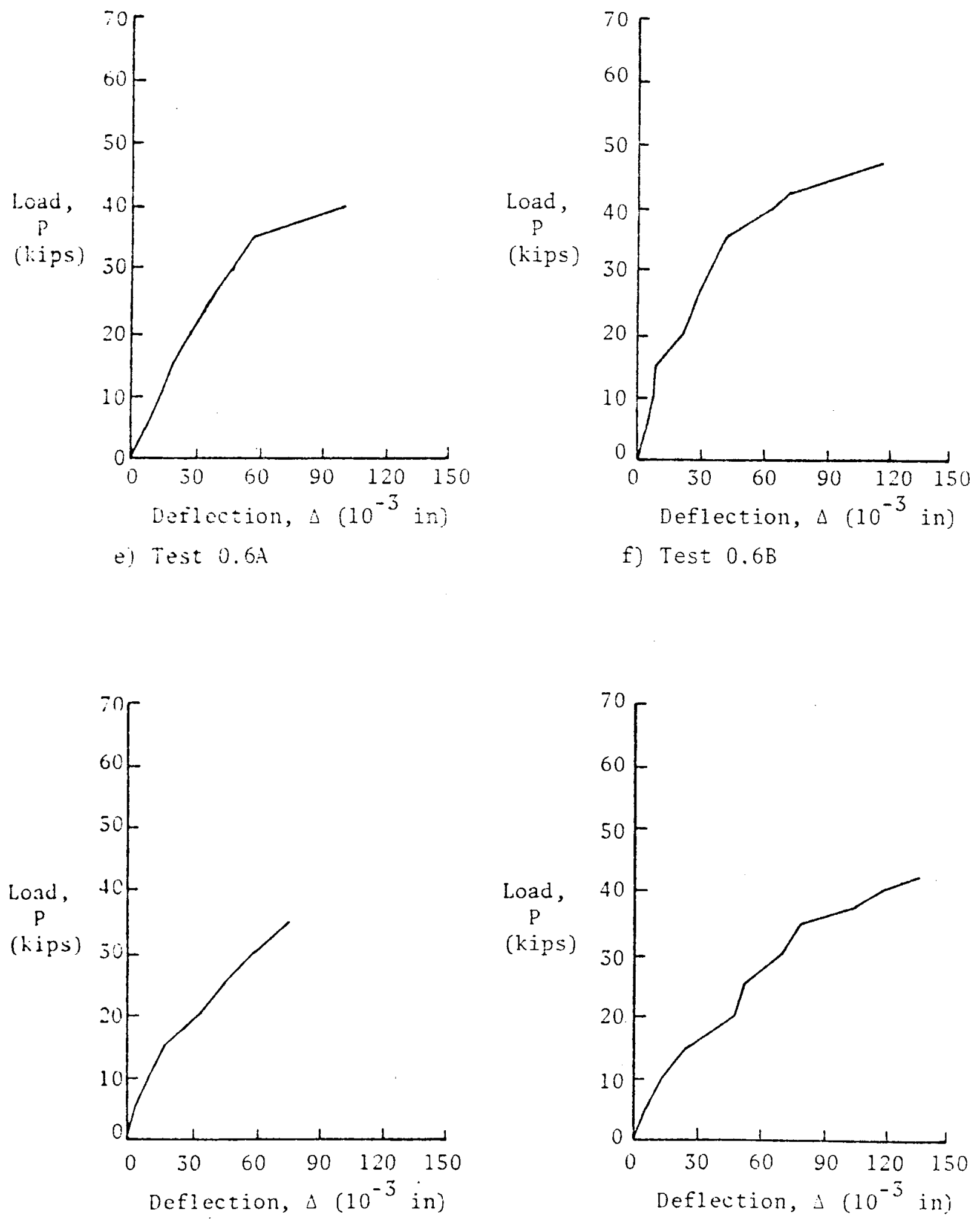

g) Test $0.6 \mathrm{C}$

h) Test 0.60

Fig. A.I (cont'd). Load Deflection Response $\mathrm{S} I \mathrm{ab} \# 2$ 
89

e

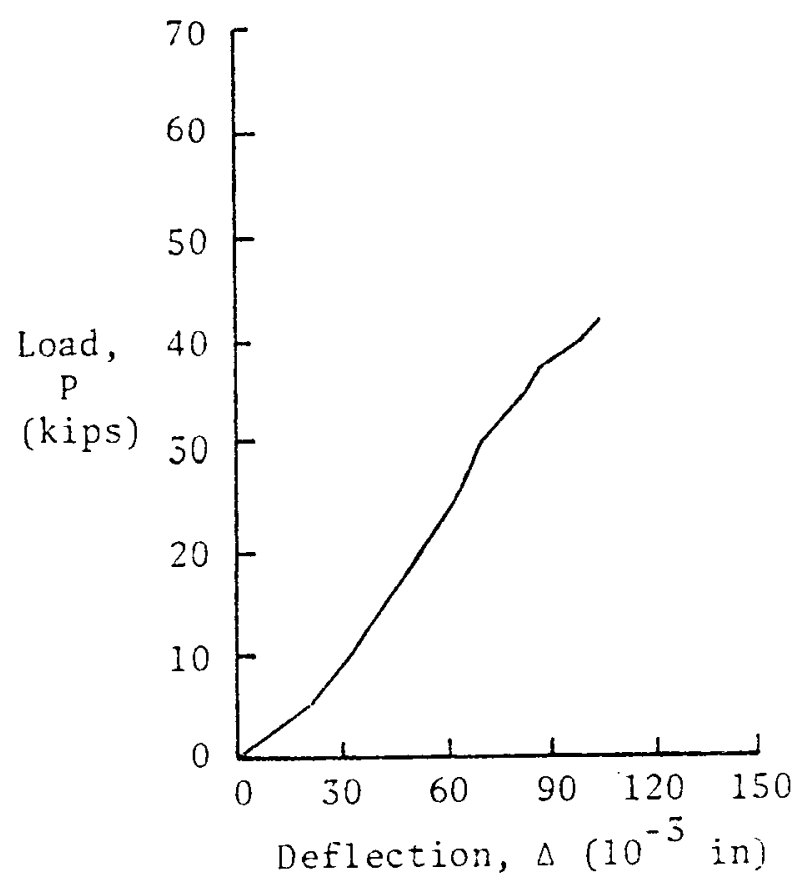

i) Test $0.6 \mathrm{E}$

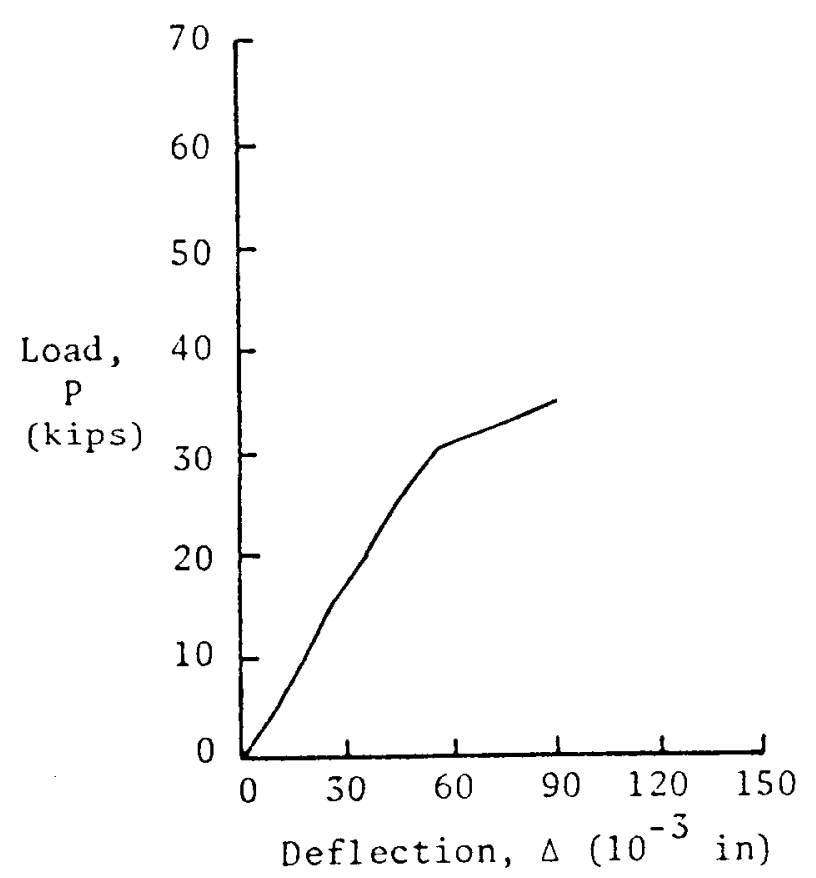

k) Test $0.3 \mathrm{~A}$

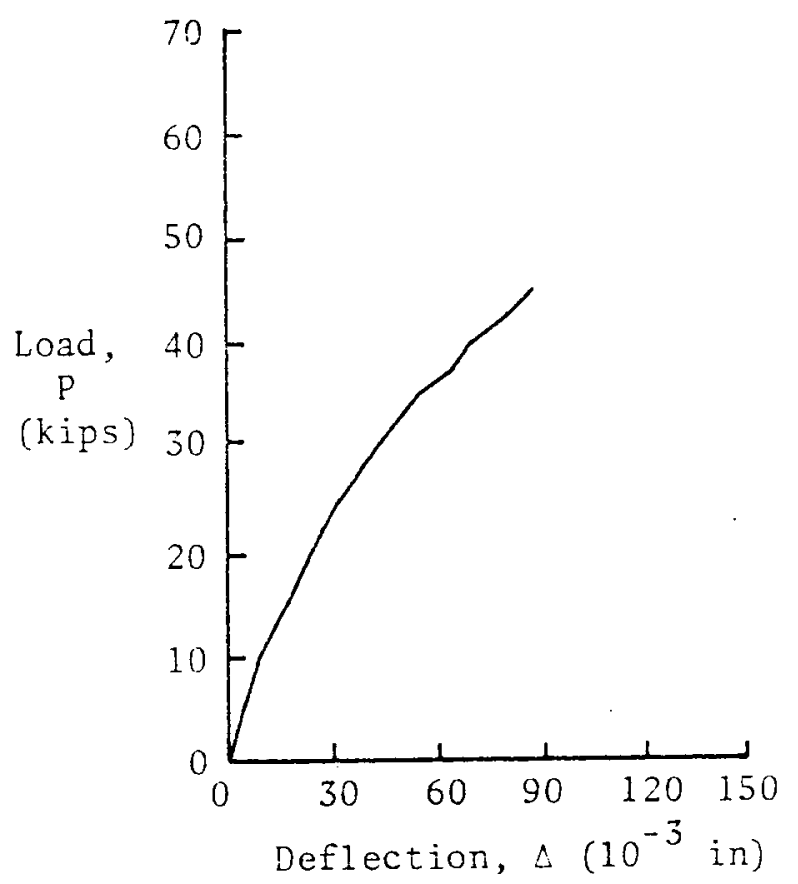

j) Test $0.6 \mathrm{~F}$

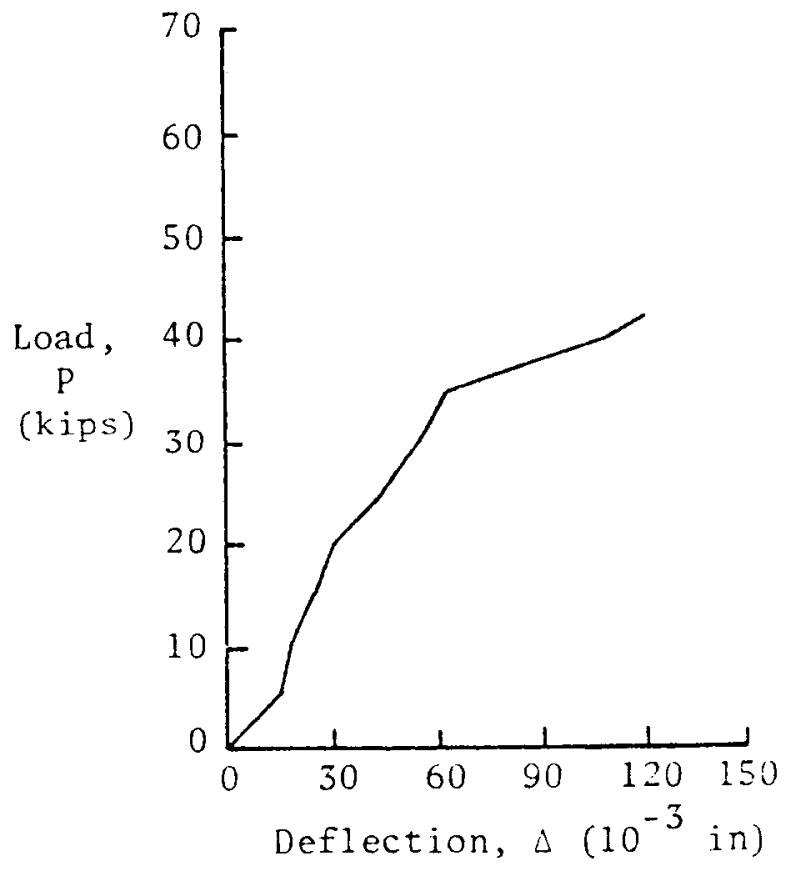

1) Test $0.3 \mathrm{~B}$

Fig. A. I (cont'd). Load-Deflection Response Slab $\# 3$ 

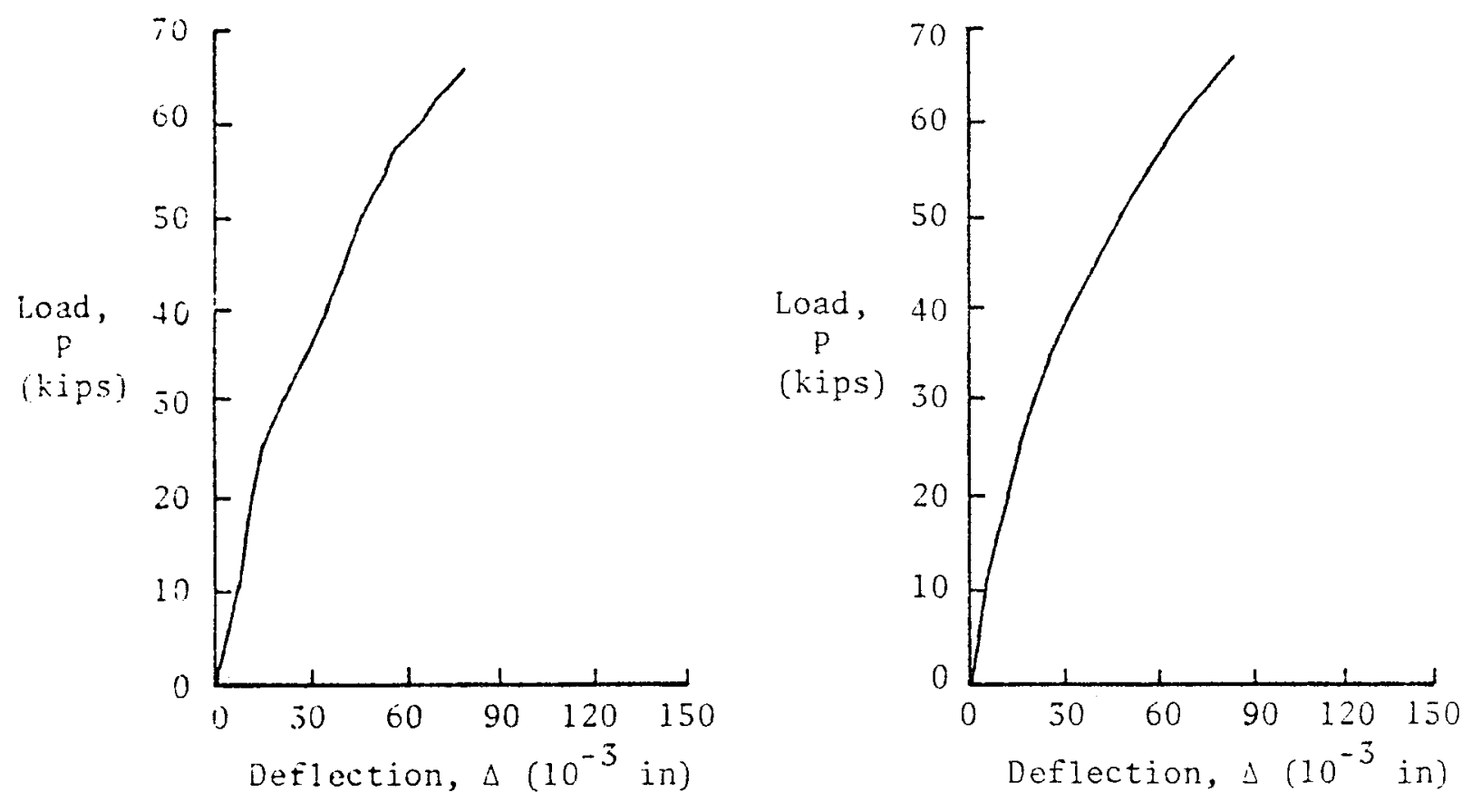

m) Test $0.0 \mathrm{~A}$

n) Test $0.0 B$
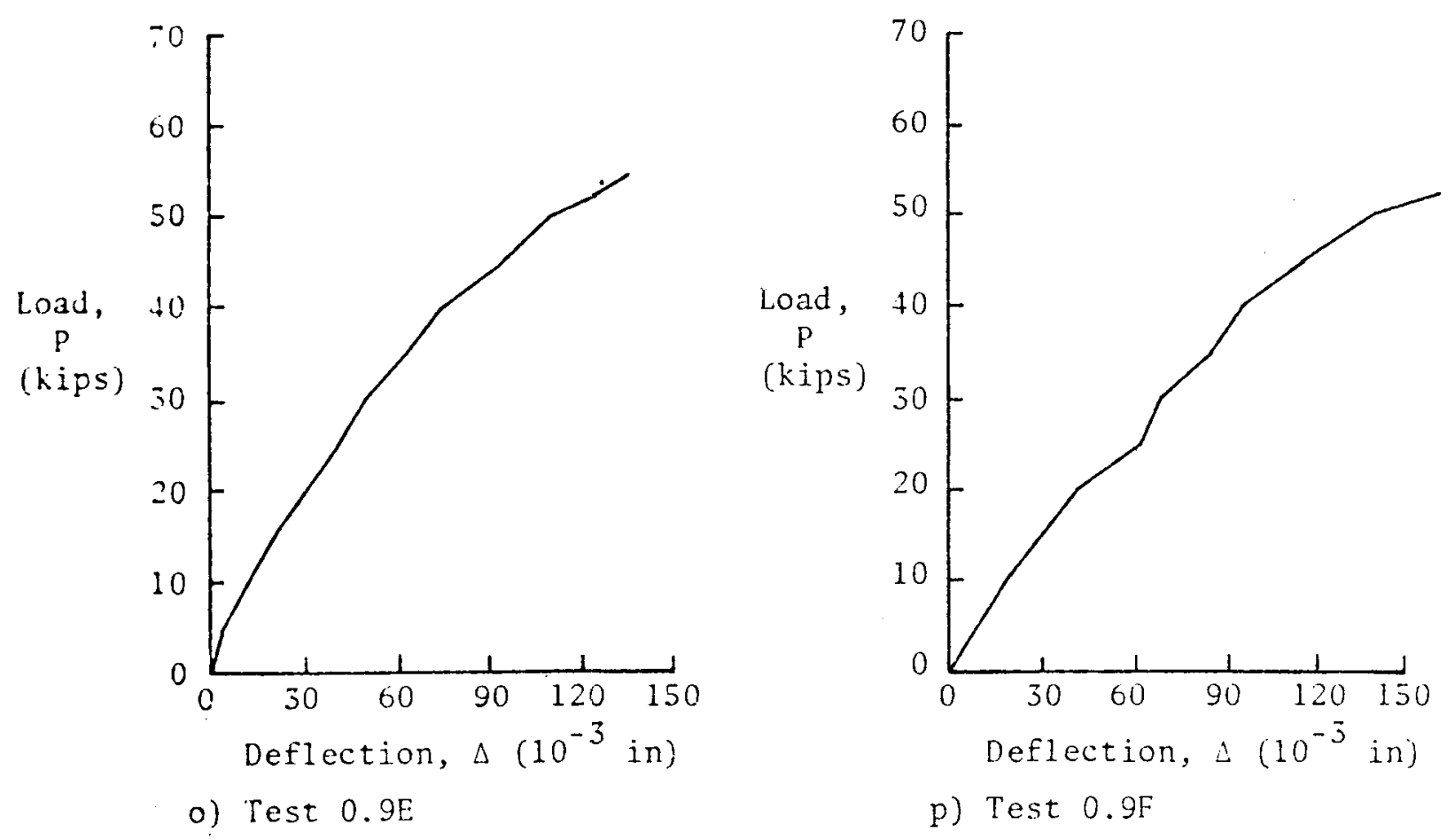

Fig. A.l (cont'd). Load-Deflection Response $S 1 a b \# 4$ 
91

e
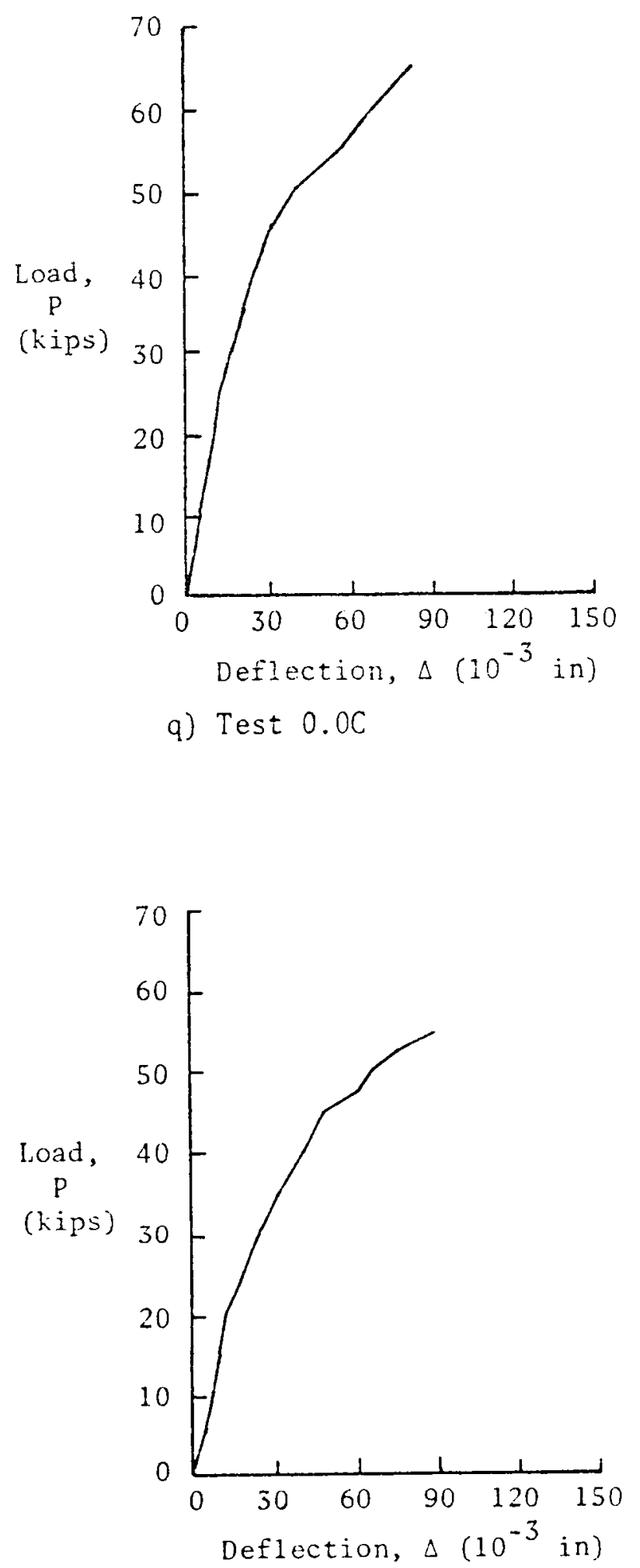

s) Test $0.4 \mathrm{~A}$
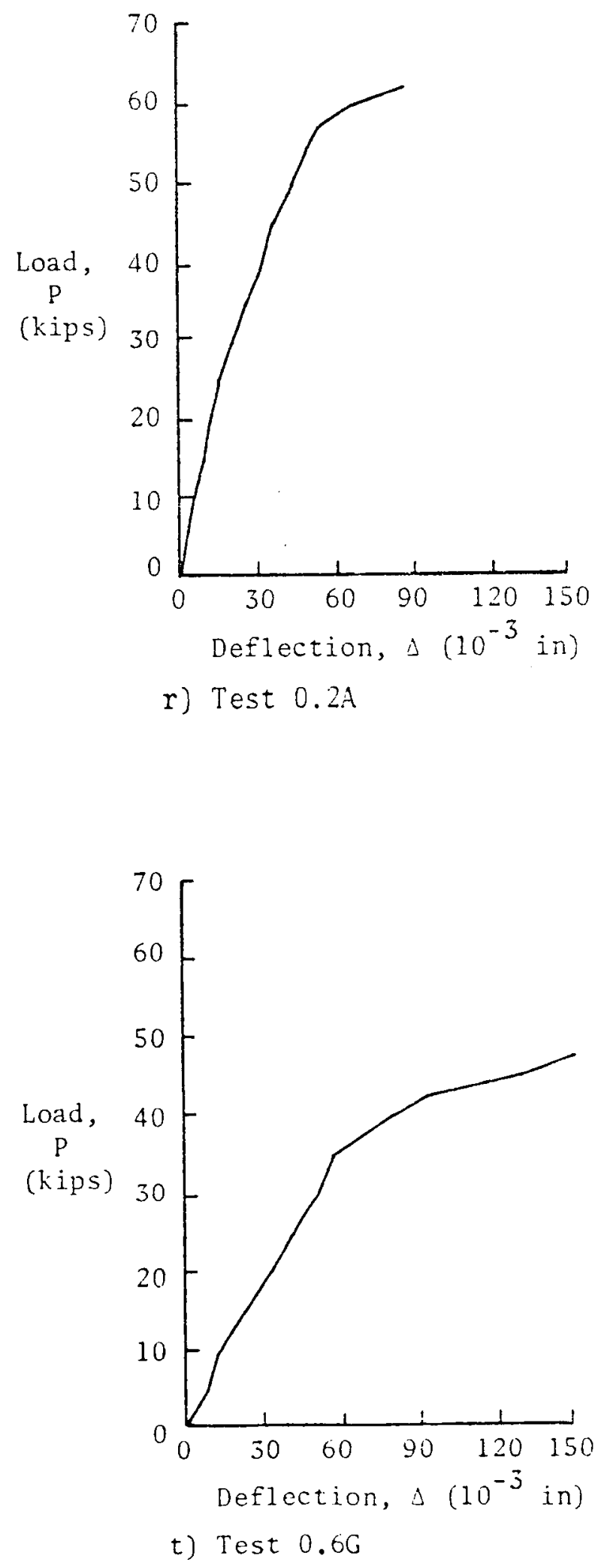

Fig. A.l (cont'd). Load-Deflection Response Slab $\neq 5$ 

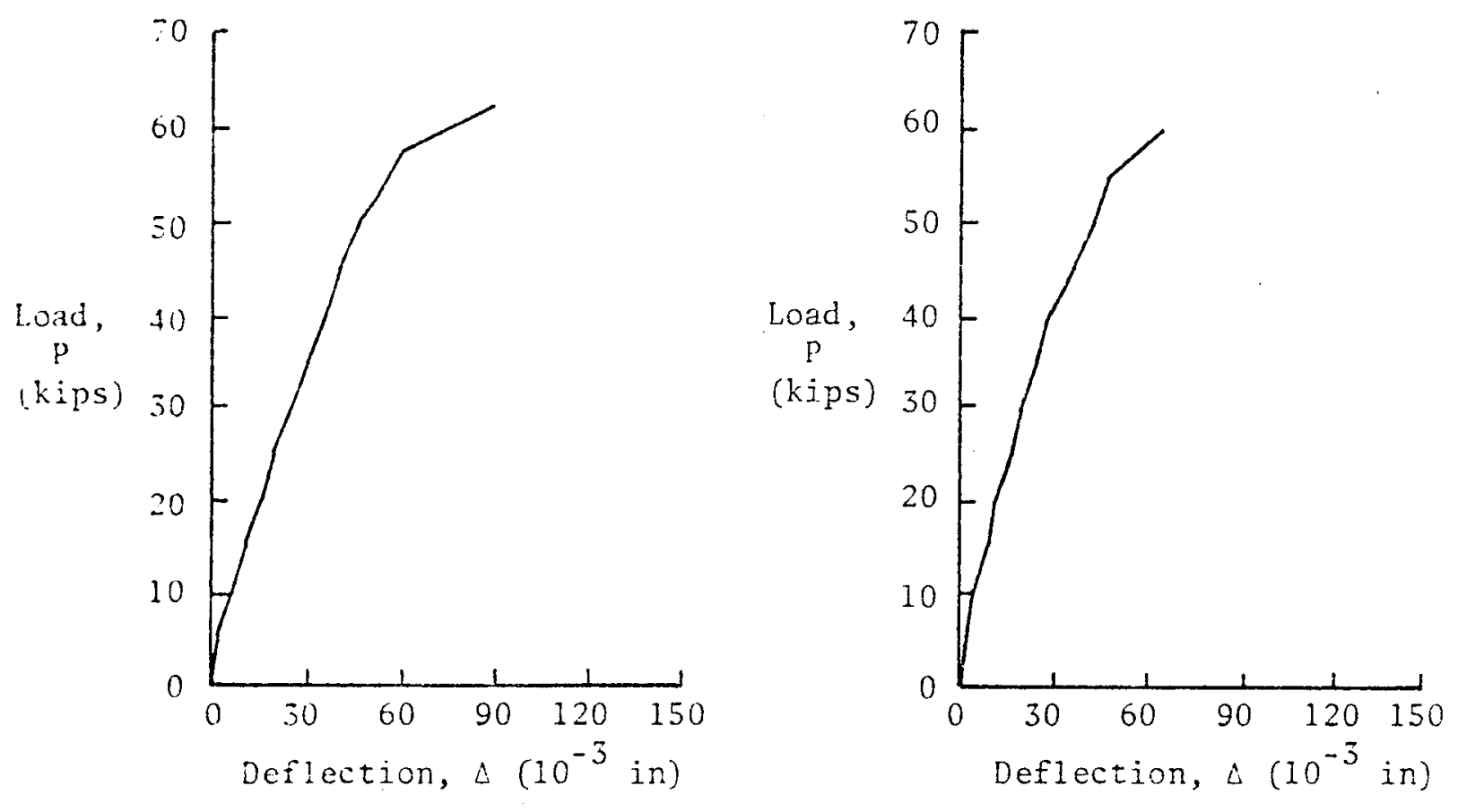

u) Test 0.0D

v) Test $0.2 \mathrm{~B}$
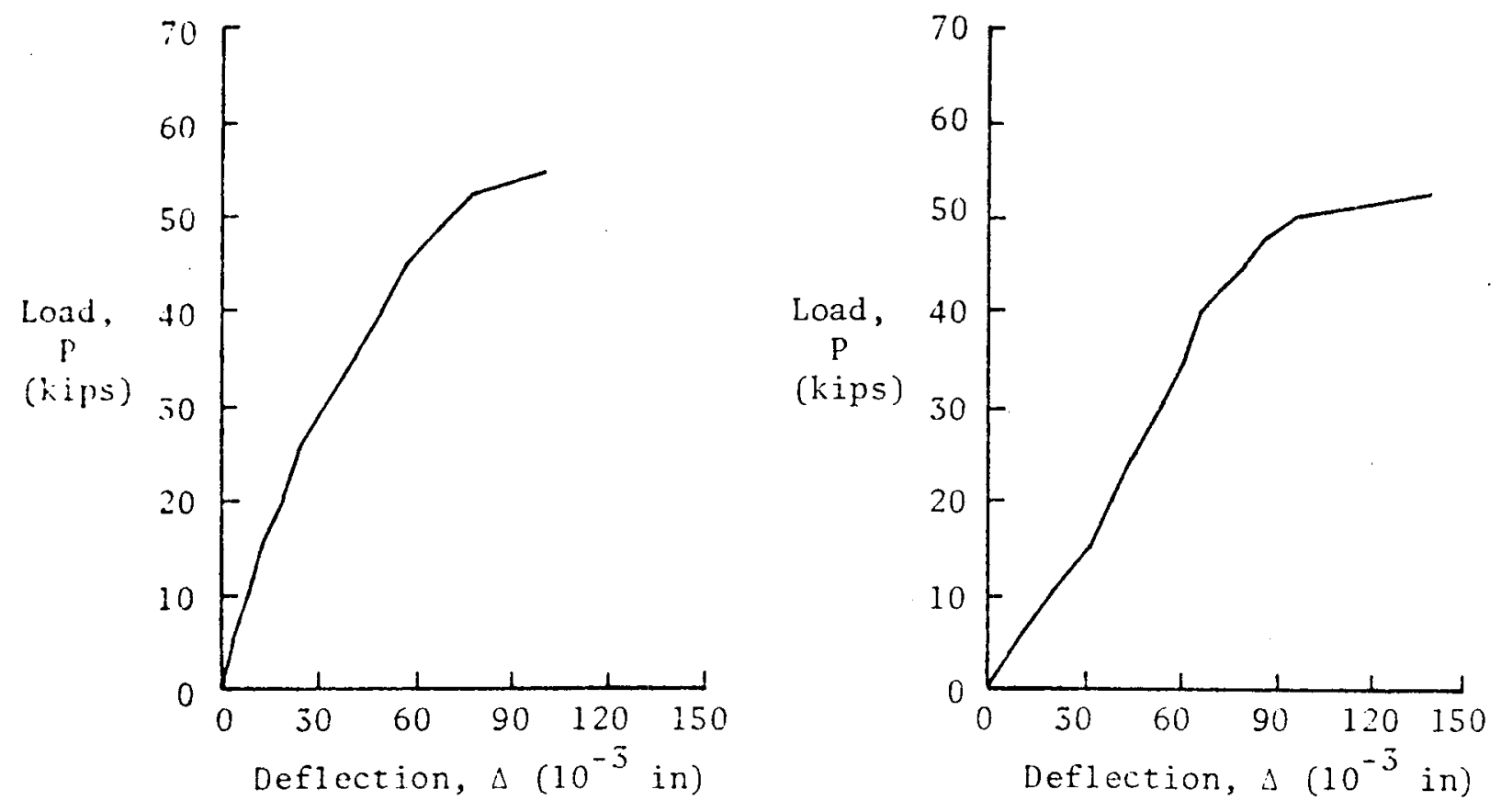

Fig. A.1 (cont'd). Load-Deflection Response Siab $\# 6$ 

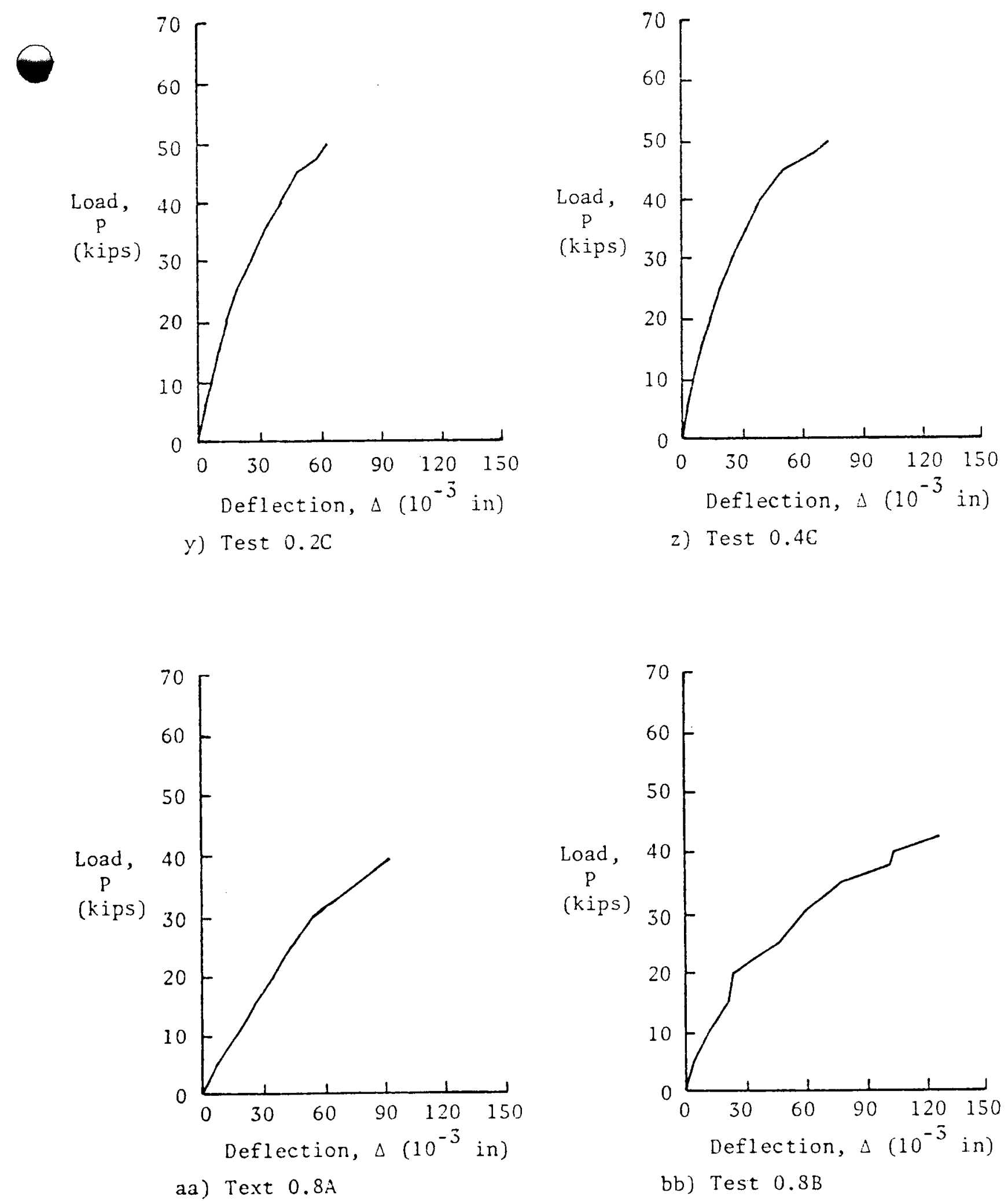

aa) Text $0.8 \mathrm{~A}$

Fig. A.1 (cont'd). Load-Deflection Response $\mathrm{S} 1 \mathrm{ab} \# 7$ 